Florida International University FIU Digital Commons

4-16-2010

\title{
Three essays on entrepreneurial entry, serial entrepreneurship, and labor turnover
}

Jing Chen

Florida International University

DOI: $10.25148 /$ etd.FI14060164

Follow this and additional works at: https://digitalcommons.fiu.edu/etd

Part of the Economics Commons

\section{Recommended Citation}

Chen, Jing, "Three essays on entrepreneurial entry, serial entrepreneurship, and labor turnover" (2010). FIU Electronic Theses and Dissertations. 2132.

https://digitalcommons.fiu.edu/etd/2132

This work is brought to you for free and open access by the University Graduate School at FIU Digital Commons. It has been accepted for inclusion in FIU Electronic Theses and Dissertations by an authorized administrator of FIU Digital Commons. For more information, please contact dcc@fiu.edu. 
FLORIDA INTERNATIONAL UNIVERSITY

Miami, Florida

THREE ESSAYS ON ENTREPRENEURIAL ENTRY,

SERIAL ENTREPRENEURSHIP, AND LABOR TURNOVER

A dissertation submitted in partial fulfillment of the

requirements for the degree of

DOCTOR OF PHILOSOPHY

in

ECONOMICS

by

Jing Chen

2010 
To: Dean Kenneth Furton

College of Arts and Sciences

This dissertation, written by Jing Chen, and entitled Three Essays on Entrepreneurial Entry, Serial Entrepreneurship, and Labor Turnover, having been approved in respect to style and intellectual content, is referred to you for judgment.

We have read this dissertation and recommend that it be approved.

Cem Karayalcin

Jungmin Lee

Jie Mi

Peter Thompson, Major Professor

Date of Defense: April 16, 2010

The dissertation of Jing Chen is approved.

\begin{tabular}{r}
$\begin{array}{r}\text { Dean Kenneth Furton } \\
\text { College of Arts and Sciences }\end{array}$ \\
\hline Interim Dean Kevin O'Shea \\
University Graduate School
\end{tabular}

Florida International University, 2010 


\section{DEDICATION}

I dedicate this dissertation to my parents. Without their understanding and continued support, the completion of this work would not have been possible. 


\section{ACKNOWLEDGMENTS}

I wish to thank the members of my committee for their support, patience, and encouragement. I am grateful to Dr. Cem Karayalcin for his effort in helping me apply for the Dissertation Yearly Fellowship so that I could concentrate on my dissertation during my final year. I am also thankful for Dr. Jungmin Lee's generosity with his time and experience whenever I had troubles with data or empirical techniques. I have also benefited greatly from Dr. Jie Mi's deep knowledge of mathematics and statistics. Finally, I would like to thank my major professor, Dr. Peter Thompson, without whom I would not be standing where I am now. 


\section{ABSTRACT OF THE DISSERTATION \\ THREE ESSAYS ON ENTREPRENEURIAL ENTRY, SERIAL \\ ENTREPRENEURSHIP, AND LABOR TURNOVER \\ by \\ Jing Chen \\ Florida International University, 2010 \\ Miami, Florida \\ Professor Peter Thompson, Major Professor}

This study explores two important aspects of entrepreneurship - liquidity constraints and serial entrepreneurs, with an additional analysis of occupational choice among wage workers. In the first essay, I revisit the question of whether entrepreneurs face liquidity constraints in business formation. The principle challenge is that wealth is correlated with unobserved ability, and adequate instruments are often difficult to identify. This paper uses the son's birth order as an instrument for household wealth. I exploit the data available in the Korean Labor and Income Panel Study, and find evidence of liquidity constraints associated with self-employment in South Korea. The second essay develops and tests a model that explains entry into serial entrepreneurship and the performance of serial entrepreneurs as the result of selection on innate ability. The model supposes that agents establish businesses with imperfect information about their entrepreneurial ability and the profitability of business ideas. Agents continually observe signals with which they update their beliefs, and this process eventually determines their next business choice. Selection on ability induces a positive correlation between entrepreneurial experience (measured by previous business earnings and founding experience) and serial 
business formation, as well as its subsequent performance. The predictions in the model are tested using panel data from the NLSY79. The analysis permits a distinction to be made between selection on innate ability and learning by doing. Motivated by previous empirical findings that white-collar workers had higher turnover rates than blue-collar workers during firm expansion, the third essay further examines job turnover among workers with or without specific skills. I present a search-matching model, which predicts that when firm growth is driven by technological advance, workers whose skills are specific to the obsolete technology show a higher tendency to separate from their jobs. This hypothesis is tested with data from the PSID. I find supportive evidence that in the context of technological change, having an occupation requiring specific skills, such as computer specialists or engineers, increases the odds of job separation by nearly eight percent. 


\section{TABLE OF CONTENTS}

CHAPTER

PAGE

Introduction 1

References. 9

Chapter 1 Wealth Constraints and self-Employment: Evidence from Birth Order 11

1.1 Introduction. 11

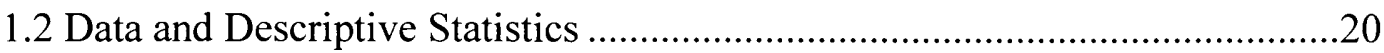

1.3 Self-Employment and Wealth Constraints: Probit Estimates ...........................23

1.4 The Hypothesis and Cultural Background .......................................................31

1.5 Self-Employment and Wealth Constraints: IV Results .....................................34

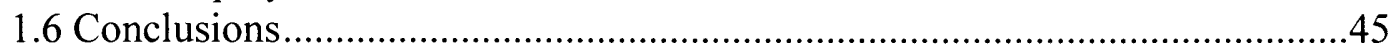

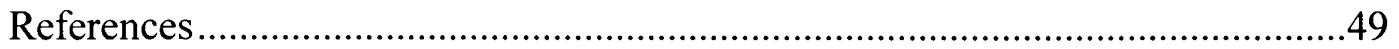

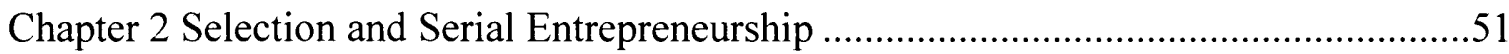

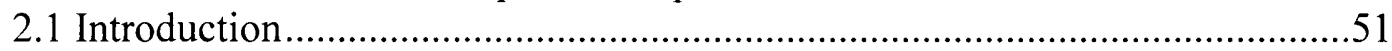

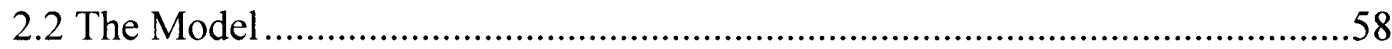

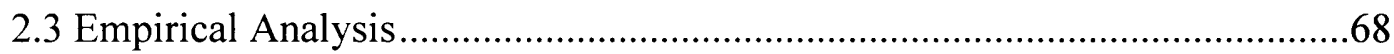

2.4 Conclusions

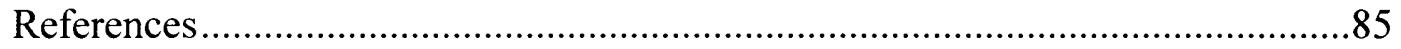

Chapter 3 Who Benefits from Firm Growth? An Analysis of Technology Effects

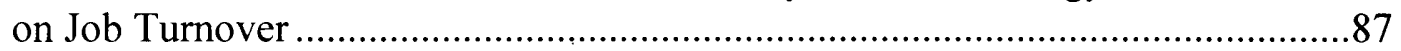

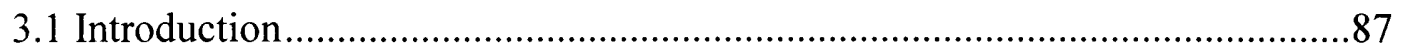

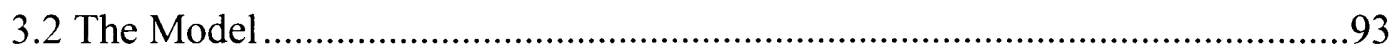

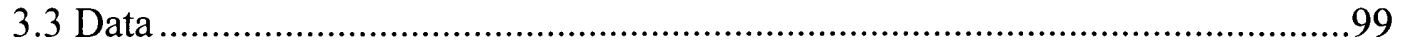

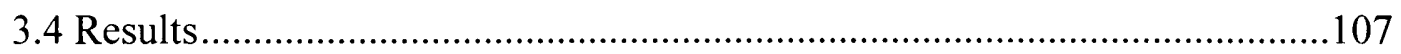

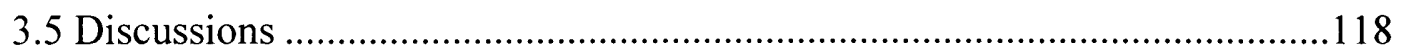

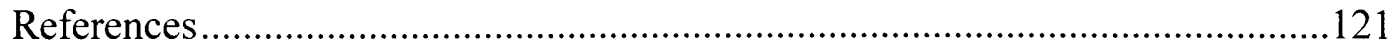

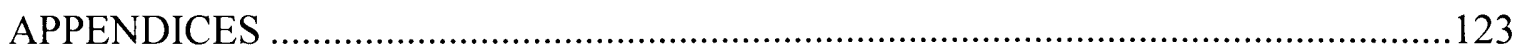

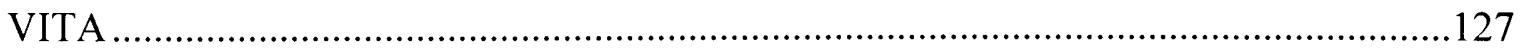




\section{LIST OF TABLES}

TABLE

Table 1.1 - Demographic Distribution by Employment Status and Transition into Self-Employment

Table 1.2 - Distribution of Employment Status by Demographic Variables .22

Table 1.3 - Summary Statistics by Industry .22

Table 1.4 - Comparing Linear and Nonlinear Specifications for Wealth .27

Table 1.5 - Probability of Becoming Self-Employed: Probit Regressions 30

Table 1.6 - The Effect of Being the Eldest Son on Net Cash Transfer. .34

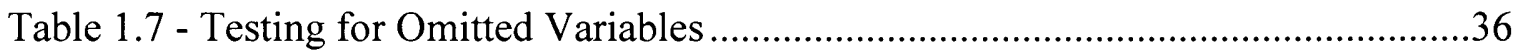

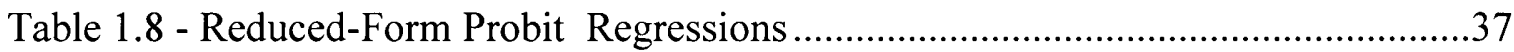

Table 1.9 - Testing for Relevant Instrument: OLS Regressions .....................................39

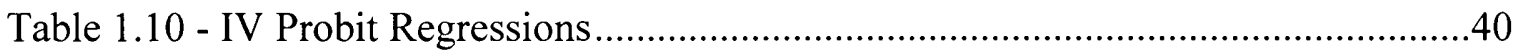

Table 1.11 - IV Probit Regressions (Controlling for Previous Occupations) ...................41

Table 1.12 - IV Probit Estimations in the Sample with Restricted Sibling Size (Male Only)

Table 1.13 - Probit IV Estimation in the Sample with Restricted Sibling Size (Both Male and Female) 46

Table 2.1 - Frequency of Serial Entrepreneurs by Year ................................................. 71

Table 2.2 - Frequency of Serial Entrepreneurs by Industry ...........................................72

Table 2.3 - Distribution of Previous Business Earnings ....................................................

Table 2.4 - The Determinants of Serial Business Formation............................................78

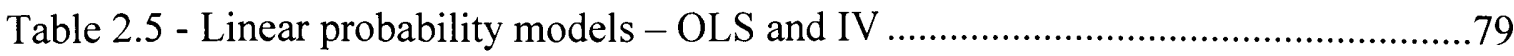

Table 2.6 - Current Business Earnings and Previous Business Experience …...................81 
Table 3.1 - Steps of Creating the Sample with Multiple Choices: Stay, Laid-off, and Quit

Table 3.2 - Summary Statistics: Demographic Variables (3 groups) 105

Table 3.3 - Summary Statistics: Industry and Occupation (multinomial) 106

Table 3.4 - Results in Multinomial Logit Model 109

Table 3.5 - Multinomial Logit Model with Individual Heterogeneity Controlled.

Table 3.6 - Multinomial Logit Model: Distinguishing Increasing Technological Growth from Decreasing Growth

Table 3.7 - Summary Statistics: Demographic Variables (quit) .114

Table 3.8 - Summary Statistics: Industry (quit) 114

Table 3.9 - Conditional Fixed-Effects Model (quit only) 116

Table 3.10 - Conditional Fixed-Effects Model (quit and laid off) 118 
Figure 1.1 - Percentage Distribution of No. of Siblings

Figure 2.1 - Probability of Forming a New Business as Business Earnings Change ........64

Figure 2.2 - Probability of Forming a New Business as the Quality of Business Idea Change .66

Figure 2.3 - Hazards of New Business Formation .68

Figure 2.4 - Distributions of Previous Business Earnings .75

Figure 2.5 - Distributions of Residual Business Earnings .75 


\section{INTRODUCTION}

Thanks to Schumpeter's (1942) seminal work relating entrepreneurship to the "gale of creative destruction", entrepreneurship has returned to the focus of public policy and attracted increasing interests from academic researchers. From a policy maker's point of view, entrepreneurship not only stimulates innovations, but provides a bridge out of poverty and sustains long-run economic growth. Thus, public programs that aim to encourage the creation of small and medium-sized businesses have been strongly favored by governments all over the world. A well-known example is the guaranteed loan programs provided by the US Small Business Administration which provides financial assistance to potential business owners.

This public enthusiasm about business creation is accompanied by an increasing inquiry of entrepreneurship from academic scholars. A large number of theories and quantitative analysis have been developed to understand entrepreneurship, and subsequently bring out many policy-relevant questions which have not been well addressed. For instance, while many governments are eager to encourage new business creation by providing financial assistance under the belief that entrepreneurs face wealth constraints, an intensive debate among authors of recent studies raises the question of how reliable the empirical evidence of wealth constraints is because of endogeneity problem (Blanchflower and Oswald 1991, etc.). Moreover, using large and representative data samples, the literature on returns to self-employment reports the evidence that entrepreneurs generally work harder, but on average earn less than wage workers, giving rise to the doubt of whether entrepreneurship really makes people better off than staying in the wage sector (Hamilton 2000). Gompers et al. (2006) further argue that business success is determined by innate entrepreneurial 
skills rather than experience in general, implying that entrepreneurship should not be overly-encouraged, but subjected to self-selection.

Discussions on these issues are interesting, as they help us understand individuals' occupational choice, entrepreneurs' business decisions, and the dynamics of firms. These studies also provide policy makers' with theoretical and empirical justification on the types of businesses that governments should encourage, the capacity of entrepreneurship that is optimal for the economy, and the role of government intervention in successfully promoting entrepreneurial innovation and economic growth.

Entrepreneurship research is tremendous, and as Parker (2005) points out, it requires wisdoms from multidisciplinary fields, and the topics could go from individual occupational choice, to firm growth, and further to economic development. The aim of this study is to focus on controversial issues associated with three aspects of entrepreneurship, that is, wealth constraints, selection on ability, and learning by doing. As an extension, I also apply the similar notion of optimizing behavior to analyzing labor turnover in the wage-employment setting.

The study consists of three chapters. In the first chapter, I revisit a familiar question of whether entrepreneurs face wealth constraints when they start businesses. The prima facie evidence of wealth constraints is a positive relationship between personal wealth and entry into self-employment. The principle challenge for testing this relationship is that wealth is correlated with unobserved (entrepreneurial) ability, and adequate instruments for wealth are often difficult to identify. In previous studies, the most commonly-adopted instruments are windfall gains, such as inheritance (Holtz-Eakin, Joulfaian, and Rosen 1994a, 1994b), lottery winnings (Lindh and Ohlsson 1996), and 
capital gains on housing (Hurst and Lusardi 2004). These studies, however, face the criticism, which emphasizes an indirect relationship between the adopted instruments and entrepreneurial ability through either family specific characteristics (e.g., parents' wealth, family business history, or family social capital) or individual personalities (e.g., degree of risk-aversion, or satisfaction of current economic condition). In this paper, I take a different approach by using birth order as an alternative instrument for wealth. The fact that primogeniture remains important in South Korea ensures a strong relationship between a person's household wealth and his birth order. Most important, as birth order is randomly determined, it does not depend on any family-specific characteristics. A potential concern about the validity of this instrument is its correlation with individual personalities and educational achievement, which may affect one's entrepreneurial propensity in the future. Nonetheless, an extensive review of evidence from the literature of psychology and labor economics shows that these correlations are not always significant, and should not induce serious bias in the results. Using data from the Korean Labor and Income Panel Study (KLIPS), I find strong and positive correlation between entry into self-employment and personal wealth instrumented with birth order. This result supports the hypothesis of wealth constraints faced by prospective entrepreneurs. From the point of view of policy makers, this means fewer employment opportunities and lower self-employment returns because of inefficient capital levels. In this particular case of South Korea, certain financial assistance from the government, therefore, becomes especially necessary.

Earlier studies of entrepreneurship mostly focus on the transition into self-employment from wage sector or unemployment. There have been extensive discussions on what 
determines entrepreneurial entry - whether this occupational choice is related to an individual's employment history (Åstebro, Chen, and Thompson 2010), degree of risk aversion (Kihlstrom and Laffont 1979), or taste for variety (Wagner 2003, 2006; Lazear 2005; Åstebro and Thompson 2007). An important insight from these studies is that there is a variety of motivations that can lead individuals to enter entrepreneurship. Aside from the classic reasoning of "entrepreneurial spirit", entrepreneurial entry could also be explained by attraction to non-pecuniary benefits (e.g., being one's boss, child caring), or lack of opportunities in wage sector (Reynolds et al. 2005). As a result, nascent entrepreneurs in general have less stable self-employment status, which poses difficulties for a deeper exploration of entrepreneurial activities over a long time span. Thus, recent studies have revealed an increasing interest in serial entrepreneurs, who have started several new businesses after having founded and exited their previous ventures. Because they are more persistent in entrepreneurship and have affluent business experiences, serial entrepreneurs are an ideal research object for understanding questions such as how entrepreneurs choose business ideas, what factors affect their investment decisions, what makes the difference between entrepreneur stars and misfits, etc.

In spite of all the desirable characteristics of serial entrepreneurs for research purposes, a more fundamental question that seems to have attracted less attention is why serial entrepreneurs exist. In other words, what motivates an entrepreneur to leave his old business and start a new venture? The answers provided by previous studies are sporadic, and are mostly drawn from small-sample surveys or interviews. Except for the earlier work of Holmes and Schumitz (1990) on business transfer, few theoretical models so far have been developed to formalize this entrepreneurial behavior. 
To fill this gap in the literature, I develop and test a model in the second chapter that explains entry into serial entrepreneurship as the result of selection on innate ability. The model supposes that agents establish businesses with imperfect information about their entrepreneurial ability and the profitability of business ideas. By continually observing signals, agents gradually update their beliefs about both factors, and this process eventually determines their next business choice. An essential insight of the model is that selection on ability is sufficient to induce a positive correlation between entrepreneurial experience (measured by previous business earnings and founding experience) and serial business formation, as well as the subsequent performance of the new business. This result provides a theoretical basis for a debate in the empirical literature on whether the impact of prior experience on current entrepreneurial performance should be explained by learning by doing (Eesley and Roberts 2006a) or should be attributed to entrepreneurial innate skills (Gompers et al. 2006).

To test the hypothesis of selection on ability and further distinguish this effect from learning by doing, I constructed a panel data set from the NLSY79, and apply both IV estimation and the fixed-effects model to isolate the above two mechanisms. The results show that both selection on ability and learning by doing could be captured by entrepreneurial experience. Selection on ability is a more dominant explanation on the positive relationship between experience and new business formation, while learning by doing plays a much bigger role in interpreting the positive impact of founding experience on new business performance.

While serial entrepreneurs have to make a decision between keeping the same business and starting a new one, a similarly interesting question is how workers make their 
occupational choice, either within the wage sector, or between wage sector and selfemployment. The latter movement has been noticed in an extensive literature that documents the coexistence of opportunity or star entrepreneurs - who enter selfemployment to seek higher returns to human capital, and necessity or misfit entrepreneurs - who are forced into self-employment because of limited work opportunities in the wage sector.

In the last chapter, I rather look away from the business sector, but focus on labor turnover and movement that occur within wage employment. This chapter is motivated by two pieces of empirical evidence presented by Dohmen and Pfann (2004) and Lazear (1999). Both studies coincidentally show that workers with more human capital exhibit higher turnover rates than those with less human capital. This result is at odds with human capital theory, which predicts that higher-ranked workers have more stable employment. To provide a possible explanation on this empirical finding, this chapter examines labor turnover in the context of firm-wise technology updating. The model suggests that when human capital is not firm-specific and there is technological change in the firm, workers who have specific capital and are occupied on high-level jobs have a greater tendency to separate from the firm and look for a better job match. The prediction is tested using data from the US Panel Study of Income Dynamics (PSID). I find supportive evidence which shows that, where there is an industry-wide increasing in productivity, having an occupation that requires specific skills, such as computer specialists, engineers, or professional workers, increases the likelihood of job separation by nearly eight percent. 
The contributions of this study are twofold. From the theoretical perspective, this is the first study that applies the notion of selection on ability to explaining the origin of serial entrepreneurship, although similar ideas have long been formalized to model firm dynamics (Jovanovic 1982). Selection yields some implications for serial entrepreneurship that can easily be misconstrued as the result of learning by doing, and therefore raises doubts about whether we have correctly understood some of the existing empirical evidence. Furthermore, the framework of job matching developed in the third chapter can be easily extended to include the option of self-employment to explore individuals' occupational choice within and beyond the wage sector in the context of technological change.

From the empirical standpoint, the present analysis is founded on three large and representative panel data samples, which not only uncover detailed information of respondents' demographic characteristics and their employment history, but allow crosscountry comparisons on labor mobility, occupational preference, and entrepreneurial culture. In terms of empirical methodology, this study proposes two novel instrumental strategies. One is to instrument household assets with the family head's birth order in the test of wealth constraints. This approach aims to tackle the endogeneity problem arising from the correlation between wealth and unobserved ability, without inducing any indirect relationship between the instrument and the troublesome variable. In the second IV estimation, I instrument previous entrepreneurial experience with the entrepreneur's initial earnings in his first job and his first business, both of which reflect a person's innate ability. This approach successfully isolates the role of selection on ability from learning by doing in determining new business formation and performance. The results 
shed light on some long-debated questions, such as what exactly (serial) entrepreneurs learned from their experience, and whether learning really improves their entrepreneurial performance. 


\section{REFERENCES}

Åstebro, Thomas, Jing Chen, and Peter Thompson (2008): "Stars and Misfits: A Theory of Occupational Choice." Working paper, Florida International University

Åstebro, Thomas, and Peter Thompson (2007): "Entrepreneurs: Jacks of All Trades or Hobos?" Working paper.

Blanchflower, David G. and Andrew J. Oswald (1998): "What Makes an Entrepreneur?" Journal of Labor Economics, 16(1): 26-60.

Dohmen, Thomas J., and Gerard A. Pfann (2004): "Worker Separations in a Nonstationary Corporate Environment." European Economic Review, 48(3): 645663.

Eesley, Charles and Edward Roberts (2006a): "Cutting Your Teeth: Learning from Rare Experiences." Working paper, MIT.

Gompers, Paul, Anna Kovner, Josh Lerner, and David Scharfstein (2006): "Skill vs. Luck in Entrepreneurship and Venture Capital: Evidence from Serial Entrepreneurs." NBER working paper, No. 12592.

Hamilton, Barton (2000): "Does Entrepreneurship Pay? An Empirical Analysis of the Returns to Self-Employment." Journal of Political Economy, 108(3):604-631.

Holmes, Thomas J. and James A. Schmitz, Jr. (1990): "A Theory of Entrepreneurship and Its Application to the Study of Business Transfers." Journal of Political Economy, 98(2): 265-294.

Holtz-Eakin, Douglas, David Joulfaian, and Harvey S. Rosen (1994a): "Sticking It Out: Entrepreneurial Survival and Liquidity Constraints." Journal of Political Economy, 102(1): 53-75.

Holtz-Eakin, Douglas, David Joulfaian, and Harvey S. Rosen (1994b): "Entrepreneurial Decisions and Liquidity Constraints." Rand Journal of Economics, 25(2): 334-347.

Hurst, Erik and Annamaria Lusardi (2004): "Liquidity Constraints, Household Wealth, and Entrepreneurship." Journal of Political Economy, 112(2): 319-347.

Jovanovic, Boyan (1982): "Selection and the Evolution of Industry." Econometrica, 50(3): 649-670.

Kihlstrom, Richard E., and Jean-Jacques Laffont (1979): "A general Equilibrium Entrepreneurial Theory of Firm Formation Based on Risk Aversion." Journal of Political Economy, 87(4):719-748.

Lazear, Edward P. (1999): "Personnel Economics: Past Lessons and Future Directions." NBER Working paper No.6957. 
Lazear, Edward (2005): "Entrepreneurship." Journal of Labor Economics, 23(4):649680.

Lindh, Thomas and Henry Ohlsson (1996): "Self-Employment and Windfall Gains: Evidence from the Swedish Lottery." The Economical Journal, 106(439): 15151526.

Parker, Simon (2005): "The Economics of Entrepreneurship: What We Know and What We Don't." Foundations and Trends in Entrepreneurship, 1(1): 1-54.

Reynolds, Paul D., et al. (2005): "Global Entrepreneurship Monitor: Data Collection Design and Implementation 1998-2003." Small Business Economics, 24(3):205-231.

Schumpeter, Joseph A. (1942): "Capitalism, Socialism and Democracy." New York: Harper and Brothers. 5th ed.

Wagner, Joachim (2003): “Testing Lazear's Jack-of-All-Trades View of Entrepreneurship with German Microdata." Applied Economics Letters, 10(11): 687689.

Wagner, Joachim (2006): "Are Nascent Entrepreneurs Jacks-of-All-Trades? A Test of Lazear's Theory of Entrepreneurship with German Microdata," Applied Economics, 38: 2415-19. 


\section{CHAPTER 1}

\section{Wealth Constraints and Self-Employment: Evidence from Birth Order}

\subsection{Introduction}

A critical problem facing a would-be entrepreneur is whether there is enough capital to start the business. If access to outside finance is restricted, his personal wealth certainly would play a significant role in meeting the initial capital requirement. As a result, a positive relationship between personal wealth and entry into self-employment provides prima facie evidence that financial constraints affect new business formation. On the basis of this logic, early empirical work, normally using net family assets to measure wealth, consistently finds evidence of liquidity constraints in entrepreneurship (Evans and Jovanovic 1989; Evans and Leighton 1989). However, as widely noted in subsequent studies, household assets are not an exogenous proxy for wealth. They are positively correlated with unobserved entrepreneurial ability, which may have a dominant effect on a person's propensity to become self-employed. Studies that fail to account for this endogeneity overestimate the role of personal wealth, and therefore yield spurious evidence of financial market imperfections.

The ideal solution is, of course, to find an instrument for wealth. A popular choice has been inheritance, lottery winnings, or capital gains on housing (Blanchflower and Oswald 1991; Holtz-Eakin, Joulfaian, and Rosen 1994a, 1994b; Hurst and Lusardi 2004; Lindh and Ohlsson 1996; Georgellis, Sessions, and Tsitsianis 2005). The underlying rationale for choosing these variables as an instrument for wealth is that inheritance, lottery winnings, or capital gains on housing are windfall gains, which one supposes should have no direct relationship with unobserved ability. However, as part of household wealth, 
these instruments still bear the risk of being indirectly related to unobserved ability either through individual personalities or family-specific characteristics.

First, consider inheritance. As we know, the size of inheritance depends on the wealth of parents; while a wealthy family is also likely to have other characteristics favorable to successful business formation, including good education, successful career experience, and extensive social networks. All these factors may affect the entrepreneurial prospects of any individual. Dunn and Holtz-Eakin (2000) offer some direct evidence in their study of the intergenerational transmission of wealth and experience. First, they find that selfemployed parents tend to be much wealthier than wage-employed parents. They further show that the entrepreneurial histories of parents have a strong positive effect on a son's entry into entrepreneurship. In contrast, the impact of the financial capital of parents is quite small. These findings suggest two separate effects that may be captured by inheritance on the entry of self-employment: a pure wealth effect and the effect of familyspecific human capital, such as entrepreneurial skills, managerial human capital, or knowledge of business. Hurst and Lusardi (2004) suggest a way to test the correlation between inheritance and these unobserved family-specific factors. The underlying mechanism is that if inheritance is simply a proxy for liquidity constraints, we would only expect a significant effect on the probability of starting a business of inheritance received in the past. In contrast, if inheritance also proxies for other factors such as entrepreneurial ability, then both past inheritance and future inheritance should predict current business entry. Their result shows almost equivalent effects of these two types of inheritance on the probability of starting a business, which proves again that inheritance is likely an invalid instrument for wealth. 
Lottery winnings might appear to be less likely than inheritance to be related to any personal or family characteristics. Nonetheless, the problem with lottery winnings is that they are likely to be associated with low-ability or low-income people who wish to change the direction of their fortune by buying lottery tickets. It is well-known that lowincome and less-educated families buy lottery tickets at a much greater rate than do highincome educated families (see McCrary and Pavlak [2002] for a review). If income and education are mismeasured, then this alone would invalidate lottery winnings as an instrument of wealth. Moreover, there is also evidence that lottery demand is related to characteristics that are likely unobservable to econometricians even in the best of circumstances. Brenner (1986), for example, reports from a Canadian survey of 93 lottery winners that " $[\mathrm{t}] \mathrm{he}$ image of the lottery ticket buyer that emerges . . . is of a person who, finding all other avenues of success closed because of one form or other of sudden adversity, turns to lotteries as a recourse."

Hurst and Lusardi (2004) use capital gains on housing as an instrument for change in wealth. There are reservations about using capital gains on housing for two main reasons. First, the size of capital gains on housing depends on the size of the house, which, again, is positively related to the owner's entrepreneurial ability. Second, the appreciation of housing price is usually higher in densely populated cities with expanding economic opportunities, places where people are more likely to be attracted to entrepreneurship because of abundant opportunities. To ameliorate these problems, Hurst and Lusardi (2004) obtained regional variations in house prices after controlling for household demographics and regional economic activity. These unpredicted variations are then 
assigned to each household by region, and then used as an instrument for household wealth.

A recent study by Nanda (2008) examines the effect of a tax reform in Denmark on entry into entrepreneurship. Departing from the prior research which looks into the existence of liquidity constraints through the relationship between wealth and entrepreneurial entry, Nanda (2008) exploits an exogenous change in the cost of finance to distinguish the effect of wealth constraints on entrepreneurship from other unobservable factors that may affect a person's propensity to become an entrepreneur.

In this paper, I follow the traditional approach of finding a suitable instrument for wealth. What distinguish the present study from previous work is that the instrument constructed solely builds on the specific primogenitary aspect of Korean culture.

South Korea has normally been regarded as a male-dominant society in which fidelity to one's parents is highly valued. Prendergast (2005) describes the traditional role of the eldest son in South Korea, which is extremely significant. In the past, the eldest son was expected to remain in the house, care for elderly parents, and take responsibilities of the whole family. In return, he would receive most, sometimes all, of the parents' bequest. Although this traditional family tie between the eldest son and his parents has weakened as more and more Koreans migrate from rural areas to the cities for either education or job opportunities, the preference for the eldest son to be the primary heir remains strong among elderly South Koreans. Indeed, until 1990, it was written into law that the eldest son should receive an inheritance twice the amount of that received by other sons. In 1990 this rule was abolished and replaced with provisions requiring an equal share of inheritance among all siblings, regardless of sex. But this change in law is frequently 
circumvented in practice. A very common way is for parents to transfer much of their wealth to their sons, and especially to their eldest son, when the parents are still alive. This practice leads to the fundamental identifying strategy of this paper. That is, being the eldest son in Korea is correlated with an individual's wealth, through either inheritance or pre-mortem wealth transfer from parents. Moreover, a person's birth order is not, ceteris paribus, likely to be affected by unobserved family characteristics, and is not correlated with economic or regional factors. Thus, an indicator variable recording whether an individual is the eldest son is a promising candidate instrument for wealth in South Korea and other countries with similar tradition, although this instrument is unlikely to be especially useful in the west such as the United States, where there is little correlation between birth order and inheritance.

There are several concerns about the usefulness of this instrument. One relates to the eldest son's responsibility of taking care of elderly parents, which inevitably involves some substantial expenditure. Although nowadays this filial obligation tends to be shared by all offspring, in customary practice, it is still the eldest son or the well-off child who is expected to provide more financial support to the parents than other siblings (see Prendergast 2005). Thus, although the eldest son receives more wealth transfer from parents, his financial responsibility for the parents may reduce this pecuniary benefit, perhaps to the extent that it fully offsets the positive wealth effect of being the eldest son. The problem hinges on how to distinguish these two methods of wealth transfer and obtain a clear-cut wealth effect of being the eldest son. My strategy relies on sorting the eldest son into two types - with or without college education, and treating them separately. The reason is as follows. For many Korean parents, paying for a child's 
college education is considered as an alternative way of wealth transmission. Hence, in many cases, if the eldest son has a college education, parents prefer to leave more wealth to his siblings who did not go to college. This behavior of parents is based on two considerations. On one hand, parents think that if they already paid for the eldest son's college education, which often consumes a large part of family wealth, his siblings should receive the bulk of the remaining family wealth. On the other hand, parents also believe that life should be relatively easier for children who have obtained college education. Hence, children without college education should receive more help from the family. According to this practice, there should be a positive relationship between being the eldest son and a person's wealth if the son is not college-educated. In contrast, this relationship should become much weaker or even turn to be negative among those with college education, as the college-educated eldest son is likely to receive relatively less wealth transfer from the parents, but instead is expected to provide more financial support to the parents and the family.

The second concern about the quality of the instrument is that birth order may capture other factors besides its impact on wealth. Among previous studies on birth order, the fundamental focus is its linkage to the allocation of parental resources (such as financial and time inputs) and the subsequent child outcomes in terms of personality, educational attainment, and other social behaviors.

In the psychology literature, there has been a long debate about whether a person's personality is associated with his or her birth order. Sulloway (1996) points out that children compete for parental resources in the family by creating distinctive niches. As a result, firstborn children tend to be more responsible, competitive, and conventional than 
younger siblings because their position is already established. In contrast, laterborn children must distinguish themselves by being playful, cooperative, and rebellious. Sulloway's (1996) theory raises doubts about using birth order as an instrument for wealth in this context, as the eldest son may possess certain characteristics that make him more likely to enter into self-employment. However, this theory does not appear to be consistent with many empirical studies, which find no significant birth order effects in various personality categories (see Jefferson et al., [1998] for a review). Furthermore, earlier studies also argue that personalities developed in childhood are not always retained in adulthood (Block [1993], Siegler et al., [1990]). These empirical findings suggest that birth-order effects on personalities, if existing, are probably very small, and should not be a concern in the following IV estimations.

Even if Sulloway's (1996) theory holds, we can indirectly test the impacts of personalities captured by birth order on entry into self-employment by examining the eldest daughter's entrepreneurial propensity. Since the eldest daughter, who has personalities associated with the first-born child, has little privilege in sharing parents' wealth, a positive relationship between being the eldest daughter and a person's probability of becoming self-employed would imply that birth order captures factors other than wealth, such as personalities, which affect entrepreneurial entry. In the unreported regressions, I include a dummy variable for the eldest daughter, and do not find any significant effect of being the eldest daughter on a person's likelihood of becoming self-employed. The results further confirm my conclusion that the potential correlation between birth order and personalities should not prevent birth order from being a valid instrument for wealth in South Korea. 
Another factor that birth order may capture is educational attainment. About birth order effects on parental educational investment, there has not been a unanimous view in the literature. While some studies find a negative birth order effect on children's education (Black, Devereux, and Salvanes 2005; Booth and Kee 2005; Conley and Glauber 2005), others find the completely opposite result. Ejrnæs and Pörtner (2004), for example, argue that in the Philippines, laterborn children actually have an advantage over their earlierborn siblings regarding completed education. ' Regardless of the exact relationship between birth order and education, an essential question is whether education is an important factor that is involved in entry into self-employment. Previous longitudinal studies relieve this concern by suggesting that the effect of formal education on the probability of becoming self-employed is not significant after we control for individuals' earnings and occupation (See Georgellis, Sessions, and Tsitsianis [2005] for a review). The third main issue regarding this instrument arises from its correlation with family size. Although in which order a person is born appears to be exogenous, the probability of being the eldest son increases if a person has a smaller number of siblings. As the size of a family is often related to the parents' education and ability, the variation in family size causes a potential endogeneity problem. Another related issue is that wealth is more diluted in a larger family. Hence, the portion of wealth transferred to the children, even the eldest son, could be relatively small in large families, which adds limited contribution to the children's overall wealth. These two problems can be alleviated by either adding controls for the sibling count or restricting the sample to individuals with a similar number of siblings.

\footnotetext{
'Black, Devereux, and Salvanes (2005) use data from Norway, Booth and Kee (2005) use data from Britain, and data used by Conley and Glauber (2005) are from the U.S.
} 
I implement the IV estimation of the effect of wealth on the probability of becoming selfemployed using data from the Korean Labor and Income Panel Study. My analysis focuses on the annual transitions from wage employment to self-employment. Individuals who were running a family business are not included in the study, as the operation of family business has its own distinctive features and is more related to family-specific characteristics. Without controlling for the number of siblings, the estimated effect of wealth instrumented with the son's birth order is positive for both the educated and uneducated groups of observations. But the result is not statistically significant. A plausible explanation for obtaining an insignificant result is the noise of the instrument caused by the variations in the sibling count. Simply adding the sibling count does not change the significance of the result, probably because of the large difference in the number of siblings which varies from 0 to 16 in my sample. If I adopt the second strategy and limit the sample to individuals who report having 3-5 siblings, the wealth effect generated in the restricted sample is positive and significant, which provides support for the existence of liquidity constraints. It is worth noting that this result does not imply that wealth constraints only exist among individuals coming from mediumsized families. Instead, by restricting the sample to individuals with similar number of siblings, I intend to improve the quality the instrument, which helps to generate more reliable results.

The paper is organized as follows. The next section provides a brief description of the data construction and some summary statistics. To illustrate the key problems of the analysis, section 3 presents the results from a baseline probit regression without instrumenting. Section 4 provides the cultural background that supports the intuition of 
the instrumental variable. Section 5 reports the IV estimates along with some robustness checks. Section 6 concludes.

\subsection{Data and Descriptive Statistics}

The data used in this paper come from the Korean Labor and Income Panel Study (KLIPS). The KLIPS is a longitudinal survey of originally 5,000 South Korean urban households and their family members. The data contain information on household and personal demographics, as well as individuals' employment history. Starting in 1998, the KLIPS has been completed up to 2005 (the $8^{\text {th }}$ wave). In this study, I focus on the five survey years spanning 2000 to 2004 (the $3^{\text {rd }}$ Wave - the $7^{\text {th }}$ Wave). This provides a sample of total 4,999 individuals who were either wage workers or self-employed workers throughout the period. Not all individuals remained in the sample for all five years. The mean participation in the sample is 2.1 years, providing me with 10,522 observations on these individuals.

In this section, I provide some of the descriptive statistical summaries of the sample. A more detailed description of the data set and variable construction is presented in the appendix. Table 1.1 summarizes the sample demographics by employment status. Sixtyeight percent of the sample was male; $26 \%$ was 35 years old or below, and $61 \%$ was aged between 36 and 55; around $35 \%$ had college degree; and the majority people in the sample were married $(88 \%)$. The fraction married is large because the sample contains observations on household heads and their spouses if they have one-if spouses are excluded, the fraction married was 79 percent.

Table 1.2 summarizes the distribution of employment status by demographics. As it shows, male, non-college educated, married, and middle-aged individuals are more likely 
to be self-employed. The column and rows labeled "TRANSITION" provide information on observations recording a one-year transition from wage employment to selfemployment.

TABLE 1.1

Demographic Distribution by Employment Status and Transition into Self-Employment

\begin{tabular}{ccccc} 
& Total & SElf-EMPloyed & WAGE-EARnER & TRANSITIONS \\
\hline MALE & 68 & 73.9 & 66.1 & 78.8 \\
COLLEGE & 35.4 & 26.8 & 38.2 & 38.8 \\
MARRIED & 87.9 & 90.6 & 87 & 90.6 \\
& & & & \\
AGE & & & & \\
$19-35$ & 26.4 & 12.9 & 30.9 & 30.6 \\
$36-45$ & 35.4 & 35.2 & 35.5 & 29.4 \\
$46-55$ & 25.4 & 32.6 & 22.9 & 30.6 \\
$>56$ & 12.8 & 19.2 & 10.7 & 9.4 \\
\hline
\end{tabular}

Figures are percentages of each column falling into each row class. 10,522 observations.

Twenty-six percent of the sample reported being self-employed, though only 0.8 percent of the total observations involved a transition from the wage sector to self-employment. This number, however, may modestly underestimate the real rate of transition, as nearly four percent of the sample already reported being self-employed the first time it was observed. Some of these observations may correspond to a switch from wageemployment to self-employment, but I am not able to identify them. Nonetheless it is clear that self-employment is both common and stable in South Korea. One percent of male respondents made at least one switch from wage-employment to self-employment, compared to only 0.5 percent among female respondents. The probability of transition is also slightly higher among married and college-educated people. Although the rate of self-employment is highest among those over age 55 , the great majority of transitions into 
self-employment occur at younger ages. This is consistent with the stylized fact that older people are less likely to switch to self-employment.

TABLE 1.2

Distribution of Employment Status by Demographic Variables

\begin{tabular}{|c|c|c|c|c|c|c|c|}
\hline & \multirow[b]{2}{*}{ TOTAL } & \multicolumn{6}{|c|}{ AGE RANGE } \\
\hline & & $19-35$ & & $36-45$ & & $46-55$ & $>55$ \\
\hline SELF-EMPLOYED & 26.2 & 12.2 & & 24.8 & & 32.1 & 37.3 \\
\hline \multirow[t]{3}{*}{ TRANSITION } & 0.81 & 0.9 & & 0.7 & & 1.0 & 0.6 \\
\hline & \multicolumn{2}{|c|}{ GENDER } & \multicolumn{3}{|c|}{ COLLEGE EDUCATED } & \multicolumn{2}{|c|}{ MARITAL STATUS } \\
\hline & MALE & FEMALE & YES & & No & MARRIED & SINGLE \\
\hline SELF-EMPLOYED & 27.0 & 20.4 & 18.9 & & 28.2 & 25.7 & 19.3 \\
\hline TRANSITION & 0.9 & 0.5 & 0.9 & & 0.8 & 0.8 & 0.6 \\
\hline
\end{tabular}

Figures are percentages of each column falling into each row class. 10,522 observations.

TABLE 1.3

Summary Statistics by Industry

\begin{tabular}{lccc} 
& \multicolumn{3}{c}{ PERCENTAGE } \\
\cline { 2 - 4 } & TOTAL & SELF-EMPLOYED & WAGE-EARNER \\
\hline MANUFACTURING & 25.6 & 14.6 & 29.3 \\
WHOLESALE AND RETAIL & 15.7 & 33.2 & 9.9 \\
CONSTRUCTION & 9.7 & 6.6 & 10.7 \\
TRANSPORTATION AND COMMUNICATION & 7.4 & 8.8 & 6.9 \\
EDUCATION & 7.3 & 3.3 & 8.7 \\
HOTELS AND RESTAURANTS & 6.5 & 11.8 & 4.7 \\
COMMUNITY, REPAIR, AND PERSONAL SERVICE & 5.8 & 8.7 & 4.8 \\
FINANCIAL INSTITUTION AND INSURANCE & 4.7 & 1.3 & 5.8 \\
OTHER & 17.3 & 11.7 & 19.2 \\
\hline TOTAL OBSERVATIONS & 10,522 & 2,620 & 7,902 \\
\hline
\end{tabular}

Table 1.3 summarizes the distribution of wage earners and the self-employed across major industries. Wage earners are more heavily represented in manufacturing, construction, and education. The self-employed are more likely to be found in service industries, especially in retail and wholesale where over one third of the self-employed worked. 


\subsection{Self-Employment and Wealth Constraints: Probit Estimates}

In the previous studies of liquidity constraints, a general baseline specification for the estimation is

$$
\text { selfe }_{n}=\beta_{0}+\beta_{1} a_{u-1}+I_{u \prime}^{\prime} \beta_{2}+X_{t t-1}^{\prime} \beta_{3}+\varepsilon_{u}
$$

where the dummy variable, selfe, indicates an annual transition into self-employment; $a_{i}$ is household wealth; $I_{i}$ and $X_{i}$ are two sets of control variables. The term, $I_{i}$, is a vector of observed demographic characteristics, such as age, gender, marital status, and educational attainment, while $X_{1}$ is a vector of employment variables, including previous wage earnings. years of work experience, indicator variables of employment and occupation, etc. ${ }^{2}$ The variable, $\varepsilon_{i}$, represents all other determinants of the transition into selfemployment, including an individual's unobserved entrepreneurial attributes. Before proceeding to estimate equation (1), assumptions about three key explanatory variables, household wealth. wages, and educational attainment, merit some discussion.

\subsubsection{Linearity in Wealth}

Equation (1) specifies a linear relationship between household wealth and the probability of becoming self-employed. ${ }^{3}$ Previous work also tends to report results from nonlinear specifications. For example, Hurst and Lusardi (2004) estimate a nonlinear wealth model with a fifth-order polynomial in wealth. They conclude that the nonlinear specification fits the data better, as a simple linear relationship is likely to be driven by households at the top of the wealth distribution.

\footnotetext{
2 Few studies actually control for all these terms. Most studies include some subset of these variables.

"Here I follow Hurst and Lusardi (2004) and refer equation (1) as the "linear" specification for wealth. In contrast. a model that involves the higher power of wealth is referred as a "nonlinear" specification for wealth.
} 
To decide which model is more appropriate for the South Korean sample, I first run several simple regressions using both linear and non-linear specifications. The variable of wealth is constructed based on the formula used by Evans and Jovanovic (1989) and Xu (1997): Net Assets=Investment in Real Estate + Financial Assets (including Savings, Stocks, Bonds, Insurance, Loans to friends or relatives, and other financial assets) Debts (including balance of debt from bank/non-bank, balance borrowed from private route, balance from loans, and other debts). All these variables are originally measured in units of 10 million Korean won (KW), approximately US\$10,000. Net assets are expressed in real value with the base year of 2000 . The essential argument for using birth order as an instrument for wealth is the plausible relationship between being the eldest son and a person's household wealth. But this relationship may not be found in poor families, as parents do not have much to give, even to the eldest son. In this case, the instrument would be uninformative, which is the downside of this approach. The concern is substantiated in an unreported analysis, where I run the first stage regression in two subsamples. The first subsample only includes observations reporting positive net household assets, and the second subsample only consists of those reporting negative net assets. In the former case, being the eldest son increases a person's household assets by $9,200,000$ won (around 8363 US dollars), and the result is significant at the one percent level. In contrast, among observations with negative household assets, which are also more likely to be associated with poor family background and low education, I find no significant relationship between wealth and a son's birth order. Based on the consideration of the relevance of the instrument, the current analysis only focuses on individuals with positive household assets. Respondents who reported negative household 
assets or had missing information on assets are removed from the sample. This way also gives me the convenience of using logarithm of wealth in the later analysis.

Column (1) in Table 1.4 shows the results from the linear specification. Consistent with previous findings, the effect of wealth on the probability of becoming self-employed is positive and significant at the ten percent level. However, the marginal effect is quite small: for each US\$100,000 increase in household assets, the probability of becoming self-employed increases by 0.3 percent. This number is close to the 0.5 percent reported by Hurst and Lusardi (2004) using data from the Panel Study of Income Dynamics.

In Column (2) of Table 1.4, a quadratic in assets is added to the regression. The marginal effect of wealth on the probability of self-employment is 0.5 percent for each $\$ 100,000$ increase in household assets, which is slightly higher than the marginal effect obtained in the linear model. The opposite signs of the two coefficients suggest that the effect of wealth on the probability of switching to self-employment declines as wealth rises, but the estimated coefficient on the squared term is not significant at the conventional ten percent level.

Bartus (2005) has suggested that, to find out whether the nonlinear effect of a variable is increasing at a decreasing rate or is inversely U-shaped, we can check the value of the original term that maximizes the linear prediction. If the value is within the range of the original term, then the effect is inversely U-shaped. In this model, the linear predictionmaximizing value of assets is 285.92 , which is higher than its maximum 225.84 . This implies that the marginal effect of assets on the odds of starting a business is positive in general, but stronger, in particular, for people at the lower end of wealth distribution. 
Unsurprisingly, a $\$ 10,000$ increase of assets means more to the poor would-be entrepreneurs than to the rich.

The conclusion is that although it is possible that the effect of wealth on the probability of becoming self-employed is not constant over the whole distribution of wealth, this nonlinear relationship does not seem to be prominent in this Korean data set. Meanwhile, a likelihood ratio test also does not reject the specification in which wealth enters linearly (p-value .12).

In this paper, I make a slight change of specification (1) by using the logarithm of wealth. By focusing on the effect of one percent change in household assets on the probability of starting a business, this specification provides the convenience to make cross-country comparisons.

\subsubsection{Wage Earnings}

Prior self-employment earnings in the wage-employment sector are usually considered as an important determinant of self-employment. Table 1.4 shows a negative relationship between previous wage earnings and entry into self-employment, which supports the common notion that people with lower earnings are more likely to choose selfemployment because of lower opportunity costs (Georgellis, Sessions, and Tsitsianis 2005).

Of course, interpretation of the wage effect is complicated by its correlation with unobserved ability. Several studies have shown that self-employment is made up of workers with the lowest or highest ability (Ohyama 2007; Åstebro, Chen, and Thompson 2008). The former are pushed into self-employment because their poor performance limits their job opportunities in the wage sector, while the latter are attracted to self- 
employment because of its higher returns. In this sense, if the wage is positively related to workers' ability, we would expect to see both high-wage and low-wage workers switching from wage sector to self-employment. Which group accounts for the larger proportion depends on the specific data sample. Furthermore, if ability is also considered as being transferable across sectors, low-wage workers would be less likely to become self-employed since they cannot expect to do better in self-employment.

TABLE 1.4

Comparing Linear and Nonlinear Specifications for Wealth

\begin{tabular}{|c|c|c|}
\hline & \multicolumn{2}{|c|}{$\begin{array}{l}\text { DEPT. VAR: PROB. BECOMING SELF- } \\
\text { EMPLOYED }\end{array}$} \\
\hline & (1) & (2) \\
\hline \multirow[t]{2}{*}{ LAGGED ASSETS/ 1000} & $0.01^{* * *}$ & $0.02 * *$ \\
\hline & $(4.26)$ & $(2.97)$ \\
\hline \multirow[t]{2}{*}{$(\text { LAGGED ASSETS } / 1000)^{2}$} & --- & $-5.28 \mathrm{e}-05$ \\
\hline & & $(-1.51)$ \\
\hline \multirow[t]{2}{*}{ WAGE $/ 1000$} & $-1.56^{* *}$ & $-1.65^{* *}$ \\
\hline & $(-2.65)$ & $(-2.73)$ \\
\hline \multirow[t]{2}{*}{ AGE } & $-0.01^{*}$ & $-0.01^{* *}$ \\
\hline & $(-1.73)$ & $(-2.03)$ \\
\hline \multirow[t]{2}{*}{ MARRIED } & 0.05 & 0.03 \\
\hline & $(0.32)$ & $(0.19)$ \\
\hline \multirow[t]{2}{*}{ MALE } & $0.25^{* *}$ & $0.26^{* *}$ \\
\hline & $(2.37)$ & $(2.42)$ \\
\hline \multirow[t]{2}{*}{ COLG } & 0.04 & 0.03 \\
\hline & $(0.41)$ & $(0.27)$ \\
\hline \multirow[t]{2}{*}{ MARGINAL EFFECTS OF ASSETS } & $0.0003^{* *}$ & $0.0005^{* *}$ \\
\hline & $(4.03)$ & $(3.06)$ \\
\hline OBS. & 6,355 & 6,355 \\
\hline
\end{tabular}

In this and subsequent tables, number of observations varies as a result of missing data on selected regressors. Significance levels: ${ }^{* * *} 0.01,{ }^{* *} 0.05,{ }^{*} 0.1$.

To partly address this endogeneity issue regarding unobserved innate ability, I replace the level of wage with its growth rate in the model for two reasons. First, workers care about the prospect of their income more than their current earnings. Anticipating a further decrease of their wage income in the future is more likely to make them consider self- 
employment. More important, the negative growth of wage can often be attributed to an exogenous shock instead of a worker's own ability. Thus, workers who are experiencing decreasing wage earnings could expect to earn more in self-employment. Thus, I expect a negative relationship between the growth of wage and the probability of entry into selfemployment. Using the growth rate of wage growth is certainly not a perfect way to solve the endogeneity problem. But it alleviates the severity of this issue.

\subsubsection{Education}

The trouble with educational attainment is that it is closely related to several other covariates, such as earnings and occupation. However, Georgellis, Sessions, and Tsitsianis (2005) show that after controlling for these variables, previous longitudinal studies show no significant effect of formal education on the probability of becoming self-employed.

Educational attainment is also correlated with wealth. This correlation arises in two ways. First, highly-educated people are better at accumulating wealth. Second, even at the same level of wealth, highly-educated people may have easier access to external finance because of better credibility, networks, or perceptions of potential financiers about the chances for success. Thus, there is a possibility that highly-educated entrepreneurs face fewer liquidity constraints compared to their less-educated counterparts. This difference, however, is neglected if education is added to the regression as a control variable, in which case the slope on wealth is forced to be the same for both educated and uneducated groups. The issue that wealth may affect entrepreneurial entry distinctively for collegeeducated and non college-educated people becomes even more substantial in the present Korean data, simply because the relationship between wealth and being the eldest son in 
Korea is likely to be negative if the son had a college education and positive if he did not, as previously discussed. Although it is so far a hypothetical argument, I will show later how the data support this hypothesis. To distinguish these two cases, I drop the variable of education from all regression models in the following analysis. Instead, I split the sample into two sub-samples: one of observations with college education and the other without. Each regression is then estimated separately on each sub-sample.

\subsubsection{A Modified Baseline Specification}

My modified baseline specification is

$$
\text { selfe }_{t \prime}=\beta_{0}+\beta_{1} \ln \left(a_{t \prime-1}\right)+\beta_{2} p g w_{t \prime-1}+X_{t \prime}^{\prime} \beta_{3}+\varepsilon_{i t},
$$

where selfe $_{i}$ is still a binary variable that takes the value one if individual $i$ switches from wage-employment to self-employment, and zero if otherwise; $\ln \left(a_{i}\right)$ is the logarithm of net assets in the previous year; $p g w_{i}$ is the growth rate of monthly wage in the previous year for individual $i$; and $X_{i}$ is a vector of demographic variables including age, gender, and marital status. At this stage, I do not control for occupation and industry. This experiment is left to the robustness check at the end of the analysis.

Table 1.5 reports the estimated effect of net assets on the probability of becoming selfemployed in the modified baseline probit regression (2). Column (1) shows that in the non college-educated sample, there is a positive relationship between the odds of becoming self-employed and the amount of assets prior to the transition into selfemployment. The coefficient on the variable of interest, lagged log assets, indicates that a ten percent increase in assets raises the probability of becoming self-employed by two percent. The result is significant at ten percent level. In column (2), the college-educated sample, the estimated coefficient on lagged log assets is positive, but it is much smaller 
and not significantly different from zero. Thus, the effect of assets appears to be stronger for the non college-educated people than their college-educated counterpart. The estimated results on other covariates suggest that men are more likely to switch from wage employment to self-employment; while people who are married or older are less likely to make this transition. Moreover, people are more likely to become self-employed when they experience declining earnings in the wage-employment sector. While the signs are consistent with intuition, none of these effects is statistically significant.

TABLE 1.5

Probability of Becoming Self-Employed: Probit Regressions

\begin{tabular}{lcc}
\hline & $\begin{array}{c}\text { DEPT. VAR=1 IF SWITCHED INTO SELF- } \\
\text { EMPLOYMENT IN CURRENT YEAR. }\end{array}$ & $(2)$ \\
& NO COLLEGE & COLLEGE \\
\hline LAGGED LOG ASSETS & $0.09^{*}$ & 0.01 \\
GROWTH OF MONTHLY WAGE IN & $(1.76)$ & $(0.25)$ \\
PREVIOUS YEAR & -0.04 & -0.45 \\
& $(-0.26)$ & $(-1.49)$ \\
AGE & -0.01 & -0.01 \\
& $(-0.78)$ & $(-0.80)$ \\
MARRIED & -0.32 & --- \\
& $(-1.55)$ & 0.19 \\
MALE & 0.07 & $(0.76)$ \\
& $(0.43)$ & -0.08 \\
\hline AV. LOG LIKELIHOOD & -0.06 & 0.02 \\
PSEUDO $R 2$ & 0.02 & 1,387 \\
OBS. & 2,605 & \\
\hline Z-scores are in parentheses. Significance levels: $* * * 0.01, * * 0.05, * 0.10$. Variable MARRIED \\
is dropped from the regression in column $(2)$ because MARRIED=0 predicts self-employment \\
perfectly. & &
\end{tabular}

The main concern with these regressions is of course the expected positive correlation between assets and unobserved entrepreneurial ability. It is worth noting that this unobserved ability is not equivalent to formal education, and it is entirely possible that people with the same level of education differ in unobserved abilities. I turn now to IV 
estimations, using birth order as an instrument. The next section begins with a justification for using this instrument in the Korean data.

\subsection{The Hypothesis and Cultural Background}

We don't have much to give, but the house will go to our eldest son. This is for two reasons. First our house was bought with some help from him. He deserves a share because of this. Second, my eldest son went through many difficult times looking after his younger brothers and sisters. We wanted them to go to school in Chonju so my first son and his wife took them into his house and cared for them there.

Prendergast (2005: 160)

This conversation comes from an interview of a Korean woman, who was asked about her plans for dividing the family's house and property. Her reply characterizes the basic role that the Korean society has defined for the son, especially the eldest son. In the old days, the social expectation for the eldest son was to take care of parents in their old age, help the family's welfare, and support younger siblings. In return, the eldest son would receive the lion's share of any inheritance. According to pre-1962 legal code, the amount of inheritance the eldest son should receive was twice the amount received by other younger sons. Sorensen (1986) and Prendergast (2005) report that it was customary for the eldest son to receive at least half the estate regardless of the number of other sons. Married daughters were usually excluded from the division altogether.

This traditional inheritance system has been notionally weakened since legal changes in 1990 stipulating that all successors have equal shares of an inheritance regardless of sex or marital status. However, Sorensen (1986) and Yang (1998) note that the influence of patriarchal rules and obligations for sons continues through either traditions in Family Law or belief in the "moral value of filial piety". In Prendergast's (2005) survey of fifty 
elderly men in southwest Korea, almost half of the respondents preferred the eldest son to receive the largest share of inheritance. Prendergast (2005) also found that elderly people find a number of ways to avoid strictly following the equal inheritance rule. One of the avenues is through article 1008-2 of the Civil Code, which states that if a person has made a special contribution to family property, this contributory portion should be considered as his inherited portion and should be added to the amount he is supposed to inherit from the rest of the property. Because this clause tends to compensate those (often sons), who remain with parents and provide them with financial support, parents have considerable latitude to pass more property to their sons. Another common way to circumvent the law is through a family meeting, in which the parents declare their wishes to transmit property to specific recipients (such as the eldest son) before all family members. But the most important way to circumvent the inheritance law is to transmit property prior to death. In fact, because of this practice, many Korean parents also count dowries and other wedding expenses, investments in education, or donations for setting up businesses, as part of their pre-mortem transfer of property. In practice, this has provided justification for providing daughters little of the inheritance. At the end of his field study, Prendergast (2005) concludes that in modern Korea, sons, especially eldest sons, remain highly favored in parents' decisions about the distribution of family wealth. As the distribution of family wealth can be either prior to death or through bequests, it seems that being the eldest son in South Korea should be positively related to a person's wealth. However, this relationship may be rather complicated when parents are still alive. As mentioned above, the eldest son has the obligation of caring for elderly parents and for providing support to other siblings. Married daughters are also expected to contribute 
to their natal family, but the amounts and frequencies of money provided by them are typically far less than those provided by their brothers. From this perspective, the eldest son has the greatest financial burden of caring parents and siblings, though he is ultimately rewarded more as well. As a result, the net effect of being an eldest son on wealth becomes a purely empirical question.

As education frequently is counted as part of the pre-mortem transfer made to children, I conjecture that net financial transfers from the eldest son to his parents are greater for the college educated. During each wave's interview, respondents were asked about financial support they gave or received from parents in the previous year. The numbers reported do not include real estate transfers or post-mortem inheritances. Based on the respondents' answers, I calculate the net financial support, which is the difference between the amount of support respondents provided to their parents and the amount they received from parents. The mean of this difference in the college-educated sub-sample is $960,000 \mathrm{KW}$, which is, as expected, more than twice the mean in the non college-educated sub-sample. Moreover, the net amount provided by the eldest sons with college education is markedly higher at the $50^{\text {th }}, 75^{\text {th }}$, and $95^{\text {th }}$ percentiles.

Table 1.6 reports the results from regressing the net financial support on a series of demographic variables. The coefficient for the variable, eldest, is positive and significant, indicating that the eldest son, in general, provides more financial support to parents than other siblings. This relationship is even stronger for the eldest sons who had college education, as shown in columns (2) and (3). The results are consistent with the conjecture that the effect of being the eldest son on wealth may differ at these two educational levels. 
To summarize, although the eldest sons often dominate the "wealth transmission" system, they are also the main provider of income to aged parents. This burden is even larger if the eldest son is wealthier or better educated, in which case his share of wealth transfer from parents might also be largely reduced. Hence, the hypothesis is that the relationship between wealth and being the eldest son in South Korea is negative if the son is college educated, and positive if he is not.

TABLE 1.6

The Effect of Being the Eldest Son on Net Cash Transfer

\begin{tabular}{lccc}
\hline & \multicolumn{3}{c}{ DEPT. VAR: NET INCOME TRANSFER TO PARENTS } \\
\cline { 2 - 4 } & ALL INDIVIDUALS & NON-COLLEGE EDUCATED & COLLEGE EDUCATED \\
\hline \multirow{2}{*}{ MALE } & $-34.77^{* *}$ & -7.49 & $-70.97^{*}$ \\
& $(-2.13)$ & $(-0.87)$ & $(-1.70)$ \\
MAREIED & 0.44 & -0.07 & -0.32 \\
& $(0.65)$ & $(-0.21)$ & $(-0.17)$ \\
ELDEST & -1.44 & -3.97 & 7.74 \\
& $(-0.07)$ & $(-0.39)$ & $(0.14)$ \\
NO. OF SIBLINGS & $39.92^{* * *}$ & $20.25 * * *$ & $74.93 * *$ \\
& $(2.67)$ & $(2.46)$ & $(2.09)$ \\
LAGGED LOG WAGE & $5.79 *$ & 1.61 & 13.63 \\
& $(1.61)$ & $(0.87)$ & $1.41)$ \\
COLG & $54.64^{* * *}$ & $24.62^{* * *}$ & $(3.54)$ \\
& $(4.89)$ & $(4.15)$ & -- \\
\hline OBS. & $23.2 *$ & -- & 1,857 \\
\hline
\end{tabular}

t-statistics are in parentheses. Significance levels: $* * * 0.01,{ }^{* *} 0.05, * 0.10$.

\subsection{Self-Employment and Wealth Constraints: IV Results}

In the $6^{\text {th }}$ wave of the KLIPS, respondents were asked the following two questions:

- Do you have either brothers or sisters? a. Number of total brothers, b. Number of total sisters, c. Birth order.

- Do you have older brothers or sisters? a. Number of older brothers, b. Number of older sisters. 
estimated coefficients on eldest are not significantly different from zero, which relieves this concern.

The main advantage of using birth order as the instrument for wealth is its little correlation with any family or social factors. Nonetheless, one may argue that the chance of being the eldest son decreases with the number of siblings, while family size is commonly considered as a reflection of parents' education and household wealth. Consequently, a critical question is whether the size of siblings could invalidate the current instrument, eldest, through an indirect correlation with household wealth, and then further bias the estimated result. Columns (3) and (4) of Table 1.7 show that the estimated coefficient on the variable of sibling number is not statistically significant, indicating that sibling size is not an omitted variable. This result excludes the possibility that the instrument is correlated with a relevant variable omitted from the regression.

TABLE 1.7

Testing for Omitted Variables DEP. VAR: = 1 IF BECOMING SELF-EMPLOYED IN CURRENT YEAR

\begin{tabular}{|c|c|c|c|c|}
\hline & \multicolumn{4}{|c|}{ DEP. VAR: $=1$ IF BECOMING SELF-EMPLOYED IN CURRENT YEAR } \\
\hline & (1) & $(2)$ & $(3)$ & (4) \\
\hline & NO COLLEGE & COLLEGE & NO COLLEGE & COLLEGE \\
\hline \multirow{2}{*}{ LAGGED LOG ASSETS } & $0.13 * *$ & 0.03 & $0.13 * *$ & 0.04 \\
\hline & $(2.11)$ & $(0.42)$ & $(2.19)$ & $(0.65)$ \\
\hline \multirow{2}{*}{ ELDEST SON $=1$} & -0.02 & -0.08 & --- & -- \\
\hline & $(-0.08)$ & $(-0.42)$ & & \\
\hline \multirow{2}{*}{ No. OF SIBLINGS } & --- & --- & -0.05 & -0.10 \\
\hline & & & $(-1.11)$ & $(-1.54)$ \\
\hline WAGE GROWTH IN & -0.23 & -0.55 & -0.22 & -0.55 \\
\hline \multirow[t]{2}{*}{ PREVIOUS YEAR } & $(-0.93)$ & $(-1.58)$ & $(-0.91)$ & $(-1.58)$ \\
\hline & 0.002 & -0.01 & 0.00 & 0.00 \\
\hline $\mathrm{AGE}$ & $(-0.18)$ & $(-0.67)$ & $(0.03)$ & $(-0.22)$ \\
\hline \multirow{2}{*}{ MARRIED } & $-0.48 * *$ & --- & $-0.48 * *$ & --- \\
\hline & $(-2.20)$ & & $(-2.20)$ & \\
\hline \multirow{2}{*}{ MALE } & 0.01 & 0.58 & 0.00 & 0.53 \\
\hline & $(0.04)$ & $(1.56)$ & $(0.00)$ & $(1.48)$ \\
\hline AV. LOG LIKELIHOOD & -0.06 & -0.08 & -0.06 & -0.08 \\
\hline PSEUDO $R^{2}$ & 0.04 & 0.03 & 0.04 & 0.05 \\
\hline OBS. & 2,017 & 1,155 & 2,017 & 1,155 \\
\hline
\end{tabular}

Z-scores are in parentheses. Significance levels: ${ }^{* *} 0.01,{ }^{* *} 0.05,{ }^{*} 0.10$. 
Even so, the remaining concern is the implicit correlation between sibling size and unobserved ability, which may subsequently affect the validity of the instrument, eldest. This problem can be resolved by restricting the sample according to a certain sibling size, which is addressed in the later part of the analysis.

TABLE 1.8

Reduced-Form Probit Regressions

\begin{tabular}{|c|c|c|}
\hline & \multicolumn{2}{|c|}{$\begin{aligned} \text { DEP. VAR: }= & 1 \text { IF BECOMING SELF-EMPLOYED } \\
& \text { IN CURRENT YEAR }\end{aligned}$} \\
\hline & $\begin{array}{c}(1) \\
\text { No COLLEGE }\end{array}$ & $\begin{array}{c}(2) \\
\text { COLLEGE }\end{array}$ \\
\hline \multirow[t]{2}{*}{ ELDEST } & 0.00 & -0.09 \\
\hline & $(-0.01)$ & $(-0.46)$ \\
\hline \multirow[t]{2}{*}{ WAGE GROWTH IN PREVIOUS YEAR } & -0.25 & -0.54 \\
\hline & $(-0.99)$ & $(-1.56)$ \\
\hline \multirow[t]{2}{*}{ AGE } & 0.00 & -0.01 \\
\hline & $(-0.01)$ & $(-0.55)$ \\
\hline \multirow[t]{2}{*}{ MARRIED } & -0.37 & --- \\
\hline & $(-1.74)$ & \\
\hline \multirow[t]{2}{*}{ MALE } & 0.01 & 0.57 \\
\hline & $(0.03)$ & $(1.54)$ \\
\hline OBS. & 2,017 & 1,155 \\
\hline
\end{tabular}

Murray (2006) suggests the use of reduced-form regressions to check the intuition behind an instrumental variable. Table 1.8 reports results from estimating the reduced-form regression in which the dependent variable is the probability of switching to selfemployment, selfe, and the independent variables include the instrument, eldest, as well as all non-troublesome explanatory variables in the modified baseline equation (2). The estimated coefficient on eldest is not statistically significant in both college-educated and non college-educated sub-samples. According to Angrist and Krueger (2001), there are three possible implications based on this result: either the model is under-identified, or IV estimation is uninformative, or the troublesome variable, lagged log assets, does not matter for the likelihood of becoming self-employed (i.e., there are no liquidity 
constraints).Under-identification should not be the case under the assumption that demographic variables (such as age, gender, and marital status) are not contemporarily correlated with the error term; the purpose of using the growth of monthly wage is also to avoid the endogeneity problem presented by wage levels. The question then pins down to whether or not the instrument, eldest, is relevant to wealth. If not, the instrument cannot properly serve the purpose of the analysis and IV estimation is uninformative; otherwise, the results in Table 1.8 offer a sign of no liquidity constraints. To examine the relevance of the instrument, eldest, I report in Table 1.9 the first stage regression estimates. It is not surprising to see in all three columns that household wealth is positively related to wage growth, age, and marriage. Column (1) shows no significant effect on wealth of the instrument, eldest, when controlling for college education. However, when splitting the sample by college education, I find opposite relationships between wealth and being the eldest son in the two sub-samples. In the non college-educated group (column 2), being the eldest son increases the household assets by 14 percent. By contrast, in the collegeeducated group (column 3), being the eldest son reduces the household assets by 19 percent. Both results are significant at around the five percent level. Thus, I am confident that the variable, eldest, is an informative instrument for wealth for this data set. Also, the results again substantiate the previous hypothesis that the effect of being the eldest son on wealth differs between the college-educated group and the non college- educated group. This provides a foundation for the strategy of carrying out the analysis separately in these two groups.

It is worth mentioning that there are very few observations in the data set that report living with parents. Recall from the overview of Korean culture, the distribution of 
property is strongly associated with the responsibility of caring elderly parents. In other words, a child other than the eldest son can receive a significant amount of bequest for living with and taking care of parents. In this case, living with parents might be an important explanatory variable that should be included in the regression. But this should not be case in the present data set, for there are at most 0.5 percent of respondents who reported living with parents during each wave of the interview.

TABLE 1.9

Testing for Relevant Instrument: OLS Regressions

\begin{tabular}{lccc}
\hline & \multicolumn{3}{c}{ DEPT. VAR: LOG LAGGED ASSETS } \\
\cline { 2 - 4 } & ALL & NO COLLEGE & COLLEGE \\
\hline ELDEST & -0.01 & $0.14^{*}$ & $-0.19^{* *}$ \\
WAGE GROWTH IN PREVIOUS & $(-0.18)$ & $(1.86)$ & $(-2.14)$ \\
YEAR & $0.12^{* *}$ & $0.10^{* *}$ & $0.19^{* *}$ \\
& $(2.85)$ & $(2.08)$ & $(2.25)$ \\
AGE & $0.03^{* * *}$ & $0.01^{* * *}$ & $0.07^{* * *}$ \\
& $(11.29)$ & $(3.67)$ & $(14.40)$ \\
MARRIED & $0.80^{* * *}$ & $0.83^{* * *}$ & $0.63^{* * *}$ \\
& $(9.16)$ & $(7.84)$ & $(4.11)$ \\
MALE & -0.06 & -0.04 & $-0.23^{* *}$ \\
& $(-0.88)$ & $(-0.51)$ & $(-2.16)$ \\
COLG & $0.69^{* * *}$ &.-- & --- \\
& $(12.78)$ & & \\
\hline ADJUSTED $R^{2}$ & 0.10 & 0.04 & 0.17 \\
OBS. & 3,267 & 2,017 & 1,250 \\
\hline -statistics are in parenthesis. Significance levels: ${ }^{* * *} 0.01,{ }^{* *} 0.05, * 0.10$. &
\end{tabular}

\subsubsection{Estimates}

After establishing the validity and relevance of the instrument, eldest, we are ready to look at the results from the IV regressions presented in Table 1.10. Columns (1) and (2) show that the estimated coefficients on wealth - instrumented with the variable of being the eldest son-are positive in both the college-educated and the non college-educated sub-samples, but the estimates are not statistically significant. Wage earning is the only 
employment-related variable that has been controlled for in all the regressions so far. But wealth effects may also vary across occupations: First, entry into self-employment in certain fields (such as lawyer, doctor, and salesperson) likely requires less capital; second,

TABLE 1.10

IV Probit Regressions

\begin{tabular}{lcc}
\hline & \multicolumn{2}{c}{ IV Probit Regressions } \\
& \multicolumn{1}{c}{ DEP. VAR: $=1$ IF BECOMING SELF-EMPLOYED IN CURRENT YEAR } \\
\cline { 2 - 3 } & NO COLLEGE & $(2)$ \\
\hline LAGGED LOG ASSETS & 0.02 & COLLEGE \\
WAGE GROWTH IN PREVIOUS & $(0.01)$ & 0.40 \\
YEAR & -0.21 & $(0.63)$ \\
& $(-0.67)$ & -0.54 \\
AGE & 0.00 & $(-1.53)$ \\
& $(-0.01)$ & -0.03 \\
MARRIED & -0.39 & $(-0.81)$ \\
& $(-0.30)$ & 3.32 \\
MALE & 0.003 & $(0.00)$ \\
& $(0.02)$ & $0.58^{*}$ \\
\hline AV. LOG LIKELIHOOD & -1.85 & $(1.77)$ \\
OBS. & 2,017 & -1.82 \\
\hline
\end{tabular}

Z-scores are in parenthesis.

a person's previous occupation is also, to some extent, related to the type of business he would start, which in turn determines different requirement for initial capital. On the basis of this consideration, I report in Table 1.11 the results from the IV estimation after adding controls for individuals' previous occupations. The correlation between household net wealth and the instrument, eldest, remains strong in the first-stage regression. As shown before, this correlation is positive in the non college-educated sub-sample and negative in the college-educated sub-sample. The IV estimation, again, shows no significant wealth effect on the probability of becoming self-employed. Before drawing the conclusion that there are no liquidity constraints in South Korea, we should return to the issue of sibling counts. As discussed before, the probability of being the eldest son 
increases if the person has fewer siblings. As the number of children is commonly believed to be negatively related to parents' education, eldest is possibly correlated with

TABLE 1.11

IV Probit Regressions (Controlling for Previous Occupations)

\begin{tabular}{|c|c|c|}
\hline & \multicolumn{2}{|c|}{$\begin{aligned} \text { DEP. VAR: }= & 1 \text { IF BECOMING SELF-EMPLOYED IN } \\
& \text { CURRENT YEAR }\end{aligned}$} \\
\hline & (1) & (2) \\
\hline & No COLLEGE & COLleGE \\
\hline \multirow[t]{2}{*}{ LAGGED LOG ASSETS } & -0.25 & 0.41 \\
\hline & $(-0.23)$ & $(0.57)$ \\
\hline \multirow[t]{2}{*}{ WAGE GROWTH IN PREVIOUS YeAR } & -0.17 & -0.53 \\
\hline & $(-0.46)$ & $(-1.38)$ \\
\hline \multirow[t]{2}{*}{ AGE } & 0.01 & -0.04 \\
\hline & $(0.38)$ & $(-1.07)$ \\
\hline \multirow[t]{2}{*}{ MARRIED } & -0.19 & 3.18 \\
\hline & $(-0.15)$ & $(0.00)$ \\
\hline \multirow[t]{2}{*}{ MALE } & -0.03 & 0.61 \\
\hline & $(-0.13)$ & $(1.71)$ \\
\hline \multirow[t]{3}{*}{ AV. LOG LIKELIHOOD } & -1.83 & -1.81 \\
\hline & \multicolumn{2}{|c|}{ FIRST STAGE ESTIMATES } \\
\hline & NO COLLEGE & COLLEGE \\
\hline \multirow[t]{2}{*}{ ELDEST } & $0.13^{*}$ & $-0.16^{*}$ \\
\hline & $(1.74)$ & $(-1.83)$ \\
\hline \multirow[t]{2}{*}{ WAGE GROWTH IN PREVIOUS YEAR } & $0.10^{* *}$ & $0.18^{* *}$ \\
\hline & $(2.07)$ & $(2.20)$ \\
\hline \multirow[t]{2}{*}{ AGE } & $0.02 * * *$ & $0.06^{* * *}$ \\
\hline & $(4.18)$ & $(13.12)$ \\
\hline \multirow[t]{2}{*}{ MARRIED } & $0.80 * * *$ & $0.60 * * *$ \\
\hline & $(7.60)$ & $(3.91)$ \\
\hline \multirow[t]{2}{*}{ MALE } & 0.03 & $-0.26^{* *}$ \\
\hline & $(0.31)$ & $(-2.23)$ \\
\hline OBS. & 2,017 & 1,250 \\
\hline
\end{tabular}

Z-scores are in parenthesis for IV estimation, and $t$-statistics are in parenthesis for first stage estimation. Significance levels: ${ }^{* * *} 0.01,{ }^{* *} 0.05,{ }^{*} 0.10$.

unobserved ability through this avenue. Furthermore, if a family has too many children, we would expect the wealth inherited by, or transferred to, each child (even the eldest son) to be too small to have a significant effect on the child's own assets. From this 
perspective, having a large number of siblings may weaken the explanatory power of the instrument.

Although the number of siblings ranges between zero and sixteen, fifty-seven percent of the sample report having three to five. To maintain the validity of the instrument, my initial strategy is to restrict the sample to the 6,220 observations with three to five siblings and leave out those with too few or too many siblings. But there exists another problem that is noteworthy. Recall when the data set was constructed, both household heads and their spouses are included in the sample. The couple shares observations on household assets (from household data), but each partner has his or her own observations on work status and number of siblings. The instrument, eldest, is one if a male respondent was the eldest son; it is zero if a person was not the eldest son, which includes the case of being a female respondent. Imagine there is a female respondent whose husband was the eldest son. Since the husband and the wife share the same household assets, the effect of being the wife of the eldest son should be identical to the effect of being the eldest son on household assets. However, because the variable, eldest, is coded as zero for the wife, I am not able to capture the effect on assets of being the wife of the eldest son. In fact, there are 408 households of this kind in the $6^{\text {th }}$ wave data set, where the variable, eldest, was initially constructed.

The easiest solution to this problem is to restrict the sample to males. A more sophisticated way is to identify each woman in the data whose husband was the eldest son, and then recode the variable, eldest, as one on these observations. The latter strategy allows me to include more valuable observations in the regressions. I report results from both strategies here. 


\subsubsection{Estimation from Males Alone}

Table 1.12 presents the result from restricting the sample to the male who had three to five siblings. First-stage estimates show that restricting the sample by sibling size increases the effect on wealth of being the eldest in the uneducated sub-sample. In the new restricted sample, being the eldest son increases household assets by 28 percent, compared to 14 percent in the unrestricted sample. The result is significant at the one percent level.

In the restricted educated sub-sample, the result shows that being the eldest son reduces household assets by 20 percent, which is similar to the 19 percent negative effect found in the unrestricted sample. More important, IV estimation shows in both sub-samples that an increase in household assets raises the chance of becoming self-employed, providing a significant evidence of liquidity constraints.

It is worth noting that for the college-educated group the baseline probit regression predicts no significant correlation between wealth and the probability of becoming selfemployed, but the IV estimation shows a positive and significant effect of wealth on selfemployment. This disparity arises for two possible reasons. The first possibility is that among people with a college degree, those with low ability ones are more likely to become self-employed because of low-quality job-matching in the wage sector. As wealth is positively related to unobserved ability, we cannot see any positive relationship between wealth and the odds of becoming self-employed without controlling for unobserved ability in the measure of wealth. This may not be a general case, but in the current Korean data set, nearly half of the observations on college-educated business 
TABLE 1.12

IV Probit Estimations in the Sample with Restricted Sibling Size (Male Only)

\begin{tabular}{|c|c|c|}
\hline & \multicolumn{2}{|c|}{$\begin{array}{c}\text { DEP. VAR: = 1IF BECOMING SELF-EMPLOYED IN CURRENT } \\
\text { YEAR }\end{array}$} \\
\hline & (1) & (2) \\
\hline & NO COLLEGE & COLLEGE \\
\hline \multirow[t]{2}{*}{ LAGGED LOG ASSETS } & $0.63^{* *}$ & $0.64 * * *$ \\
\hline & $(2.13)$ & $(3.80)$ \\
\hline \multirow{2}{*}{$\begin{array}{l}\text { WAGE GROWTH IN PREVIOUS } \\
\text { YEAR }\end{array}$} & -0.60 & -0.38 \\
\hline & $(-1.17)$ & $(-1.31)$ \\
\hline \multirow[t]{2}{*}{ AGE } & $-0.03 * *$ & $-0.03 * *$ \\
\hline & $(-2.26)$ & $(-2.21)$ \\
\hline \multirow[t]{2}{*}{ MARRIED } & -0.52 & 1.45 \\
\hline & $(-1.36)$ & $(0.00)$ \\
\hline \multirow[t]{3}{*}{ AV. LOG LIKELIHOOD } & -1.8 & -1.78 \\
\hline & \multicolumn{2}{|c|}{ FIRST STAGE EsTIMATES } \\
\hline & No COLLEGE & COLLEGE \\
\hline \multirow[t]{2}{*}{ ELDEST } & $0.28 * * *$ & $-0.20^{*}$ \\
\hline & $(2.85)$ & $(-1.89)$ \\
\hline \multirow{2}{*}{$\begin{array}{l}\text { WAGE GROWTH IN PREVIOUS } \\
\text { YEAR }\end{array}$} & 0.09 & 0.15 \\
\hline & $(1.39)$ & $(1.24)$ \\
\hline \multirow[t]{2}{*}{ AGE } & $0.03 * * *$ & $0.06 * * *$ \\
\hline & $(6.23)$ & $(8.56)$ \\
\hline \multirow[t]{5}{*}{ MARRIED } & $0.69 * * *$ & $0.64 * * *$ \\
\hline & $(4.06)$ & $(2.84)$ \\
\hline & \multicolumn{2}{|c|}{ BASELINE PROBIT REGRESSIONS } \\
\hline & (1) & (2) \\
\hline & NO COLLEGE & COLLEGE \\
\hline \multirow[t]{2}{*}{ LAGGED LOG ASSETS } & $0.20^{*}$ & -0.07 \\
\hline & $(1.85)$ & $(-0.84)$ \\
\hline AV. LOG LIKELIHOOD & -0.05 & -0.1 \\
\hline OBS. & 864 & 563 \\
\hline
\end{tabular}

Z-scores are in parenthesis for IV and baseline estimations, and $t$-statistics are in parenthesis for the first stage estimation. Significance levels: ${ }^{* *} 0.01,{ }^{* *} 0.05,{ }^{*} 0.10$.

owners were engaged in wholesale and retail business or manufacturing sector. This business distribution is very similar to that observed among non college-educated selfemployers. Normally, we would expect a much sharper difference in the fields where these two groups started their businesses, considering their distinct skill sets. 
The second possibility, as suggested in Nanda (2008), is that individuals who are wealthy but have no college education represent the majority of self-employed workers in the data set. If this is the case, a positive and significant relationship between wealth and selfemployment entry may not be found in the baseline regression for the college-educated group. However, this explanation does not seem to be plausible in the present data set. A comparative analysis (results not shown here) suggests that, among people who switched to self-employment, pre-entry assets of college-educated workers are on average three times larger than those of workers without college degree. After adjusting for the percentage of each group among all the transitions, I still find that college-educated selfemployers were twice wealthier than the non college-educated prior to the transition.

\subsubsection{Estimation Including Wives of Eldest Sons}

Table 1.13 reports the results from the second strategy. The sample consists of all male respondents who had three to five siblings, as well as their spouses if there are observations. The first-stage regressions consistently show the same positive (negative) correlation between wealth and being the eldest son in the non college-educated (collegeeducated) subsample. IV estimations indicate that liquidity constraints exist in both subsamples. All the results are highly significant at the one percent level.

\subsection{Conclusions}

If a person considers starting a business but has little access to external loans, he has to rely on his own assets at least to meet the initial requirement of capital. The wealthier he is, the more likely he would become self-employed. Thus, a positive effect of household assets on the probability of becoming self-employed can serve as evidence of liquidity 
TABLE 1.13

Probit IV Estimation in the Sample with Restricted Sibling Size (Both Male and Female)

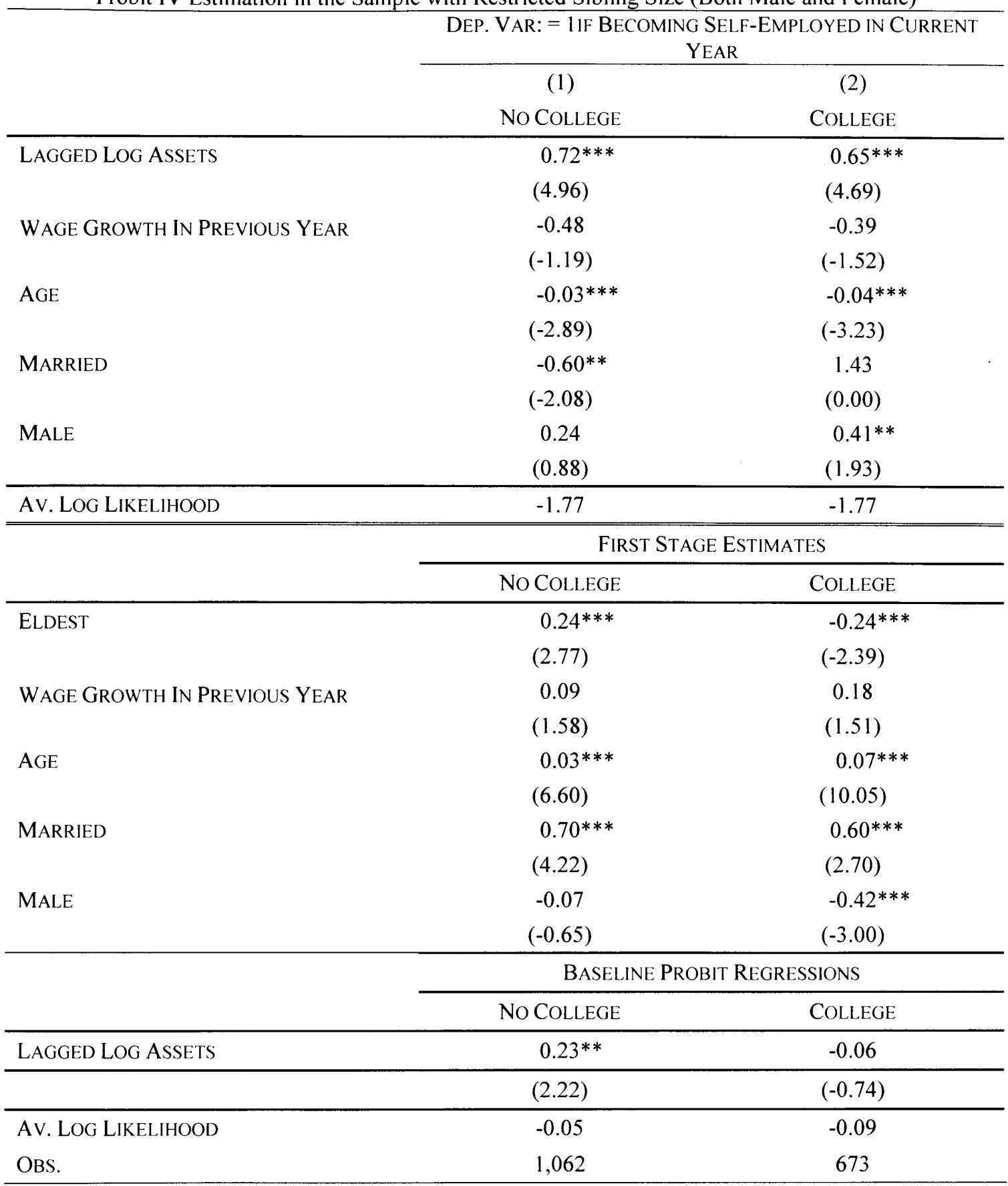

Z-scores are in parenthesis for IV and baseline estimations, and $t$-statistics are in parenthesis for the first stage estimation. Significance levels: ${ }^{* *} 0.01,{ }^{* *} 0.05,{ }^{*} 0.10$.

constraints in entrepreneurship. The idea is straightforward, but the analysis becomes complicated because of the endogeneity problem caused by the correlation between wealth and unobserved ability. Moreover, finding an instrument for wealth that is 
unrelated to any factor that might stimulate entrepreneurship is also a challenge. This paper proposes an instrument different from those used in previous studies, a son's birth order, to test the existence of liquidity constraints faced by entrepreneurs in South Korea. Two prominent features of Korea culture, male-dominance and fidelity, determine a strong relationship between birth order and wealth. Eldest sons are more likely to receive larger wealth transferred from parents either through bequests or pre-mortem in-kind transfers. Pre-mortem, they are also supposed to provide more financial support to parents than are other siblings. Hence, the net effect of being the eldest son on his household wealth is ambiguous. The data show a positive effect for the eldest sons without college education, and a negative effect for those with college education.

The merit of this instrument is that it is unlikely to be correlated with any family-specific variables, except that the probability of being the eldest is higher in a family with fewer children. Without controlling for sibling size in the IV estimation, I do not find any significant wealth effect on the probability of becoming self-employed. After restricting the sample to observations with three to five siblings, I find significantly positive wealth effect on entry into self-employment in both college-educated and non college-educated sub samples. The results provide strong evidence on liquidity constraints.

It is reasonable to question whether the eldest sons, rather than the first-born child, possess some special characteristics as they grew up under different expectations. For example, parents may intentionally make more investment in the eldest son's education, teach him to be more responsible, or develop his ambition for achievement. It is also possible that being the eldest son in a primogenitary culture is associated with certain personal characteristics that do not always apply to eldest sons in other cultures. All these 
thoughts point out the limitation of this instrument and raise new challenges for the future work. The plausibility of the correlation between being the eldest son in South Korean culture and the development of certain personal traits may need further exploration. More evidence is also needed to demonstrate the impact of these characteristics on entrepreneurial entry. 


\section{REFERENCES}

Angrist, Joshua D. and Alan B. Krueger (2001): "Instrumental Variables and the Search for Identification: From Supply and Demand to Natural Experiments." Journal of Economic Perspectives, 15(4): 69-85.

Åstebro, Thomas, Jing Chen, and Peter Thompson (2008): "Stars and Misfits: A Theory of Occupational Choice." Working paper, Florida International University

Blanchflower, David G. and Andrew J. Oswald (1998): "What Makes an Entrepreneur?" Journal of Labor Economics, 16(1): 26-60.

Bartus, Tamás (2005): "Estimation of Marginal Effects Using Margeff." Stata Journal, 5(3): 309-329.

Brenner, Gabrielle A. (1986): "Why do People Gamble? Further Canadian Evidence." Journal of Gambling Studies, 2(2):121-129.

Dunn, Thomas and Douglas Holtz-Eakin (2000): "Financial Capital, Human Capital, and the Transition to Self-Employment: Evidence from Intergenerational Links." Journal of Labor Economics, 18(2): 282-305.

Evans, David S. and Boyan Jovanovic (1989): "An Estimated Model of Entrepreneurial Choice under Liquidity Constraints." Journal of Political Economy, 97(4): 808-827.

Evans, David S. and Linda S. Leighton (1989): "Some Empirical Aspects of Entrepreneurship." American Economics Review, 79(3): 519-535.

Georgellis, Yannis, John G. Sessions, and Nikolaos Tsitsianis (2005): "Self-Employment Longitudinal Dynamics: A Review of the Literature." Economic Issues, 10(2): 1-38.

Holtz-Eakin, Douglas, David Joulfaian, and Harvey S. Rosen (1994a): "Sticking It Out: Entrepreneurial Survival and Liquidity Constraints." Journal of Political Economy, 102(1): 53-75.

Holtz-Eakin, Douglas, David Joulfaian, and Harvey S. Rosen (1994b): "Entrepreneurial Decisions and Liquidity Constraints." Rand Journal of Economics, 25(2): 334-347.

Hurst, Erik and Annamaria Lusardi (2004): "Liquidity Constraints, Household Wealth, and Entrepreneurship." Journal of Political Economy, 112(2): 319-347.

Johansson, Edvard (2000): "Self-Employment and the Predicted Earnings DifferentialEvidence from Finland." Finnish Economic Papers, 102(1): 123-134.

Lindh, Thomas and Henry Ohlsson (1996): "Self-Employment and Windfall Gains: Evidence from the Swedish Lottery." The Economical Journal, 106(439): 15151526. 
McCrary, Joseph, and Thomas J. Pavlak (2002): "Who Plays the Georgia Lottery. Evidence From a Statewide Survey." Monograph, Carl Vinson Institute of Government, The University of Georgia

Murray, Michael P. (2006): "The Bad, the Week, and the Ugly: Avoiding the Pitfalls of Instrumental Variables Estimation." Working paper, Bates College

Nanda, Ramana (2008): "Cost of External Finance and Selection into Entrepreneurship." Working paper, Harvard University

Ohyama, Atsushi (2007): "The Rewards for Entrepreneurial Ability to Learn, Adopt, and Implement Advanced Technical Knowledge." Working paper, SUNY Buffalo

Prendergast, David (2005): "From Elder to Ancestor: Old Age, Death and Inheritance in Modern Korea." Global Oriental Ltd

Sorensen, Clark (1986): "Migration, the Family, and the Care of the Aged in Rural Korea: An Investigation of a Village in the Yongso Region of Kangwon Province 1918-1983." Journal of Cross-Cultural Gerontology, 1(2): 139-161.

Xu, Bin (1998): "A Reestimation of the Evans-Jovanovic Entrepreneurial Choice Model." Economics Letters, 58(1): 91-95.

Yang, Hyunah (1998): "Envisioning Feminist Jurisprudence in Korean Family Law at the Crossroads of Tradition / Modernity." PhD manuscript, New School for Social Research 


\section{CHAPTER 2}

\section{Selection and Serial Entrepreneurs}

\subsection{Introduction}

What motivates some individuals to become serial entrepreneurs, and how does this influence their performance? Is serial entrepreneurship driven by taste or personal accidents of history, or are there more systematic predictors? Do agents become serial entrepreneurs because their prior business failed, or because their prior business was a success? Despite an emerging literature on serial entrepreneurship we continue to have little confidence in our answers to these questions.

Early work, largely based on small-sample interviews with serial entrepreneurs, suggest they are motivated by a variety of factors. Wright, Robbie, and Ennew (1997), for example, identify half a dozen disparate motivations. Prominent among them, some start a new venture because they want to explore new business opportunities, while others are attempting to rebuild a failed business. Williams (2000) also identified disparate motivations. While some interviewees were motivated by a desire to seize timely opportunities, Williams also documents instances in which serial entrepreneurs enjoy starting businesses because they can relate the products to their personal experiences. ${ }^{4}$ More recent work has exploited larger samples, focused on more objectively measurable attributes of serial entrepreneurs, and provided performance comparisons with first-time entrepreneurs (cf. Eesley and Roberts 2006a; Stam et al. 2006; Gompers et al. 2006). These studies have yielded the following evidence:

\footnotetext{
${ }^{4}$ Jeff Jacober, for example, started his first business when he was still in college, selling sportswear to fraternities and sororities. After his brother was diagnosed with chronic kidney failure, Jacober found Ocean Diagnostic Inc. which produced a home health test that helped people to self-diagnose various diseases.
} 
- Serial entrepreneurs are more likely to have successfully sold their prior ventures before starting a new business (Eesley et al. 2006b; Stam et al. 2006).

- The current firm has a higher chance of going public if the entrepreneur's previous venture was acquired (Eesley et al. 2006a).

- Entrepreneurs whose business performs poorly are less likely to create a new business (Stam et al. 2006).

- Entrepreneurs who succeeded in prior business have a much higher chance of succeeding in the current business, compared to first-time entrepreneurs and entrepreneurs who previously failed (Gompers et al. 2006).

These findings are consistent with at least two distinct interpretations. Eesley and Roberts (2006a), and Stam et al. (2006) interpret their results as evidence that learning from prior founding experience has a positive impact on serial entrepreneurial performance. In contrast, Gompers et al. (2006) conclude that self-selection based on innate entrepreneurial skill, rather than learning by doing matters most for serial business formation and performance.

There is, of course, an extensive theoretical literature on learning by doing (see Thompson 2008a for an extensive review), from which many of the insights are readily adaptable to entrepreneurship. Indeed, there is already an emerging literature that focuses on issues such as how serial entrepreneurs learn from their successful or unsuccessful prior experiences (Minniti and Bygrave 2001), or how experiential learning positively or negatively affects their entrepreneurial performance (Politis 2005; Corbett 2005; Pástor, Taylor, and Veronesi 2009). 
In contrast, there has been little theoretical work on the role of innate ability among serial entrepreneurs. Among the very few contributions, Holmes and Schmitz' (1990) seminal theory of business transfer focuses on serial entrepreneurs who have a comparative advantage in developing new businesses. In their theory, people differ in their ability to respond to business opportunities. Thus, high-ability people become entrepreneurs, specializing in forming new businesses, the low-ability concentrate on managing existing businesses, and those in the middle are "jacks-of-all-trades". To pursue new business opportunities, entrepreneurs need to free up their resources, such as time, through discontinuing or selling their previously developed businesses to their low- or middleability counterparts. In their model, an essential assumption is that individuals can perfectly observe their abilities. Then, serial entrepreneurship serves as a natural avenue for them to allocate their talents to the best use.

The present paper also develops a framework that formalizes serial entrepreneurial behavior based on selection on ability. I follow Holmes and Schmitz (1990) by assuming that business performance is jointly determined by an entrepreneur's time-invariant ability and the quality of his business idea. I also assume these two determinants of performance are statistically independent. However, in the spirit of Jovanovic (1979, 1982), the entrepreneur does not perfectly observe his ability and the quality of the business idea ex ante, but only has some prior beliefs about them. Every period, he observes the earnings of his business, as well as the average earnings of the same kind of businesses in the market. The latter is a signal of the value of his business idea. By comparing the performance of his business with other similar ventures, the entrepreneur gradually updates his belief about his entrepreneurial ability. Based on this belief, he 
makes a choice between keeping the current business and leaving the business to explore a new idea.

Although misleading signals may induce mistakes on the part of entrepreneurs, the model predicts that high ability entrepreneurs are more likely to establish serial businesses. This result has two further implications. First, entrepreneurs with a successful experience in the last business have a higher probability of starting a new venture, as ability is positively related to business earnings. Second, the ability of serial entrepreneurs is stochastically higher than that of first-time entrepreneurs. This in turn indicates that the more founding experience an entrepreneur has, the higher is the probability of him forming a new business, and the better is the performance of his new venture.

These implications bring out the essential insight of the model, that selection on ability is sufficient to induce a positive correlation between entrepreneurial experience (measured by previous business earnings and founding experience) and serial business formation as well as its subsequent performance. As previously mentioned, there has been a debate in the empirical literature on whether the impact of prior experience on current entrepreneurial performance can be explained by learning by doing (Eesley and Roberts 2006a) or should be attributed to entrepreneurial skills (Gompers et al. 2006). This paper provides a theoretical basis for the hypothesis of selection on ability.

Learning about one's ability and learning about operating a business are of course not mutually exclusive phenomena, and we would like to understand more about their relative importance. From the empirical standpoint, it has always been a challenge to separate these two types of learning. Thompson (2008a) develops a simple framework incorporating both types of learning, and highlights the difficulty in distinguishing them 
in empirical analysis. So far, two studies on learning by doing have attempted to do so: one is by Farber (1994), who focuses on differences in the hazards of job separation implied by the two models; the other is by Nagypál (2007), who looks at firm-specific price shocks and their distinctive impacts on employee turnover in the two learning models (See Thompson 2008a for a more detailed discussion). In this paper, I take alternative approaches of fixed effects and IV estimations to test the predictions of the selection-based model, and to distinguish selection from learning by doing.

The data come from the NLSY79. The distinctive feature of the $N L S Y 79$, which makes it an ideal data source for this study, is its focus on a young cohort that was first interviewed between the ages of 14 and 22 . This allows me to trace these individuals' employment history from their first job after graduation, thereby avoiding potential leftcensoring problems. Starting in 1979, the survey was conducted annually through 1994 and biennially afterwards. As information from the previous year is often needed in the present analysis, I focus on the period from 1980 to 1993 . The sample includes 1,830 individuals who were, on average, interviewed for 5.8 survey rounds and had been selfemployed at least once during these years. In each year, serial entrepreneurs are identified from the respondents`self-employment records. Nearly 30 percent of them reported ever forming a serial business. Their entrepreneurial experience is characterized by two variables. One is previous business performance, measured by their earnings in the last business. The other is their founding experience, indicated by the number of businesses they had previously formed.

A simple examination of the likelihood that a former entrepreneur currently started a new business consistently demonstrates its positive correlation with entrepreneurial 
experience. That is, entrepreneurs with higher earnings in the last business or with more founding experience are more likely to form a serial business. Clearly, this result can be explained by either selection on ability, or learning by doing, or even both. To explicitly separate these two effects, I first run a fixed-effects model to control for time-invariant ability, an essential element in the theoretical model. By fixing entrepreneurial ability, the two variables, previous business earnings and the number of previously-owned businesses, would only be proxies for learning by doing. Surprisingly, neither of these two variables has a positive effect on the likelihood of new business formation. This suggests that learning by doing is not the cause of the positive effect that entrepreneurial experience has on new business formation.

Perhaps a better way to investigate how selection on ability affects serial business formation and its performance is to find instrumental variables that are closely related to the two measures of business experience (i.e., previous business earnings and the number of previously-owned businesses), but that are not subject to learning by doing. I construct two variables, which record an entrepreneur's earnings in his first business and his earnings in his first job, respectively. As mentioned above, the structure of the NLSY79 survey allows me to precisely identify most respondents' first jobs and especially their first businesses. As there was no previous working experience for learning to occur, both earnings variables are only related to a person's ability, which, as predicted in the model, positively affects his earnings in subsequent businesses and the number of ventures he would ever form. Consistent with the results from the regular logit regressions, the IV estimations show that, not only do high-ability entrepreneurs (proxied by previous 
business earnings and the number of previously-owned businesses) have a higher chance of starting a new business, they are also likely to earn more in the new venture.

The contributions of this paper are threefold. First, to my knowledge, this is the first paper that applies the notion of selection on ability to explain the origin of serial entrepreneurship, although similar ideas have long been formalized to model firm dynamics (Jovanovic 1982). Selection yields some implications for serial entrepreneurship that can easily be misconstrued as being the result of learning by doing, and therefore raises doubts about whether we have correctly interpreted some of the existing empirical evidence. Second, the paper offers a plausible way to empirically examine the mechanism through which entrepreneurial experience affects the likelihood that an entrepreneur starts a new business and his entrepreneurial performance. The results shed light on some long-debated questions, such as what exactly (serial) entrepreneurs learned from their experience, and whether learning really improves their entrepreneurial performance. Third, this paper focuses on a broad definition of entrepreneurs, i.e., self-employed workers. The model applies not only to serial entrepreneurs clustered in high-tech industries and likely to obtain venture capital funding, but also to those who were self-employed in various small businesses. Compared to previous empirical studies which usually use hand-collected data from a relatively small survey sample, the empirical findings in this paper relate to a much more representative group of young workers in the US. Thus, the results provide us with a better understanding of serial entrepreneurship from the perspective of individual occupational choice. 
The paper is organized as follows. Section 2 presents the model in which entrepreneurs make a business choice based on the evolution of beliefs about their time-invariant abilities. In section 3, several implications in the model are tested using data from the NLSY79. Section 4 concludes.

\subsection{The Model}

\section{(1) Technology}

Agents start in the business sector as entrepreneurs, and their lifetime is infinite. An entrepreneur's business earnings, $q$, are given by,

$$
q=a e^{b}
$$

where $a$ is his entrepreneurial ability, and $b$ is the quality of his business idea. Neither $a$ nor $b$ is perfectly observable to the entrepreneur. Let $F_{0}(b)$ denote a common prior belief about $b$, which is normal with mean $\bar{b}$ and variance $\sigma_{b}^{2}$. The prior belief about $a, F_{0}(a)$, is assumed to be diffuse.

Each period, an active entrepreneur observes $q$, which does not change over time. He also observes a signal of $b$, for example, from the average performance of this business idea in the market. The signal, $s$, is normally distributed with mean $b$ and variance $\sigma_{s}^{2}$. Using Bayesian updating, the entrepreneur's posterior belief about $b$ in period $t, F_{t}(b)$, is normal with mean $\tilde{b}_{t}$ and variance $\tilde{\sigma}_{b, t}^{2}$, where $\tilde{b}_{t}=\left(\sigma_{s}^{2} \bar{b}+t \bar{s} \sigma_{b}^{2}\right) /\left(\sigma_{s}^{2}+t \sigma_{b}^{2}\right), \tilde{\sigma}_{b, t}^{2}=$ $\sigma_{s}^{2} \sigma_{b}^{2} /\left(\sigma_{s}^{2}+t \sigma_{b}^{2}\right)$, and $\bar{s}=\left(\sum_{i=1}^{t} s_{i}\right) / t$. The expectation of his ability at $t, E_{t}(a)$, is therefore given by

$$
E_{t}(a)=q \int_{-\infty}^{\infty} e^{-b} d F_{t}(b)
$$




\section{(2) The entrepreneur's decision}

The entrepreneur faces two choices each period. He can choose to stay with the current business, or he can sell this business and start a new one with a different idea. Assume the market price of a business in period $t$ is given, and only depends on the average market performance of this business idea at time $t$, i.e., $P=P\left(s_{t}\right)$. In addition, assume a sunk cost, $c$, is incurred if the entrepreneur forms a new business.

Let $V\left(F_{t}(b), t ; q\right)$ be the value to the entrepreneur of having a business that generates earnings $q$ at time $t$ when his belief about the business idea, $b$, is $F_{t}(b)$. Let $\gamma$ denote the discount factor. Suppose, for simplicity, that the entrepreneur expects to form at most one serial business. Then the Bellman equation can be written as

$V\left(F_{t}(b), t ; q\right)=\max \left\{q+\gamma \int_{-\infty}^{\infty} V\left(F_{t+1}(b), t+1 ; q\right) d F_{t}(b),-c+P\left(s_{t}\right)+\frac{1}{1-\gamma} E_{t}(a) e^{\bar{b}+\sigma_{b}^{2} / 2}\right\}$

The first component in the bracket is the sum of the immediate earnings generated by the current business at time $t$ and the value of continuation. The second component represents the discounted present value of forming a new business at time $t$. As the new business idea is unknown ex ante, the expected quality of his new idea takes the value of the prior mean, $\bar{b}$; because the entrepreneur expects to form only one serial business, the present value of this business is simply $E_{t}(a) e^{\bar{b}+\sigma_{b}^{2} / 2} /(1-\gamma)$.

The question of particular interest is how the evolution of an entrepreneur's belief about his ability and the quality of the business idea affects his decision. To address this question, I follow the approach developed by Thompson and Chen (2009) and redefine the dynamic problem in equation (3) in terms of beliefs about $b$. Then, equation (3) can be rewritten as

$$
V(\tilde{b}, t ; q)=\max \left\{q+\gamma \int_{-\infty}^{\infty} V\left(\widetilde{b^{\prime}}, t+1 ; q\right) d G_{t+1}\left(\widetilde{b^{\prime}} \mid \tilde{b}\right),-c+P\left(s_{t}\right)+\frac{1}{1-\gamma} E_{t}(a) e^{\bar{b}+\sigma_{b}^{2} / 2}\right\}
$$


where $\tilde{b}$ is the mean of the posterior belief about $b$ at time $t$, as previously defined. $G_{t+1}\left(\tilde{b}^{\prime} \mid \tilde{b}\right)$ is the subjective distribution of $\widetilde{b^{\prime}}$, given the entrepreneur's updated belief about $b$ at present. Thus, it is normal with mean $\tilde{b_{t}}$ and variance $\sigma_{b}^{2} \tilde{\sigma}_{b, t+1}^{2} /\left(\sigma_{s}^{2}+(t+1) \sigma_{b}^{2}\right)$.

Let $\tilde{b}^{*}$ be the critical value of the posterior mean. Forming a new business at time $t$ is preferred if an entrepreneur's posterior expectation of $b$ falls below $\tilde{b}^{*}$. There is no explicit solution for the critical value because it fluctuates over time in complicated ways. First, it is a function of the signal received at time $t$, so the critical value is state dependent. Second, the function itself changes over time because of the evolution in the posterior variance. ${ }^{5}$ In order to continue with analytical rather than computational analysis, and especially to derive an expression for the hazard of new business formation as a function of time, I impose a form of myopia where the entrepreneur ignores the option value of remaining one more period with the current business. This approximation has been employed in similar problems by Jovanovic (1979), Thompson (2008b), and Thompson and Chen (2009). This implies the entrepreneur will form a new business at time $t$ if

$$
\frac{q}{1-\gamma} \leq-c+E_{t}(a) e^{\bar{b}+\frac{\sigma_{b}^{2}}{2}} /(1-\gamma)+P\left(s_{t}\right)
$$

which yields the approximate critical value

$$
\tilde{b}_{t}^{*}=\frac{1}{2} \tilde{\sigma}_{b, t}^{2}+\ln \left[\frac{q \bar{B}}{q+(1-\gamma)\left(c-P\left(s_{t}\right)\right)}\right]
$$

\footnotetext{
${ }^{5}$ The posterior variance declines monotonically, but this has two competing effects on the value function. On the one hand, the option value of staying with the current business is increasing in the conditional variance of $\tilde{b}^{\prime}$. This induces $\tilde{b}^{*}$ to rise over time. On the other hand, an entrepreneur's expectation of his ability is increasing in the variance of this posterior belief about $b$. This causes $\tilde{b}^{*}$ to fall over time as the expected value of developing a new business idea declines.
} 
where $\bar{B}=e^{\bar{b}+\sigma_{b}^{2} / 2}$. As $\tilde{\sigma}_{b, t}^{2}=\sigma_{s}^{2} \sigma_{b}^{2} /\left(\sigma_{s}^{2}+t \sigma_{b}^{2}\right)$, reorganizing equation (6) yields

$$
\tilde{b}_{t}^{*}=\frac{\sigma_{s}^{2} \sigma_{b}^{2}}{2\left(\sigma_{s}^{2}+t \sigma_{b}^{2}\right)}+\ln \left(\frac{q \bar{B}}{q+(1-\gamma)\left(c-P\left(s_{t}\right)\right)}\right)
$$

Clearly, the critical value, $\tilde{b}_{t}^{*}$, is decreasing in the cost, $c$, of forming a new business, but increasing with noisy signals $\left(\sigma_{s}^{2}\right)$ and imprecise priors $\left(\sigma_{b}^{2}\right)$. It is also positively related to business earnings, $q$, the market price of an entrepreneur's business idea, $P\left(s_{t}\right)$, and his discount factor, $\gamma$.

\section{(3) A first-passage problem}

The event that an entrepreneur first forms a serial business can be analyzed as a firstpassage problem. Let $T$ be a Markov time that satisfies

$$
T=\min _{t}\left\{t: \tilde{b}_{t} \leq \tilde{b}_{t}^{*}\right\}
$$

As $\tilde{b}_{t}$ is normally distributed with mean $\left(\sigma_{s}^{2} \bar{b}+b t \sigma_{b}^{2}\right) /\left(\sigma_{s}^{2}+t \sigma_{b}^{2}\right)$ and variance $t \sigma_{s}^{2} \sigma_{b}^{4} /\left(\sigma_{s}^{2}+t \sigma_{b}^{2}\right)^{2}$. I construct a variable, $\omega_{t}$, such that

$$
\omega_{t}=\frac{\sigma_{s}^{2}+t \sigma_{b}^{2}}{\sigma_{b}^{2} \sigma_{s}} \tilde{b}_{t}-\frac{\sigma_{s}^{2} \bar{b}+t b \sigma_{b}^{2}}{\sigma_{b}^{2} \sigma_{s}}
$$

which is a random walk with mean equal to zero and variance equal to $t$. When $\tilde{b}_{t} \leq \tilde{b}_{t}^{*}$,

$$
\omega_{t} \leq \frac{\sigma_{s}^{2}+t \sigma_{b}^{2}}{\sigma_{b}^{2} \sigma_{s}} \tilde{b}_{t}^{*}-\frac{\sigma_{s}^{2} \bar{b}+t b \sigma_{b}^{2}}{\sigma_{b}^{2} \sigma_{s}}
$$

Let $\omega(t)$ denote the continuous-time counterpart to $\omega_{t}$. Then, I can rewrite equation (8) in terms of $\omega(t)$, i.e.,

$$
T=\min _{t}\left\{t: \omega(t) \leq \lambda_{1}+\lambda_{2} t\right\}
$$

where

$$
\lambda_{1}=\frac{1}{2} \sigma_{s}+\frac{\sigma_{s}}{\sigma_{b}^{2}}\left[\ln \left(\frac{q \bar{B}}{q+(1-\gamma)\left(c-P\left(s_{t}\right)\right)}\right)-\bar{b}\right]
$$




$$
\lambda_{2}=\frac{1}{\sigma_{s}}\left[\ln \left(\frac{q \bar{B}}{q+(1-\gamma)\left(c-P\left(s_{t}\right)\right)}\right)-b\right]
$$

Equations (11)-(13) define a stochastic process that may reach a linear absorbing barrier located below where the random walk starts. In a symmetric problem where the linear barrier is located above the origin, the distribution of first passage times can be easily derived using the Bachelier-Lévy formula (Cox and Miller 1965 pp221). For this purpose, I make a transformation of equation (11) to obtain the upcrossing time

$$
T=\min _{t}\left\{t: \omega(t) \geq \zeta_{1}+\zeta_{2} t\right\}
$$

where $\zeta_{1}=-\lambda_{1}$, and $\zeta_{2}=-\lambda_{2}$. Equations (11) and (14) describe two symmetric stochastic processes that generate identical results for the first passage time.

Two issues regarding the absorbing barrier merit discussion. First, to ensure the present problem is valid, we need the process, $\omega(t)$, to start below the absorbing barrier. This requires $\zeta_{1}>0$. Second, the sign of the slope of the barrier, $\zeta_{2}$, has some implications on whether an entrepreneur will ever form a serial business. If $\zeta_{2}<0$, the barrier is downward sloping. Thus, no matter in what direction $\omega(t)$ moves, it will eventually reach the barrier. This indicates that the probability of an entrepreneur ever forming a serial business is one in this case, and new business formation is only a matter of time. If $\zeta_{2}>0$, the absorbing barrier has a positive slope. In this case, whether $\omega(t)$ will ever reach the barrier is uncertain, depending on the specific sample path. Both results can be easily derived in the following analysis of the probability of serial business formation.

\section{(4) The probability of serial business formation}

The probability distribution of the first passage times $T$ is given by the Bachelier-Lévy formula,

$$
P\left(T, \zeta_{1}, \zeta_{2}\right)=\Phi\left(-\frac{\zeta_{1}+\zeta_{2} T}{\sqrt{T}}\right)+e^{-2 \zeta_{1} \zeta_{2}} \Phi\left(-\frac{\zeta_{1}-\zeta_{2} T}{\sqrt{T}}\right)
$$


where $\Phi($.$) is a standard normal integral. Let T \rightarrow \infty$. Equation (15) generates some intuitive results about the probability that an entrepreneur ever forms a new business,

$$
\lim _{T \rightarrow \infty} P\left(T, \zeta_{1}, \zeta_{2}\right)= \begin{cases}1 & \text { if } b \leq W \\ e^{-2 \zeta_{1} \zeta_{2}<1} & \text { if } b>W\end{cases}
$$

where $W=\ln \left(\frac{q \bar{B}}{q+(1-\gamma)\left(c-P\left(s_{t}\right)\right)}\right)$.

When $T \rightarrow \infty$, an entrepreneur has perfectly learned about the true value of his current business idea, $b$. Meanwhile, equation (6) indicates that the critical value of forming a new business, $\tilde{b}_{t}^{*}$, equals $W$, as $t \rightarrow \infty$ and the posterior variance, $\tilde{\sigma}_{b, t}^{2}$, becomes zero. Thus, consistent with the previous intuition, an entrepreneur will eventually get rid of a lowvalue business idea and form a new business if $b \leq W$. On the contrary, if the current business idea is profitable, there is only a certain possibility that an entrepreneur may unwisely give up this business in order to pursue a different one. The probability of mistakenly starting a new business increases if the cost, $c$, of forming a new business is low, the market price of the current business, $P\left(s_{t}\right)$, is high, or the entrepreneur's discount factor, $\gamma$, is large. Also notice the precision of public signals, $1 / \sigma_{s}^{2}$, does not affect an entrepreneur's decision.

As far as empiricists are concerned, the only element that is observable in the present model is business earnings, which is a common variable recorded in almost all survey data. Thus, it would be interesting to question how business performance affects the likelihood that an entrepreneur decides to form a new venture. Figure 1 presents plots of the probability distribution (15) against business earnings, $q$. Holding the quality of business idea, $b$, constant, the graph shows that the probability of an entrepreneur forming a new business is monotonically increasing in business earnings, although at a 
decreasing rate. At any level of business earnings, the probability of new business formation is higher if the entrepreneur has a lower-value business idea. This result yields the first testable proposition in the model.

P1. For any given business quality, the probability of selling the current business and forming a new business is increasing in current business earnings.

In Figure 2, the probability of new business formation varies with the value of the business idea, $b$, when business earnings, $q$, are held constant. For five possible values of $q$, we consistently observe the pattern that the probability of new business formation starts from nearly one when $b$ is very small, decreases at an increasing rate as business quality rises, and eventually declines asymptotically to zero as $b$ becomes sufficiently large. Moreover, as I gradually increase business earnings from 2000 to 6000 , the probability curve is also moving to the right. Because ability and quality of business idea

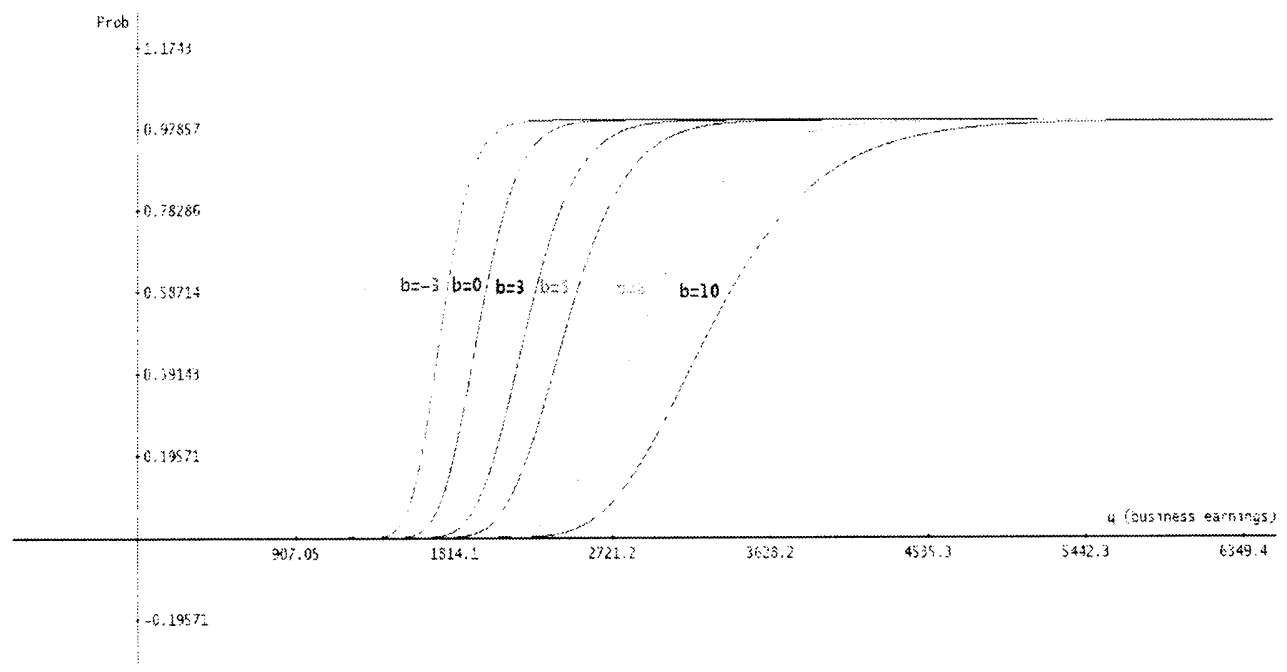

FIGURE 2.1 Probability of Forming a New Business as Business Earnings Change (Parameter values: $c=200, P\left(s_{t}\right)=0, \bar{b}=20, \sigma_{s}^{2}=5, \sigma_{b}^{2}=0.1, T=5, \gamma=0.5$ ) are independent in the model, but complementary to each other in the production technology, entrepreneurs who achieved greater earnings must have higher ability 
relative to people in the same or similar line of business. Thus the model also predicts that higher-ability entrepreneurs are more likely to form a serial business. The above results are summarized in the following two propositions.

P2. The likelihood of an entrepreneur forming a serial business is decreasing in the quality of his current business idea.

P3. Serial business formation is more likely to happen if an entrepreneur has higher ability.

The present model focuses on first-time entrepreneurs and their decision to form a second business. This framework can be easily extended to characterize their subsequent behavior of starting a third or even more serial ventures. This time I focus on entrepreneurs who are in their second businesses, and relax the assumption that entrepreneurs can only start one serial venture. These second-round entrepreneurs then face the same business choice as they did the first time, and the whole decision-making process starts again. Recall from Proposition 1, entrepreneurs who started a second venture are those who had higher earnings from the first business. Moreover, given the quality level of business idea, higher earnings correspond to higher entrepreneurial abilities. Because the business idea is a random draw and has no correlation with ability, ability in the population of second-round entrepreneurs is stochastically greater than ability among first-round entrepreneurs. This result has two further implications.

First, as Proposition 3 suggests, higher-ability entrepreneurs have a higher likelihood of forming a new business. Thus, second-round entrepreneurs have a higher probability of forming another new business than do first-time entrepreneurs. More generally, the model predicts that the more businesses an entrepreneur previously owned, the more 
likely he is to form another serial business. This prediction is consistent with the empirical evidence presented by Stam, Audretsch and Meijaard (2005). Their study, based on 240 ex-entrepreneurs in a longitudinal data set of Dutch firm founders, shows that entrepreneurs who exited from their previous businesses reveal a higher preference for re-entering the business sector if they had previously formed more than one firms.

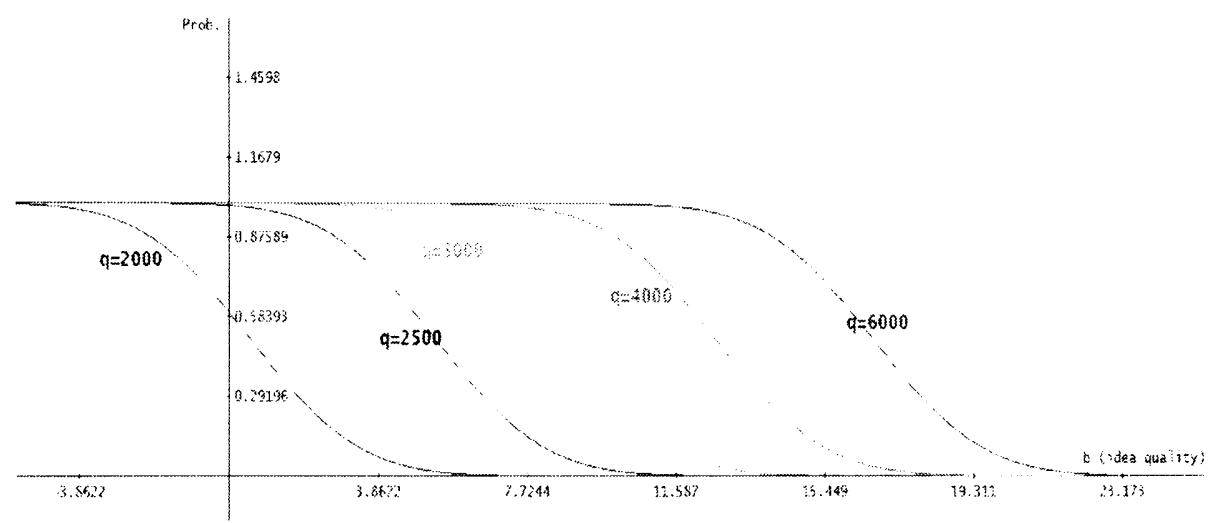

FIGURE 2.2 Probability of Forming a New Business as the Quality of Business Idea Change (Parameter values: $c=200, P\left(s_{t}\right)=0, \bar{b}=20, \sigma_{s}^{2}=5, \sigma_{b}^{2}=0.1, T=5, \gamma=0.5$ )

P4. The probability of new business formation is increasing in the number of ventures an entrepreneur previously founded.

Second, as ability is positively related to business performance, but independent of the quality of the business idea, second-round entrepreneurs are also expected to have better performance in the current business than nascent entrepreneurs. Regarding this implication, one thing is worth emphasizing. Gompers et al. (2006) find a positive effect of entrepreneurial experience on current business performance (measured by the likelihood of success) among venture-capital backed entrepreneurs, but they also demonstrate that adding the success of previous experience as an indication of entrepreneurial skills eliminates this effect. Eesley and Roberts (2006a) also have found a 
positive correlation between firm revenues and entrepreneurial experience in their survey of MIT alumni, and consider it the result of learning by doing. The present model generates this similar relationship purely based on selection on ability, consistent with the insight of Gompers et al. (2006). It suggests that not only do higher business earnings increase the likelihood of serial business formation (Proposition 1), but more serial businesses and better performance in previous businesses predict higher performance in the future.

P5. A greater number of serial businesses is an indicator of higher entrepreneurial ability, which in turn predicts better entrepreneurial performance.

P6. Better performance in previous businesses is an indicator of higher entrepreneurial ability, which in turn predicts better performance in serial businesses.

(5) The hazard of new business formation

The hazard of forming a new business, $h\left(T, \zeta_{1}, \zeta_{2}\right)$, is given by

$$
h\left(T, \zeta_{1}, \zeta_{2}\right)=\frac{P^{\prime}\left(T, \zeta_{1}, \zeta_{2}\right)}{1-P\left(T, \zeta_{1}, \zeta_{2}\right)}
$$

Figure 2.3 plots the hazards for two distinct cases. In the first case, the true value of the business idea, $b$, is smaller than $W$. As indicated in expression (16), the probability that an entrepreneur ever forms a new business equals one in this case. Consistent with this result, we can see from the graph that the hazard of new business formation rapidly increases in the early period and gradually falls to a strictly positive asymptotic bound. In the second case, the entrepreneur has a better idea and the value of $b$ exceeds $W$. Thus, switching to a new business is a mistake. Unsurprisingly, the hazard of new business formation is much lower in this case. It also reaches its peak faster as mistakes tend to happen early. The longer an entrepreneur waits, the more he learns about his ability and 
business idea, and the less likely he will leave a good business. As the graph shows, the hazard of new business formation eventually declines to zero in the second case.

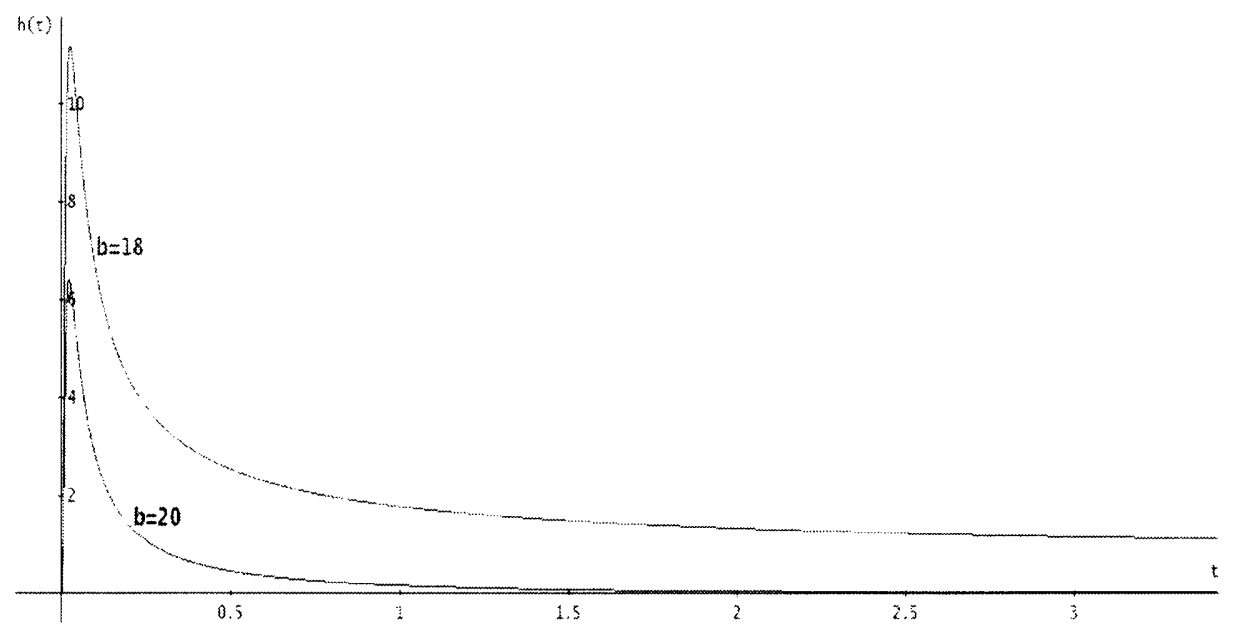

FIGURE 2.3 Hazards of New Business Formation

(Parameter values: $c=500, P\left(s_{t}\right)=0, \bar{b}=20, \sigma_{s}^{2}=1, \sigma_{b}^{2}=1, \gamma=0.5, q=100, W=19$ )

P7. The hazard of new business formation increases rapidly to a unique peak, and then declines gradually. It moves towards a positive lower bound if an entrepreneur has a bad business idea, and to zero if his business idea is sufficiently good.

\subsection{Empirical Analysis}

This section tests the relationships summarized in Propositions 1, 4, and 5 between previous entrepreneurial earnings, the likelihood of serial business formation, and new business performance. I also examine whether the results should be explained by selection on ability as perceived in the present model, or be attributed to learning by doing as demonstrated in previous studies (Eesley et al. (2006a, b)).

(1) The data

The data come from the NLSY79. Fairlie (2005) has pointed out a number of features of the NLSY79 that make it a rich data source to study self-employment. For the present 
analysis of serial entrepreneurs, what is most important is that the NLSY79 cohort was at the age of 14-22 when they were first surveyed in 1979. This allows me to track the respondents' employment history almost since the first time they entered the labor market. This property of the NLSY79 largely alleviates potential left-censoring problems in the present analysis, although right-censoring still exists.

In order to identify serial businesses and create historical variables, I impose two restrictions on the selection of the sample. First, respondents included in each yearly subsample must have participated in all the survey rounds prior to the current year. In doing so, I can keep a complete record of each individual's employment history for the sample periods. so that any serial entrepreneur would be identified. Most important, all individuals included in the sample must have been self-employed at least once in previous years in order for them to have a risk of starting a serial business in the current year. Second, the sampling periods are limited to the years 1980 through 1993. The reason is that the NLSY79 surveys only report income from the previous year. This raises an issue after 1993 when the survey is conducted biennially. For example, if I want to collect income data for 1994, I should look at the numbers reported in 1995 survey. However, there was no survey conducted in that year. The next survey was in 1996 and only income in 1995 was reported. As income is an important variable for the analysis, I have to restrict the sample to the periods prior to 1994, even though it means I would not be able to capture all the observations on self-employment in the following seven survey rounds (from 1994 to 2006).

The final sample consists of 25,620 observations on 1,830 individuals, who were on average interviewed for 5.8 years from 1980 to 1993 . Fifty-six percent of the sample was 
male, and 30 percent had a college degree. Because of the previous restriction on the observation periods, individuals in this sample appear to be very young. At the last interview date (1993), the average age was 32 , and the oldest was 36 . This age pattern reveals one drawback of the sample. As Fairlie (2005) shows, the self-employment rate in the NLSY79 data steadily increases as the cohort became older. By the age of 42 , the selfemployment rate for men nearly doubled the rate at the age of 22 . Given the current sample period, it is possible that the present analysis only captures a relatively small portion of entrepreneurs and their businesses in the NLSY79 data. However, for people who started businesses at the early age, the observation period is long enough to generate results that shed light on serial business formation, entrepreneurial performance, and their relationship with selection on ability.

\section{(2) Descriptive statistics}

The four key variables created in the data set are: (1) a dummy variable, serial, that identifies whether a respondent started a serial business in the current year; (2) a variable, $n p b$, that records the number of businesses a respondent ever founded prior to the current survey; (3) a variable, pearn, that records a respondent's earnings in his last business; and (4) a variable, span, that measures the time period between the current survey year and the last time a respondent was self-employed. Below, I provide additional information on how these variables are constructed, followed by some descriptive results.

Serial Business Formation (serial=1). In each survey year, serial business owners are defined as former entrepreneurs who started a new business in the current year. This definition applies to two cases. In the first case, I look at business owners who switched to wage-employment but currently returned to the business sector. In the second case, I 
focus on self-employed people who were running a business different from the one they had a year before.

In the sample, there are 10,659 observations on serial business formation over 1,827 individuals. Seven percent of these observations correspond to years in which the individual had formed a new serial business, while thirty percent of respondents had formed a serial business at some point during the observation window. Conditional on a respondent ever forming a serial business, seventeen percent of his observations are associated with a new venture.

Following Gompers et al. (2006), I provide in Table 2.1 the number of serial entrepreneurs observed in each period. Consistent with Fairlie's (2005) finding, the total number of entrepreneurs reported in each year is strictly increasing as the NLSY79 cohort

TABLE 2.1

Frequency of Serial Entrepreneurs by Year

\begin{tabular}{lccc}
\hline & Serial Entrepreneurs & Total Entrepreneurs & Fraction Serial \\
\hline 1980 & 1 & 10 & 0.10 \\
1981 & 7 & 31 & 0.23 \\
1982 & 18 & 64 & 0.28 \\
1983 & 24 & 106 & 0.23 \\
1984 & 39 & 134 & 0.29 \\
1985 & 49 & 177 & 0.28 \\
1986 & 47 & 210 & 0.22 \\
1987 & 71 & 263 & 0.27 \\
1988 & 85 & 292 & 0.29 \\
1989 & 96 & 390 & 0.25 \\
1990 & 71 & 368 & 0.19 \\
1991 & 80 & 352 & 0.23 \\
1992 & 84 & 365 & 0.23 \\
1993 & 73 & 378 & 0.19 \\
\hline
\end{tabular}


TABLE 2.2

Frequency of Serial Entrepreneurs by Industry

\begin{tabular}{lccc}
\hline \hline & $\begin{array}{c}\text { Serial } \\
\text { Entrepreneurs }\end{array}$ & $\begin{array}{c}\text { Total } \\
\text { Entrepreneurs }\end{array}$ & $\begin{array}{c}\text { Fraction } \\
\text { Serial }\end{array}$ \\
\hline AGRICULTURE, FORESTRY AND FISHERIES & 70 & 379 & 0.18 \\
MINING & 3 & 11 & 0.27 \\
CONSTRUCTION & 133 & 525 & 0.25 \\
MANUFACTURING & 39 & 155 & 0.25 \\
TRANSPORTATION, COMMUNICATION, PUBLIC & 32 & 92 & 0.35 \\
UTILITIES & 96 & 433 & 0.22 \\
WHOLESALE AND RETAIL TRADE & 19 & 50 & 0.38 \\
FINANCE, INSURANCE AND REAL ESTATE & 105 & 457 & 0.23 \\
BUSINESS AND REPAIR SERVICES & 164 & 681 & 0.24 \\
PERSONAL SERVICES & 38 & 105 & 0.36 \\
ENTERTAINMENT AND RECREATION SERVICES & 46 & 246 & 0.19 \\
PROFESSIONAL AND RELATED SERVICES & 0 & 1 & 0.00 \\
PUBLIC ADMINISTRATION & & & \\
\hline
\end{tabular}

aged, except for a slight drop in the last four periods. The frequency of serial entrepreneurs exhibits a similar pattern. Among total entrepreneurs, the percentage of serial entrepreneurs stays in the range between 0.2 and 0.3 throughout the fourteen periods. Compared to the maximum number of $13 \%$ Gompers et al. (2006) observe in their sample of venture capital-backed firms, the fraction of serial entrepreneurs counted in this sample is quite large.

The distribution of serial businesses across twelve industries is presented in Table 2.2. Although self-employment is common in most industries, serial entrepreneurship is mostly related to construction, trade, and business services.

Number of Previous Businesses (npb). On the basis of information on serial business owners, I construct the variable, $n p b$, to record how many different businesses a person had ever owned prior to the current surve . This variable is a measure of entrepreneurs' 
founding experience. In the overall sample, the average number of reported previous businesses is one point one, with the maximum equal to five.

Previous Business Earnings (pearn). In each round of the survey, respondents were asked about their income in the past calendar year from three main sources: military, wage and salaries, and business. Fairlie (2005) suggests that self-employment earnings should be measured by the total income from these three sources because most self-employed workers in the NLSY79 reported their earnings under wages and salary, instead of business income. Three reasons are presented by Fairlie (2005) to explain why this happened. First, incorporating business owners often count their income as wages; second, because of the ordering of the questions, it is possible that respondents already reported their business income when being asked about wages, and did not make any revision on the answer afterwards; Third, some self-employed workers only reported their labor income from the business under wages and salary.

To create a variable that captures a respondent's earnings from his last business, I first construct a yearly variable, rinc, which is the sum of a respondent's wage and business income in the previous calendar year. The variable previous (last) business earnings, pearn, is created in the following way. Let the 1982 data set be an example. If a person was self-employed in 1981 , the variable, pearn_82, takes the value of rinc_82 as it records his self-employment earnings in 1981. If the person was not self-employed in 1981, but had a business in 1980 , the variable, pearn_82, takes the value of rinc_81, which captures his business earnings in 1980, and so on. Each year, the respondents' previous business earnings are inflated to 2000 dollars. As noted here, military income does not play a part in this variable. The reason is that, compared to wages and salary, it 
is much less likely that a self-employed worker would report his business earnings under this category.

In the sample, average business earnings are $\$ 18,617$, with $\$ 25,599$ for men and $\$ 9,593$ for women. Table 2.3 compares the distributions of previous business earnings for those who started a new business and those who did not. Results from the raw data shows that people who started a new business had higher previous business earnings at all five percentiles listed in Table 2.3, though the difference starts to fade at the $99^{\text {th }}$ percentile. This pattern is consistent with what is observed from the residual earnings, obtained after partialing out the contributions of age, sex, education, industry and year. Figures 4 and 5 provide a better illustration. Both figures show that serial entrepreneurs are more likely to be associated with higher earnings in previous businesses, although little difference between the two groups is observed at the very top end.

TABLE 2.3

Distribution of Previous Business Earnings

\begin{tabular}{lcccc}
\hline \hline & \multicolumn{2}{c}{ Total Earnings } & \multicolumn{2}{c}{ Residual Earnings* } \\
\hline Mean & Non-Serial & Serial & Non-Serial & Serial \\
Std. Dev & 18,400 & 22,272 & -136 & 2,307 \\
$25^{\text {th }}$ percentile & 27,860 & 27,742 & 26,605 & 25,660 \\
$50^{\text {th }}$ percentile & 1,364 & 3,112 & $-13,562$ & $-12,646$ \\
$75^{\text {th }}$ percentile & 9,780 & 13,887 & $-5,318$ & $-3,562$ \\
$95^{\text {th }}$ percentile & 24,547 & 28,885 & 5,408 & 8,701 \\
$99^{\text {th }}$ percentile & 63,037 & 85,354 & 42,961 & 57,077 \\
\hline Observations & 121,241 & 129,150 & 106,209 & 103,578 \\
\hline
\end{tabular}

* Summary statistics for residual earnings from a regression of previous business earnings on observables (age, gender, highest grade completed, and industry and year dummies)

Time Span. This variable is created in each survey round to record how many years had passed since the last time a respondent reported being self-employed. Time span can have two effects on the probability that an ex-entrepreneur re-enters the business sector. On the 
whose earnings from the last business fell into the top one percentile. Wealth constraints may explain these differences.

\section{(3) Results}

Before reporting the results, a brief discussion on the regression models I used is in order. It is common practice to conduct earnings and employment choice regressions using fixed effects. However, the fixed-effects model removes individuals' time-invariant entrepreneurial ability from the estimation process. Thus, it is not a right model for testing any prediction that is based on selection on ability. For this reason, the baseline regressions in this section are carried out without fixed effects. I will then compare the results from these regressions with those generated using instrumental variables and fixed effects (conditional) logits ${ }^{6}$, and OLS. The IV estimates are intended to eliminate the contribution of learning by doing, while the fixed effects models eliminate innate ability effects.

\section{A. The Likelihood of serial business formation}

The first round of the analysis examines predictions (1) and (4) of the model. That is, the likelihood that an entrepreneur starts a new business is higher if his previous earnings were higher or he had formed more ventures before. My initial approach is to estimate a set of logit regressions where the dependent variable, serial, equals one if a person opened a serial business in the current year. Columns (1) and (2) in Table 2.4 report how this outcome responds to entrepreneurs' previous business earnings (pearn) and their prior founding experience $(n p b)$, respectively, while controlling for age, gender, education, time span, and industries. I do not control for year because there is only

\footnotetext{
${ }^{6}$ Katz (2001) and Coupé (2005) suggest that when the observing period is less than 16 , conditional fixedeffect logit models are preferred to unconditional models because the former produces estimators that have less bias. Respondents in the current sample were on average observed for less than six years.
} 
limited number of serial entrepreneurs observed each period. Adding this control, we are probably demanding too much from the regressions. Nevertheless, in an unreported analysis, I repeat all the estimations presented in this section with extra controls for years, and find no qualitative changes in the results.

The results reported in columns (1) and (2) of Table 2.4 demonstrate a positive and significant effect of the two variables, pearn and $n p b$, on new business formation, as predicted in the model, although the coefficient of previous business earnings is quite small. Column (3) further shows that adding both variables to the regression does not change the previous results. However, even though the results are consistent with what is implied by the notion of selection on ability, they could also reflect learning by doing in entrepreneurship. Thus, the real challenge is to show what is actually being captured in the data by the two variables, pearn, and $n p b$.

I take two approaches to distinguish the effect of selection on ability from the effect of learning by doing on serial business formation. The first approach is to repeat the analysis in column (3) using the conditional logit model. As the conditional logit regression removes the effect of innate entrepreneurial ability, any surviving effects of pearn, and $n p h$ are likely to be attributed to learning by doing.

The results reported in column (4) are markedly different from those reported in the previous columns. Not only do previous business earnings no longer matter for serial business formation, but prior founding experience has a strong negative effect on the probability that a person forms a serial business. This sharp contrast suggests that learning by doing may not be an adequate explanation for the results generated by the logit regressions. 


\begin{tabular}{|c|c|c|c|c|}
\hline & \multicolumn{4}{|c|}{$\begin{array}{c}\text { DEP VAR: SERIAL }=1 \text { IF A NEW BUSINESS WAS FORMED IN } \\
\text { THE CURRENT PERIOD }\end{array}$} \\
\hline & \multicolumn{3}{|c|}{ LOGIT REGRESSIONS } & \multirow{2}{*}{$\begin{array}{l}\text { CONDITIONAL LOGIT } \\
\text { (4) }\end{array}$} \\
\hline & (1) & (2) & (3) & \\
\hline \multirow[t]{2}{*}{ PREVIOUS BUSINESS EARNINGS $(\$ 1,000 \mathrm{~S})$} & $0.003 * * *$ & & $0.003 * *$ & 0.001 \\
\hline & $(2.45)$ & & $(2.18)$ & $(0.51)$ \\
\hline \multirow[t]{2}{*}{$\begin{array}{l}\text { NUMBER OF PREVIOUSLY-OWNED } \\
\text { BUSINESSES }\end{array}$} & & $0.19^{* * *}$ & $0.18^{* * *}$ & $-3.73 * * *$ \\
\hline & & $(2.75)$ & $(2.52)$ & $(-15.44)$ \\
\hline \multirow[t]{2}{*}{ SPAN } & 0.01 & 0.01 & 0.02 & $0.22 * * *$ \\
\hline & $(0.38)$ & $(0.56)$ & $(0.93)$ & $(3.62)$ \\
\hline \multirow[t]{2}{*}{ HIGHEST GRADE COMPLETED } & 0.02 & 0.03 & 0.02 & 0.04 \\
\hline & $(0.94)$ & $(1.56)$ & $(1.15)$ & $(0.53)$ \\
\hline \multirow[t]{2}{*}{$\operatorname{MALE}(=1)$} & 0.13 & $0.17^{*}$ & 0.12 & -- \\
\hline & $(1.34)$ & $(1.80)$ & $(1.27)$ & --- \\
\hline \multirow[t]{2}{*}{ AGE } & $0.35^{* * *}$ & $0.35 * * *$ & $0.35^{* * *}$ & $0.93 * * *$ \\
\hline & $(2.38)$ & $(2.43)$ & $(2.41)$ & $(3.64)$ \\
\hline \multirow[t]{2}{*}{$(\mathrm{AGE}) 2$} & $-0.01 * * *$ & $-0.01 * * *$ & $-0.01 * * *$ & -0.01 \\
\hline & $(-2.41)$ & $(-2.49)$ & $(-2.49)$ & $(-1.35)$ \\
\hline AV. LOG LIKELIHOOD & -0.25 & -0.25 & -0.25 & -0.20 \\
\hline NO. OF OBS & 9665 & 9665 & 9665 & 3601 \\
\hline
\end{tabular}

$\mathrm{Z}$-scores are in parentheses. Significance levels: ${ }^{* * *} 0.01,{ }^{* *} 0.5,{ }^{*} 0.1$. Additional controls include 11 industry dummies.

In the second approach, I apply IV estimation. Two additional variables are constructed, earnings in one's first job (fincome) and earnings from the first-year of one's first business (fearn). Both variables are positively related to an entrepreneur's ability, but have little to do with learning by doing from previous experience. Moreover, they are both closely related to entrepreneurs' previous business earnings and even their founding experience through entrepreneurial ability. For this reason, I use these two earnings variables as instruments for previous business earnings and the number of previouslyformed businesses. 
DEP VAR: SERIAL=1 IF A NEW BUSINESS WAS FORMED IN THE CURRENT

\section{PERIOD}

OLS IV OLS IV OLS IV

(1)

(2)

(3)

(4)

(5)

(6)

PREVIOUS BUSINESS EARNINGS $(\$ 1,000 \mathrm{~s})$

$2.5 \mathrm{E}-04 * * * 3.9 \mathrm{E}-04 * * *$

$(2.55)$

$2.3 \mathrm{E}-04 * * 5.3 \mathrm{E}-04 * * *$

(2.32)

NUMBER OF PREVIOUSLY-OWNED BUSINESSES

\begin{tabular}{|c|c|c|c|c|c|c|}
\hline & & & $(2.83)$ & $(2.50)$ & $(2.62)$ & $(3.14)$ \\
\hline \multirow[t]{2}{*}{ SPAN } & 0.000 & 0.001 & 0.001 & $0.006^{* *}$ & 0.001 & $0.01 * * *$ \\
\hline & $(0.41)$ & $(0.66)$ & $(0.58)$ & $(2.26)$ & $(0.98)$ & $(3.14)$ \\
\hline \multirow[t]{2}{*}{ HIGHEST GRADE COMPLETED } & 0.001 & 0.001 & 0.002 & $0.003 * * *$ & 0.001 & $0.002 *$ \\
\hline & $(0.87)$ & $(0.59)$ & $(1.54)$ & $(2.37)$ & $(1.06)$ & $(1.80)$ \\
\hline \multirow[t]{2}{*}{$\operatorname{MALE}(=1)$} & 0.01 & 0.01 & $0.01^{*}$ & 0.00 & 0.01 & -0.01 \\
\hline & $(1.26)$ & $(0.88)$ & $(1.79)$ & $(0.74)$ & $(1.19)$ & $(-0.67)$ \\
\hline \multirow[t]{2}{*}{$\mathrm{AGE}$} & $0.02 * * *$ & $0.02 * * *$ & $0.02 * * *$ & $0.02 * * *$ & $0.02 * * *$ & $0.02 * * *$ \\
\hline & $(2.36)$ & $(2.34)$ & $(2.41)$ & $(2.53)$ & $(2.38)$ & $(2.48)$ \\
\hline \multirow[t]{2}{*}{$(\mathrm{AGE}) 2$} & $\begin{array}{l}-3.6 \mathrm{E}- \\
04 * * *\end{array}$ & $\begin{array}{l}-3.6 \mathrm{E}- \\
04 * * *\end{array}$ & $\begin{array}{l}-3.8 \mathrm{E}- \\
04 * * *\end{array}$ & $\begin{array}{l}-4.9 \mathrm{E}- \\
04 * * *\end{array}$ & $\begin{array}{l}-3.8 \mathrm{E}- \\
04 * * *\end{array}$ & $\begin{array}{l}-5.4 \mathrm{E}- \\
04 * * *\end{array}$ \\
\hline & $(-2.38)$ & $(-2.38)$ & $(-2.48)$ & $(-3.01)$ & $(-2.47)$ & $(-3.20)$ \\
\hline ADJ R-SQUARED & 0.01 & 0.01 & 0.01 & -- & 0.01 & --- \\
\hline No. OF OBS & 9665 & 9665 & 9665 & 9665 & 9665 & 9665 \\
\hline
\end{tabular}

First, I repeat the analysis in columns (1) through (3) of Table 2.4, substituting the linear probability model for the logit. The results, shown in columns (1), (3) and (5) of Table 2.5, are consistent with those from the logit regressions. Next, three IV estimations are implemented with both instruments. The results are reported in columns (2), (4) and (6) of Table 2.5, which all, again, have the predicted signs and are statistically significant. It is interesting to note that, contrary to expectations, the IV estimations generate larger coefficients for both variables of interest. As the results from IV estimations are solely driven by selection on ability, they provide support for propositions 1 and 4 in the model. 


\section{B. Earnings from the Current Business}

The second task in the analysis is to examine propositions (5) and (6) which predict a positive effect of the number of ventures an entrepreneur has founded and performance in prior business on earnings in the current business.

Column (1) of Table 2.6 reports the results of the OLS regression, which confounds selection and learning effects. The regression shows a positive effect of previous business earnings on current earnings, but no effect of the number of businesses previously owned. Column (2) reports IV regressions, using the same instruments as previously, and intended again to isolate the effects of selection on ability. The IV estimation returns a large positive point estimate for the effect of founding experience, although this is very imprecisely estimated and statistically insignificant. The effect of previous business earnings on current earnings is more precisely estimated, and plausibly indicates that current business earnings increase by $\$ 720$ with each $\$ 1,000$ increase in previous business earnings. Finally, column (3) of Table 2.6 reports the results of fixed effects estimation. The positive effect of previous business earnings is eliminated. The point estimate of the effect of previous business ownership remains large and positive, and is now significant at the ten percent level.

These results suggest that selection on ability and learning by doing both have a role to play in determining current business earnings. First, the persistence of the effect of prior business earnings as we move from OLS to IV, and its elimination in the fixed effects model, indicate that the correlation between previous and current business earnings is entirely because of selection effects; Second, the significance of the number of 
previously-owned businesses in the fixed effects model, suggests that learning by doing plays a role in linking prior founding experience to current earnings.

TABLE 2.6

Current Business Earnings and Previous Business Experience

\begin{tabular}{lccc}
\hline & \multicolumn{3}{c}{ DEP VAR: CURRENT BUSINESS EARNINGS, \$1,000S } \\
\cline { 2 - 4 } & OLS & IV & FIXED-EFFECTS OLS \\
\cline { 2 - 4 } & $(1)$ & $(2)$ & $(3)$ \\
\hline NUMBER OF PREVIOUSLY-OWNED BUSINESSES & -0.05 & 9.33 & $8.08^{*}$ \\
PREVIOUS BUSINESS EARNINGS (\$1,000S) & $(-0.03)$ & $(0.47)$ & $(1.79)$ \\
& $0.62^{* * *}$ & $0.72^{* * *}$ & -0.07 \\
SPAN & $(13.01)$ & $(9.49)$ & $(-0.81)$ \\
& -0.23 & 0.61 & 0.88 \\
HIGHEST GRADE COMPLETED & $(-0.37)$ & $(0.43)$ & $(0.71)$ \\
& $1.72^{* * *}$ & $1.65^{* *}$ & -1.5 \\
AGE & $(3.28)$ & $(2.28)$ & $(-0.38)$ \\
& 3.88 & 2.48 & 2.4 \\
(AGE)2 & $(0.9)$ & $(0.53)$ & $(0.36)$ \\
& -0.07 & -0.06 & -0.06 \\
MALE(=1) & $(-0.91)$ & $(-0.72)$ & $(-0.54)$ \\
& $8.37^{* * *}$ & $6.69^{* *}$ &.-- \\
F-STATISTIC & $(2.98)$ & $(2.21)$ & --- \\
NO. OF OBS & 19.28 & 14.45 & 1.41 \\
\hline
\end{tabular}

As the contribution of entrepreneurial ability is eliminated from the fixed effects regression, the results suggest that entrepreneurs learn from past experience without regard to their performance in previous businesses. This finding is in contrast to the Gompers et al. (2006) study of venture capital-backed firms, where it was suggested that only successful past experiences engender future success. In their study, business performance is measured by a binary indicator of success or failure. They find that serial entrepreneurs with successful prior businesses have a higher rate of success than first- 
time entrepreneurs or entrepreneurs who failed before. Founding experience, however, does not matter once prior success is considered. ${ }^{7}$ Gompers et al. (2006) favor an interpretation of selection on ability over selective learning by doing. However, using prior success as a proxy for entrepreneurial skills may raise a potential issue as this variable also captures heterogeneous learning by entrepreneurs. The result of Gompers et al.'s (2006) result, therefore, could be driven by different forces other than entrepreneurial skills. For example, their result could arise because learning from successful experience is more valuable, or because high-ability entrepreneurs learn faster from prior experience.

\subsection{Conclusions}

This paper explores the idea that serial entrepreneurial behavior could be a reflection of selection on ability. It develops a framework where entrepreneurs do not perfectly observe their abilities, and their business ideas come as a random draw. Without learning by doing, the model predicts that entrepreneurs from successful ventures are exposed to a higher incentive to pursue a new business idea if the current idea does not appear to be particularly attractive. It also predicts a positive correlation between prior entrepreneurial experience and the likelihood of new business formation and the performance of current venture.

While the model focuses on the role of selection in serial entrepreneurship, I do not intend to discount the notion that learning by doing in prior experience could also encourage entrepreneurs to explore new business opportunities and further improve their performance in new ventures. In fact, the empirical analysis provides evidence of both

\footnotetext{
${ }^{7}$ Indeed, they observe little difference between the predicted success rate of serial entrepreneurs who had failed in the previous business $(22.1 \%)$ and that of entrepreneurs who had founded only one business $(20.9 \%)$.
} 
types of learning among serial entrepreneurs. On the one hand, the results show that, after reducing their correlation with entrepreneurial learning by means of IV regressions, both higher previous business earnings and more founding experience predict a higher probability that entrepreneurs start a new business and better performance in these businesses. These findings support the theory of selection on ability. On the other hand, after eliminating the contribution of entrepreneurial ability by means of fixed effects regressions, I find that learning from prior experience has a significant impact on entrepreneurs' current business performance. This result is consistent with the story of learning by doing in entrepreneurship.

This paper is closely related to the study of Eesley and Roberts (2006a) on entrepreneurial learning from founding experience and the recent work of Gompers et al. (2006) which emphasizes entrepreneurial skills rather than learning from prior experience. The present paper suggests that the empirical evidence presented in both studies does not contradict, but rather complement each other. Thus, the paper sheds some light on a controversial issue raised by the finding of Gompers et al. (2006) that almost no learning would happen in an unsuccessful venture. ${ }^{8}$

The present paper argues that entrepreneurial experience is an important indicator of entrepreneurial ability. Serial entrepreneurs with successful business backgrounds are more likely to be associated with superior ability, such as discovering a promising business opportunity, or choosing the right management team. Thus, it would not be surprising if they continue to be successful in a new venture. Learning by doing, on the other hand, could help entrepreneurs overcome their initial inexperience in some specific

\footnotetext{
${ }^{8}$ Their finding is also at odds with numerous entrepreneurial legends who suffered several failures before great success eventually came. As Gordon Moore, a co-founder of Intel, put it, "[y]ou're more valuable because of the experiences you've been through under failures" (Berlin, 2009).
} 
cases, and improve their performance later. But if selection on ability dominates entrepreneurial learning, previously-successful entrepreneurs on average would be expected to have a better performance in a new business than those who failed before, especially if we consider the possibility that high-ability entrepreneurs often learn faster from their previous experience than their low-ability counterparts.

In this paper, I adopt a simplified production technology in order to derive some basic insights for the mechanism of selection. For future research, this model can be extended in several directions. First, some random noise could be added to the production function so that the omitted factors, such as technology shocks or a sudden change in management team, would also have an influence on output. Second, instead of assuming independence of ability and business quality, complementarity between these two variables can be introduced to the model. In this case, high-ability entrepreneurs are more likely to be associated with a good business idea, and also to have a better chance of discovering a promising new business opportunity. It would be interesting to see how differently entrepreneurs behave in this new context. Third, it is also worthwhile to estimate from the model the maximum time it will take an entrepreneur to learn precisely his ability. Lastly, given the widely-accepted view that entrepreneurs are overconfident, adding this element to the model would allow us to explore whether overconfidence accelerates entrepreneurial learning, and whether this would in turn reduce serial entrepreneurial activities. 


\section{REFERENCES}

Berlin, Leslie (2009): "Try, Try Again, or Maybe Not." The New York Times (March 21).

Cooper, Andrea (2008): "Serial Starter." Entrepreneur Magazine, 2008(4).

Corbett, Andrew C. "Experiential Learning within the Process of Opportunity Identification and Exploitation." Entrepreneurship Theory and Practice, 29(4): 473491.

Coupé, Tom (2005): "Bias in Conditional and Unconditional Fixed Effects Logit Estimation: A Correction." Political Analysis, 13(3): 292-295.

Cox, David R., and H.D. Miller (1965): The Theory of Stochastic Processes. New York: Wiley.

Eesley, Charles and Edward Roberts (2006a): "Cutting Your Teeth: Learning from Rare Experiences." Working paper, MIT.

Eesley, Charles and Edward Roberts (2006b): "The Second Time Around?: Serial Entrepreneurs from MIT." Working paper, MIT.

Fairlie, Robert W. (2005): "Self-employment, Entrepreneurship, and the NLSY79." Monthly Labor Review, 128(2): 40-47.

Farber, Henry S. (1994): "The Analysis of Interfirm Worker Mobility." Journal of Labor Economics, 12(4): 554-593.

Gompers, Paul, Anna Kovner, Josh Lerner, and David Scharfstein (2006): "Skill vs. Luck in Entrepreneurship and Venture Capital: Evidence from Serial Entrepreneurs.

"NBER working paper, No. 12592.

Holmes, Thomas J. and James A. Schmitz, Jr. (1990): "A Theory of Entrepreneurship and Its Application to the Study of Business Transfers." Journal of Political Economy, 98(2): 265-294.

Jovanovic, Boyan (1979): "Job Matching and the Theory of Turnover." Journal of Political Economy, 87(5, part1):972-990.

Jovanovic, Boyan (1982): "Selection and the Evolution of Industry." Econometrica, 50(3): 649-670.

Katz, Ethan (2001): "Bias in Conditional and Unconditional Fixed Effects Logit Estimation." Political Analysis, 9(4): 379-384.

Minniti, Maria and William Bygrave (2001): "A Dynamic Model of Entrepreneurial Learning." Entrepreneurship Theory and Practice, 25(3): 5-16. 
Nagypál, Éva (2007): "Learning by Doing vs. Learning about Match Quality: Can We Tell Them Apart?" Review of Economic Studies, 74(2):537-566.

Pástor, Luboš, Lucian A. Taylor, and Pietro Veronesi (2009): "Entrepreneurial Learning, IPO Decision and the Post-IPO Drop in Firm Profitability." Review of Financial Studies, 22(8): 3005-3046.

Politis, Diamanto (2005): "The Process of Entrepreneurial Learning: a Conceptual Framework." Entrepreneurship Theory and Practice, 29(4): 399-424.

Stam, Erik, David Audretsch, and Joris Meijaard (2006): "Renascent Entrepreneurship: Entrepreneurial Preferences Subsequent to Firm Exit." Working paper 2006-06, Max Planck Institute of Economics, Entrepreneurship, Growth and Public Policy Group.

Thompson, Peter (2008a): "Learning by Doing." Handbook of Economics of Technical Change, Elsevier/North-Holland. Forthcoming.

Thompson, Peter (2008b): "Desperate Housewives? Communication Difficulties and the Dynamics of Marital (Un)happiness, The Economic Journal, 118:1640-1669.

Thompson, Peter and Jing Chen (2009): "Employee Spinoffs and Solipsistic Entrepreneurs." Working paper, Florida International University.

Wang, Jennifer (2009): "Confessions of Serial Entrepreneurs." < http://www.entrepreneur.com/startingabusiness/successstories/article199436.html $>$.

Wright, Mike, Ken Robbie, and Christine Ennew (1997): "Serial Entrepreneurs." British Journal of Management, 8(3): 251-268.

Williams, Geoff (2000): “There Ought to Be A Law.” Entrepreneur Magazine, 2000(2). 


\section{CHAPTER 3}

\section{Who Benefits from Firm Growth? An Analysis of Technology Effects}

\section{on Job Turnover}

\subsection{Introduction}

A conventional wisdom regarding human capital and labor mobility suggests that highlevel workers should have more stable employment. The reason is straightforward. Highlevel jobs are often thought to have more technology elements and higher requirement for (firm-) specific human capital. As articulated in human capital theory, workers acquire firm-specific human capital by investing in specific training on the job. They then earn higher wages than they could receive in any other firm because of greater productivity resulting from the stock of human capital. Meanwhile, their investment in firm-specific capital is of no use somewhere else. Considering these two aspects, the more firmspecific capital a rational worker has accumulated, the less likely he would be to quit his job (Becker (1962), Moretensen (1978), Jovanovic (1979)). Empirical literature also provides supportive evidences. The most stylized fact is the negative relationship between job turnover and job tenure with the latter being positively related to the accumulation of specific human capital. Earlier studies also observe higher turnover rates for the low-level production workers (Jovanovic and Mincer (1978)). In addition, Topel and Ward (1992) document that worker-firm separation is less likely to occur on jobs with high wage-growth than on those with low-wage growth.

Regardless of these consistent findings, there are two exceptions in the recent studies. Dohmen and Pfann (2004) investigate a personnel dataset based on a Dutch aircraft firm and find that white-collar workers are more likely to quit jobs than their blue-collar 
counterparts during the demand-driven expansions of employment. A similar phenomenon, documented by Lazear (1999), is at play in a financial services company where higher level workers tend to separate from the firm more often. Both findings are at odds with the conventional view discussed above. This paper does not intend to generalize these results, for they may be specific to the individual firms. Instead, the purpose of this paper is to suggest some explanations on this atypical labor mobility pattern in the context of the existing human capital and search theories.

One essential element in this line of research is firm-specific human capital. It is accumulated through on-the-job-training and is only valuable within the firm. A direct result is that the worker's wage in the current firm, which is often equal to his marginal productivity, is an increasing function of the stock of firm-specific human capital. In contrast, the worker's outside offer has little to do with how much firm-specific human capital the worker accumulates in the current firm. Since separation occurs only if the value of the outside offer exceeds the value of the current job, it is easy to see that workers with more firm-specific capital are less likely to quit. Compared to firm-specific human capital, workers with general capital do not have such constraints. When the outside wage rises, they have greater tendency to leave for another job because the human capital they have are equally valued elsewhere. In addition to firm-specific and general human capital, there is a third type of human capital in between. As Becker (1962) points out, some on-the-job-trainings are neither applicable in all firms nor exclusively useful in a single firm. Instead, they are specific to an industry or an occupation. Other studies also argue that few skills are really exclusively used in one specific firm and then become useless elsewhere. Most human capital and skills are occupation-specific 
(Kambourov and Manovskii 2005), task-specific (Gibbons and Waldman 2003), or industry-specific (Neal 1995). Following this idea, if a worker's skill is industry-specific, the amount of increase in the worker's marginal productivity because of the accumulation of specific capital is the same elsewhere in the industry. This new condition increases the worker's incentive to quit for two reasons: first, if he quits, he can find a similar job somewhere inside this industry without incurring any loss for the investment in human capital; second, he now has more bargaining powers on wage. If the current firm does not pay enough to the worker, there is always a chance for him to receive better payment somewhere else. In this sense, workers with specific human capital may have as high turnover rate as those with general capital. Relating this last point to high-level workers, we can show that high-level workers do not always have lower rate of separation as long as their human capital is not firm-specific. In reality, we see many cases in which specific skills are transferable across firms or even industries. A typical example is Silicon Valley. Saxenian (1994) documents that job tenures for computer professionals in Silicon Valley is on average two or three years. Not only did these engineers moved frequently between firms, but some became venture capitalists, bringing their technical skills and experience to ventures they funded.

As we have seen so far, skill transfer alone is not sufficient enough to interpret why highlevel workers may exhibit higher turnover rates. To see how this happens, we need another input, firm growth. Firm growth can be driven by two forces: demand expansion and technology advancement. In the first case, if demand increase is temporary, the firm needs to hire more low-level production workers just to meet the rising demand. Thus, there is really no incentive for either high-level or low-level workers to quit jobs, or for 
the firm to fire workers. If the increase is widespread in the whole industry, for example, a cyclical demand increase, the firm needs an expansion of employment of both types of workers. Intuitively, the demand for high-level workers (such as technical workers, professional managers) is particularly competitive because of the high productivity and the limited amount of supply. This latter type of demand increase may explain why Dohmen and Pfann (2004) find that white-collar workers in the Dutch aircraft firm are more likely to separate from their workplace in the period of employment expansion but less likely to leave during the following contraction.

In this paper, I only focus on technological change as the driving force of firm growth. For the help of intuition, let us first consider a simple story. There are two groups of workers in the firm: blue-collar workers and white-collar workers. Within both groups, workers differ in how specific their skills are to the technology used by the firm. For instance, both blue-collar technicians and white-collar engineers have skills specific to a certain technology currently adopted by the firm, though the degree of specificity may vary. In contrast, skills of low-level assemblers or office secretaries are more general and less attached to any specific technology. An important assumption here is that skills are specific at the industry level. This assumption has a direct implication. That is, if a worker who has the specific skill leaves the current firm, he can find a similar job somewhere else within the same industry. Job separation occurs if the outside offer exceeds the worker's current wage, which is assumed to be an increasing function of the worker-firm match. Here I follow Jovanovic (1996) and assume that technology upgrading in the firm has little impact on the match quality for workers with general skills, but it decreases the match quality for those with specific skills. The underlying 
reason is that general skills can be transferred freely from one technology grade to another, while specific skills do not have this flexibility. Therefore, the higher is the degree of specificity, the greater the loss in expertise and match quality. As a result, these workers will choose to leave and work for another firm in the same industry, where their skills are still valuable. Their positions in the old firm will then be replaced with those who are skilled at the latest technology. In contrast, workers whose jobs involve little specific skills would prefer to stay with the firm and benefit from its growth. Thus, the story predicts that workers with technology-specific skills have higher turnover rates in the presence of technological advancement. This hypothesis receives more support in the theoretical context of Chari and Hopenhayn (1991) and Jovanovic (1996). Both studies suggest that the worker will hardly switch to the new technology if he is very skilled at the old one.

In the second part of the paper, this hypothesis is tested with data from the Panel Study of Income Dynamics (PSID). The data set consists of 7285 household heads who were employed workers at the time of survey. The observation period spans 1981 to 1987 . One problem with using the PSID is that there is no information on firms. Because of this data limitation, I am not able to observe technological change at firm level, and therefore cannot directly test whether or not workers with specific skills are more likely to separate from jobs when firms are experiencing technological change. A compromising way is to look at industry-level data. The idea is that given the industry is on average experiencing technological change, according to what the model predicts, we would expect to see higher rates of turnover among workers with specific capital who left the previous firms because of technology upgrading and moved to firms which have not caught up with the 
new technology. Thus, the main focus of this analysis is to see how technological change in industries affected these workers' employment choice. Especially, how these choices differ among workers with different types of skills? The dependent variable, which indicates a worker's employment choice in the current survey year, is constructed based on the PSID's employment history data. Depending on the certain regression, this variable is either a dummy variable which equals 1 if a worker quit previous job, or a categorical variable which takes the value of 1 if a worker stayed at the same job, 2 if he was laid off, and 3 if he quit the previous job. While there is no direct measure of skill specificity, I take the conventional approach by focusing on each individual's occupation. In the data set, a worker is defined as having skills specific to a certain technology if his occupation falls into one of the three categories: engineers and computer specialist, professional workers, or managers. Technological change is measured by productivity growth per production worker in each industry. The data come from the Bureau of Economic Analysis (BEA).

The analysis proceeds in three steps. First, I run a multinomial logit regression of employment choice on a dummy variable for being a worker with specific capital on the previous job, specific, and its interaction with productivity growth, vaskill. Observed heterogeneity such as demographic characteristics and previous industry categories are controlled in the regression. The results show that workers with specific skills in general have relatively stable employment, which is consistent with previous findings. However, when technological change is considered, workers with specific skills exhibit higher probability of quitting the jobs, which supports the prediction in the model. This result 
remains significant even after I control for the unobserved heterogeneity, which is approximated by the number of previous turnover.

Second, I run a conditional logit regression to control for individuals' fixed effects. The categorical dependent variable in the previous multinomial logit model is replaced with a dummy variable which equals one if a person quit the previous job. Both variables of interests (specific and vaskill) obtain expected signs, but the estimated coefficient on vaskill is not statistically significant. The most probable reason for obtaining the insignificant result is that 70 percent of total observations dropped in the conditional logit regression because of all positive or negative outcomes. To avoid the problem of losing so many observations, the final analysis examines the linear probability model. With controls for individuals' observed and unobserved heterogeneity, the results again show that in the presence of technological change, being a worker with specific skills increases the chance of quitting by eight percent. The result is significant at 5 percent level.

The organization of the paper is as follows. Section 2 is the theoretical part of the paper. In this section, I present a simple match-searching model incorporated with technology upgrading, which generates some testable implications. Empirical tests on these implications are taken up in Sections 3 and 4, where I describe the data set and report the results from three main regression models. The final section concludes the paper.

\subsection{The Model}

All search and separations in the model are assumed to be initiated by the worker. The worker's wage at time $t$ depends on the firm's technology level at that time $\left(y_{t}\right)$ and his employment match with the firm in terms of skill. I define skill match as the difference 
between the worker's skill at job $i\left(z_{i}\right)$ and the skill required on job $i$ at time $t\left(x_{i t}\right)$. Thus, the wage function for job $i$ at time $t$ can be characterized as

$$
w_{i t}=y_{t}-\left(x_{i t}-z_{i}\right)^{2}
$$

It is easily to see in equation (1) that on the one hand, the worker benefits from working for a firm at a higher technological level ( $w_{i t}$ increases in $\left.y_{t}\right)$; on the other hand, his wage falls if his skill on the job does not match with the skill required by the firm. Mismatch happens in two cases: disqualified and overqualified. If a worker is disqualified, his skill level is below the required level. Conversely, an overqualified worker's skill is too advanced for the skill currently needed in the firm. Both of these cases would negatively affect his productivity on the job, therefore are treated equally in the model.

Firm's technological change follows

$$
y_{t}=\left(1+g_{t}\right) y_{t-1}
$$

where the rate of change at time $t\left(g_{t}\right)$ is a serially correlated random variable, i.e. the change rate of technology in next period, $g^{\prime}$, is drawn form $F\left(g^{\prime} \mid g\right)$, and $\partial F\left(g^{\prime} \mid g\right) / \partial g \leq$ 0 . Skill required on the job $i$ in two consecutive years satisfies the following condition

$$
x_{i t}=x_{i t-1}+\varepsilon_{i t}
$$

where $\varepsilon_{i i} \sim N\left(0, \sigma_{\varepsilon}^{2} g_{t} \alpha_{i}\right)$. According to equation (3), given the previous requirement of skill, the current requirement of skill is expected to be consistent with its previous level $\left(E\left(x_{i t} \mid x_{i t-1}\right)=x_{i t-1}\right)$. A deviation $\left(\operatorname{var}\left(x_{i t} \mid x_{i t-1}\right)=\sigma_{\varepsilon}^{2} g_{t} \alpha_{i}\right)$ can be caused by the rate of technological change $\left(g_{t}\right)$ or the variable $\alpha_{i} \in[0,1]$. The term, $\alpha_{i}$ measures the responsiveness of skills required on job $i$ to technological change. A higher value of $\alpha_{t}$ indicates a higher requirement for skill adaptation to new technology. 
Consider a two-period model: $t-1$ and $t$. In period $t-1$, there is technological change occurring in the firm. As a result, the skill required on job $i$ is upgraded to $x_{t-1}$, which, by assumption, is not observable to the worker until the end of this period.

At the end of period $t-1$, the worker needs to make a stay-or-leave decision, which would be based on the expected match between his skill and the skill required on the job in period $t$. Given the requirement in period $t-1, x_{t-1}$, we can rewrite wage function (1) as

$$
w_{i t}=y_{t}-E_{t-1}\left(x_{i t}-z_{i}\right)^{2}
$$

where $x_{t}$ denotes the skill required on job $i$ in period $t$. Substituting (2) and (3) into (4) yields

$$
w_{i t}=\left(1+g_{t}\right) y_{t-1}-\sigma_{\varepsilon}^{2} g_{t} \alpha_{i}-x_{i t-1}^{2}+2 z_{i} x_{i t-1}-z_{i}^{2}
$$

It is easy to see from equation (5) that if the worker maximizes his expected wage by improving his skill $\left(z_{i}\right)$, he would improve it to $x_{i t-1}$, the skill required by the firm in period $t-1.9$

In period $t$, if the worker stays at the firm, he would keep this skill level, $x_{i t-1}$. over the period. This is because that he does not observe any change of skill requirement caused by possible technological progress until the end of period $t$. Substituting $z_{1}^{*}=x_{i t-1}$ into (5), we have

$$
w_{i t}=\left(1+g_{t}\right) y_{t-1}-\sigma_{\varepsilon}^{2} g_{t} \alpha_{i}
$$

Differentiating both sides of the equation with respect to $g_{t}$ gives

$$
\frac{d w_{i t}}{d g_{t}}=y_{t-1}-\sigma_{\varepsilon}^{2} \alpha_{i}^{2}
$$

${ }^{9} w_{t}^{*}=\max \left(1+g_{t}\right) y_{t-1}-\sigma_{\varepsilon}^{2} g_{t} \alpha_{i}-x_{i t-1}^{2}+2 z_{i} x_{i t-1}-z_{i}^{2}$. The first order condition gives $z_{t}^{*}=x_{i t-1}$. Notice that If the worker is overqualified, he would choose to keep his original skill. 
P1. $w_{i t}$ is increasing in $g_{t}$ if $\alpha_{i}<\frac{y_{t-1}}{\sigma_{\varepsilon}^{2}}$, and decreasing in $g_{t}$, if otherwise.

Proposition 1 has an implication for two types of jobs: jobs employing specific technical skills and jobs using regular skills. Workers associated with the former type of job vary from production workers, technicians to $R \& D$ researchers. As the set of skills needed on these jobs is more responsive to technological change (higher $\alpha$ ), there expects to be a larger variance between the skill required in period $t-1$ and that required in period $t$. We can easily see from equation (5) that this would increase the expected mismatch in period $t$, even if the worker improves his skill to $x_{t-1}$ at the end of period $t-1$. In turn, the expected wage on these jobs decreases as technological change accelerates. Conversely, for workers associated with the latter type of job-ranging from unskilled blue-collar workers to low-level office workers, the rapid change of technology increases their wage for skills required on those jobs are hardly affected by new technology. There are two things worth noting. First, as a benchmark, technological change has no impact on wage if $\alpha_{i}=y_{t-1} / \sigma_{\varepsilon}^{2}$. The fact that the threshold value of $\alpha_{i}$ increases in $y_{t-1}$ and the wage decreases in $g_{t}$ if $\alpha_{i}>y_{t-1} / \sigma_{\varepsilon}^{2}$ implies that firms at lower technological level $\left(y_{t-1}\right)$ have more jobs which are vulnerable to technological change.

Second, the worker's skill, $z_{i}$, does not appear in equation (6). This implies that being overqualified on the job would not influence the worker's expectation of future match quality $^{10}$. In the model, the only crucial factor that matters to the expected quality of future match is the responsive variable $\alpha_{i}$. Therefore, technology growth may still cause a decrease in an overqualified worker's wage, in spite of the possibility that overqualified skills might become more valued during technological change.

\footnotetext{
${ }^{10}$ As shown in equation (3), the expected requirement of skill in period $t, x_{t}$, given that in period $t-1, x_{t-1}$, is still $x_{t-1}$.
} 
On the basis of the above specification, let us now consider a simple search story. Firm growth is achieved by the adoption of new technology. Technological change in the firm affects the worker's wage through productivity growth (because of the adoption of new technology) and the change of employment match between the worker and the firm. Every period, the worker receives an offer outside the firm. The dynamic problem facing the worker is to decide whether to quit the job and accept the outside offer at the end of each period. If he stays, the value of working through the next period is $V\left(g^{\prime}\right)$ considering next period's technological change. Otherwise, he would earn Q by quitting. Since searching is random, it is convenient to assume that the value of quitting, Q, is constant for all new offers. Let $V(g)$ be the value of working in a firm where technology changes at the rate of $g$, then with a discount factor of $\beta$, the Bellman equation for the worker is

$$
V(g)=w(g)+\beta E \max \left(V\left(g^{\prime}\right), Q\right)
$$

The existence of a unique solution $g *$ to equation (7) can be proved by following the standard way in the literature. The analysis below is broken down into two cases regarding the type of job.

\subsubsection{Case 1: Jobs associated with specific technical skills}

It is shown in the appendix that when $w$ is decreasing in $g$, there is a unique solution to the optimal problem in (7), and $V(g)$ is strictly decreasing in $g$. This yields the following proposition:

P2. The optimal stopping problem has a unique solution, $g^{*}$, and $V\left(g^{*}\right)=Q$. In the case where $w(g)$ is decreasing in $g$, staying is preferable when $g<g^{*}$ and quitting is chosen when $g \geq g^{*}$. 
The reservation equation is

$$
Q=[1 /(1-\beta)] w\left(g^{*}\right)-[\beta /(1-\beta)] \int_{0}^{g *} F\left(g^{\prime} \mid g^{*}\right) V_{g^{\prime}}(g) d g^{\prime}
$$

where $V_{g^{\prime}}\left(g^{\prime}\right)<0$. Differentiating equation (9) with respect to $\alpha$ gives

$$
\left[y_{t-1}-\sigma_{\varepsilon}^{2} \alpha-\beta \int_{0}^{g *} V_{g^{\prime}}\left(g^{\prime}\right) \frac{\partial F\left(g^{\prime} \mid g *\right)}{\partial g^{*}} d g^{\prime}\right] \frac{d g^{*}}{d \alpha}=\sigma_{\varepsilon}^{2} g^{*}
$$

To see the first term on the LHS of equation (5) is negative, note that $y_{t-1}$ is less than $\sigma_{\varepsilon}^{2} \alpha$ when $d w / d g<0$. Moreover, $F\left(g^{\prime} \mid g\right)$ and $V_{g^{\prime}}\left(g^{\prime}\right)$ are decreasing in $g^{\prime}$ by assumption. Thus, $d g^{*} / d \alpha<0$. Since $V(g)$ is decreasing in $g$, this result means a worker facing a higher $\alpha$ would choose to quit the job even at a low reservation growth rate $\left(g^{*}\right)$. In this case, it indicates a higher probability of quitting for technology workers whose job are related to the latest technology, as they face a higher value of $\alpha$. In this sense, workers who specialize in high-end production (the white-collars) tend to have a higher probability of quitting than those employed at low-end assembly work (the blue-collars). This leads to prediction 1 .

Prediction 1. During technological change, the more technology-intensive the worker's skill, the more likely he is to quit his jobs.

\subsubsection{Case 2: Jobs associated with nonspecific skills}

P3. The optimal stopping problem has a unique solution, $g^{*}$. In the case where $w(g)$ is increasing in $g$, staying is preferable when $g>g^{*}$ and quitting is chosen when $g \leq g^{*}$.

It is shown in the appendix that when $w(g)$ is increasing in $g, V(g)$ is increasing in $g$ as well. As specified in the model, if the worker chooses to stay in the firm for the current period, it implies that $V(g)>Q$. Since firm growth is characterized by the increasing rate of technological change, $V(g)$ is greater than $Q$ as well. This indicates that workers 
with $\alpha$ lower than a threshold (i.e., $y_{t-1} / \sigma_{\varepsilon}^{2}$ ) would always prefer to stay in a growing firm.

Prediction 2. Workers with nonspecific skills prefer to stay in the firm with increasing technological growth.

\subsection{Data}

\subsubsection{Data Sources}

The data are from the Panel Study of Income Dynamics (PSID), a longitudinal survey of a representative sample of U.S. individuals and their families. The advantage of using individual-level data is that it provides an opportunity to address the issue of labor turnover across different industries. It is reasonable to believe that a pattern prevalent in an industry can also be observed in individual firms.

Among the special public-release files in the PSID, the work-history file contains complete information for individuals about all of their spells of employment, including employment status, occupation, industry, etc. Combining these variables with a few identifiers allows us to track individuals' employment history.

Since primary data on technological change are not available, productivity growth per worker in each industry (value-added GDP / number of production workers) is used as a proxy for technological change. The Bureau of Economic Analysis (BEA) compiles industry economic accounts; from here I obtain the data needed for the above ratio.

One potential problem relating to the data is that they do not provide firm-specific but industry-specific information while the model develops a relationship between worker turnover and firm growth. However, this problem turns out to be harmless to the analysis. For instance, the turnover of white-collar workers can be observed in four scenarios: first, 
white-collar workers from firms at higher technological level leave for firms at low technological level; this flow can also be reversed for overqualified workers; third, workers left the industry; finally, both white-collar and blue-collar workers are forced to leave firms which are driven out of the market. The last scenario does not exist in the data, for observations of job separation because of firm closure is not considered as quit, and are removed from the dataset. Without firm-level data, an exact turnover pattern cannot be observed in a particular firm. However, with industry-level data, we can observe the turnover of white-collar workers in the industry, which is the overall flow of white-collar workers in this industry. Since the study is interested in the magnitude of turnover rather than the direction, industry-level data should be qualified for serving the purpose of this empirical test.

\subsubsection{Data Construction}

This section describes how the dataset is constructed to test the predictions of the model. One way to extract data from PSID is by selecting variables of interest for given years. There are two types of variables in PSID: family-level variables related to family records (along with other topical categories such as work history) and individual-level variables with information about individuals (such as age, gender, and educational attainment). Additional variables are also available for identifying each individual.

I first choose nine variables related to employment from the family-level variables. These include 1968 FAMILY ID, LOCATION, INDUSTRY OF PRESENT MAIN JOB, PRESENT OCCUPATON, COLLEGE DEGREE, HPND PREV JOB (HD-E), HPND LST JOB (H-U), EMPLMT STATUS, and MOS THIS JOB. Three other variables1968 PERSON NUMBER, GENDER, and AGE-are selected from the individual-level 
variables. The combination of 1968 FAMILY ID and 1968 PERSON NUMBER constitutes the unique identifiers for individuals. The variables HPND PREV JOB (HD-E) and HPND LST JOB (H-U) are based on individuals' responses to the question about what had happened to their previous jobs. Eight possible categories for the response are created. The first variable is for household heads who were currently employed; for this, the data are available from 1968 to 1987 . The second variable applies to household heads who were currently unemployed; these data span 1969 to 1993 , and then every other year from 1999 to 2005 . As data on most selected variables are only available after 1980, the whole sample with the selected ten variables was restricted to the period 1981 to 1987.

There is one concern with the dataset. The variables relating to employment have data only for household heads and wives. Other family members do not have their own records for these variables, instead they are automatically assigned the values belonging to the household heads. An analysis based on this dataset will be prone to error since data applied to heads or wives would be mistaken if used for non-head individuals. To avoid this problem, I restrict the data sample to household heads.

\section{A. Selection of household heads}

Table 3.1 illustrates how the dataset is generated. The original sample is composed of eight subsamples for each year from 1981 to 1987 . The PSID provides two individuallevel variables that together indentify household heads in the current year. One variable is RELATIONSHIP TO HEAD, which describes the individual's relationship to the head of his family in a given wave. The household head from the current or previous year is coded "l" from 1981 to 1982 , and it is coded as "10" since 1983. The other variable is SEQUENCE NUMBER, which identifies an individual's presence in each wave. An 
individual who was present in the family during the interviewing year is coded "1". In each sample, I use list-wise deletion to remove observations with a code not equal to " 10 " (or "l" for years 1981 and 1982) for the RELATIONSHIP TO HEAD variable, as well as observations with a code not equal to " 1 " for SEQUENCE NUMBER. This leaves a total sample of 9423 individuals who were current household heads in each wave.

\section{B. Laid off and Quit}

A job move is identified by the variable MOS THIS JOB, which represents the number of months an individual had been at his present job. The value of this variable is in the range of 0-999. A code of 0 refers to people who were not in the labor force (i.e., unemployed, permanently disabled, retired, housewife, or student), and a code of 999 corresponds to data not being available. A person is identified as staying with the same job if MOS THIS JOB $\geq 12 ;$ MOS THIS JOB $<12$ implies that at least one job change occurred during the year. ${ }^{11}$

To determine whether a job change occurred because the worker voluntarily quit or was laid off, I use the variable HPND PREV JOB for currently employed household heads and HPND LST JOB for currently unemployed household heads. Among the eight possible categories, category 3 refers to lay-offs, and category 4 includes voluntary quits, resignations, retirements, and other various types of separations.

In this paper, quit is defined as leaving for another job. This implies that a person would still be working after he quits his previous job. Under this definition, the entire sub-

"11] PSID data collection for a given wave starts from March through September. So it is quite possible that the person who had the present job for less than 12 months actually changed his last job in a year before. To avoid the confusion, this job change would still be accounted as change happening in the present interview year. As the data collection procedure is the same for each year, the consistency can be reserved.

[2] Since PSID data collection process is conducted only once in a year, there is no variable in PSID that can record all job changes that an individual had in each wave. Therefore, if an individual had changed more than one jobs in one year, the current dataset can only capture the last one. 
sample of unemployed household heads does not qualify to be included in my analysis of quits. This exclusion does not apply in the analysis of lay-offs. However, in PSID, there are no industry or occupation data available for the unemployed. Given these constraints, I choose to focus on currently employed household heads, and I exclude the sub-sample of unemployed from the empirical analysis.

As discussed above, category 4 alone cannot be used to identify the occurrence of a quit. Therefore, I use the variable EMPLMT STATUS to preclude the other reasons for turnover listed in category 4, as well as to ensure that people who quit were currently working. Observations on people who voluntarily quit their previous jobs but were currently unemployed were removed from the sample. Analogously, the observations on people who did not quit (but were neither currently working nor temporarily unemployed) were also eliminated. In the end, I am left with a sample of 7285 currently employed household heads.

Finally, the dependent variable CHOICE equals 1 if a person stayed with the same job, 2 if he was laid off from the previous job, and 3 if he quit his last job.

\section{Industry and Occupation Dummies}

Variables on industry and occupation for present jobs are selected from the PSID familylevel set. These two variables are coded using the 3-digit code of industry and occupation from the 1970 Census of Population. A categorical variable with thirteen values is generated for the industries ${ }^{12}$. Industries such as agriculture forestry, fishery, and public

12 These values refer to agriculture, forestry, and fishery; mining; construction; manufacturing; transportation and warehousing; information; utilities: wholesale and retail trade; finance, insurance, and real estate; professional, business, education, and health services; entertainment and recreation; other services including repair, personal services, membership association; and public administration. 
TABLE 3.1

Steps of Creating the Sample with Multiple Choices: Stay, Laid-off, and Quit

\begin{tabular}{|c|c|c|}
\hline SAMPLES & SAMPLE SOURCE & NUMBER OF INDIVIDUALS \\
\hline 1 & Individuals in 1981-1987 & 42970 \\
\hline 2 & $\begin{array}{l}\text { Individuals in SAMPLE } 1 \text {, whose } \\
\text { 1. RELATIONSHIP TO HEAD }=1 \text { or } 10 \text { (after 1982) } \\
\text { 2. SEQUENCE NUMBER }=1\end{array}$ & 9423 \\
\hline 3 & $\begin{array}{l}\text { Individuals in SAMPLE } 2 \text {, whose } \\
\text { 1. MOS THIS JOB } \geq 12 \text {, and } \\
\text { EMPLMT STATUS }=1 \text { or } 2 \\
\text { 2. MOS THIS JOB }<12 \\
\text { HPND PREV JOB }(\mathrm{H}-\mathrm{U})=3 \text {, and } \\
\text { EMPLMT STATUS }=1 \\
\text { 3. MOS THIS JOB }<12 \\
\text { HPND PREV JOB }(\mathrm{HD}-\mathrm{E})=4 \text {, and } \\
\text { EMPLMT STATUS }=1\end{array}$ & 7285 \\
\hline 4 & $\begin{array}{l}\text { Individuals in SAMPLE 3, whose value of } \\
\text { 1. industry categorical variable is in the range from } 2 \text { to } \\
12 \\
\text { 2. occupation categorical variable is in the range from } 1 \\
\text { to } 9\end{array}$ & 6700 \\
\hline
\end{tabular}

Notes:

SAMPLE

1

2

3

4
INCLUDES

7 separate subsamples for each year from 1981-1987. Each subsample was obtained after the selection of 7 family-level variables and 3 individual level variables.

7 separate subsamples, which only include current household heads in each dataset from SAMPLE 1.

7 separate subsamples based on SAMPLE 2, but each of them only includes currently-employed household heads who stayed with the jobs or were laid off or quit from last jobs.

7 separate subsamples based on SAMPLE 3, excluding individuals whose present occupation and industry couldn't be defined, or who worked in agriculture, forestry, fishery and public administration.

Numbers of individuals in column (3) were calculated after integrating the 7 separate subsamples into one big sample.

administration were excluded from the analysis because of their weak linkage to firm growth and technical change. From the remaining industries, eleven dummy variables (indy1-11) were generated. Analogously, for the occupation data, a categorical variable consisting of nine values was created ${ }^{13}$. Nine occupation dummy variables (ocp1-9) were

${ }^{13}$ These include computer specialists and engineers; professional and kindred workers; managers and administrators; sales workers, clerical, and kindred workers; craftsman and kindred workers; operatives, laborers, and farmers; and service and private household workers. 
thus obtained. Observations with undefined industry or occupation were removed from the sample. The final sample consists of 6700 individuals.

TABLE 3.2

Summary Statistics: Demographic Variables (3 groups)

\begin{tabular}{|c|c|c|c|c|c|c|c|}
\hline & \multirow[b]{2}{*}{$\begin{array}{c}\text { No. of } \\
\text { Observations }\end{array}$} & \multirow[b]{2}{*}{$\begin{array}{c}\text { Missed } \\
\text { Observations }^{14}\end{array}$} & \multicolumn{5}{|c|}{ FRACTIONS } \\
\hline & & & Total & $\begin{array}{c}\text { (1) } \\
\text { People } \\
\text { who } \\
\text { stayed }\end{array}$ & $\begin{array}{c}(2) \\
\text { People } \\
\text { who } \\
\text { were } \\
\text { fired }\end{array}$ & $\begin{array}{l}\text { (3) } \\
\text { People } \\
\text { who } \\
\text { quit }\end{array}$ & $\begin{array}{c}(4)^{15} \\
\text { No } \\
\text { observations } \\
\text { on CHOICE }\end{array}$ \\
\hline MALE & 34573 & 0 & 0.74 & 0.52 & 0.03 & 0.06 & 0.40 \\
\hline FEMALE & 12327 & 0 & 0.26 & 0.38 & 0.02 & 0.07 & 0.52 \\
\hline AGE & 26770 & 20130 & & & & & \\
\hline$<35$ & 13358 & & 0.50 & 0.77 & 0.07 & 0.17 & 0 \\
\hline $35-44$ & 6275 & & 0.23 & 0.89 & 0.03 & 0.08 & 0 \\
\hline $45-54$ & 3834 & & 0.14 & 0.92 & 0.02 & 0.05 & 0 \\
\hline$>=55$ & 3303 & & 0.12 & 0.95 & 0.01 & 0.04 & 0 \\
\hline $\begin{array}{l}\text { COLLEGE } \\
\text { DEGREE }\end{array}$ & 26770 & 20130 & & & & & \\
\hline YES & 5667 & & 0.21 & 0.86 & 0.02 & 0.12 & 0 \\
\hline No & 21103 & & 0.79 & 0.84 & 0.05 & 0.11 & 0 \\
\hline
\end{tabular}

Table 3.2 provides demographic statistics for the sample. Seventy-four percent of the sample is male, $50 \%$ is under 35 and about $20 \%$ has a college degree. Among the observations for males, $52 \%$ percent reported no change in jobs, contrasted with $38 \%$ for female. This difference is consistent with the stylized facts in the literature that women tend to have more unstable employment than men. However, this variation can also be attributed to the larger proportion of missing values of employment choice among female workers. The data also show that turnover rates are decreasing in age. Of the sample aged 55 years and above, $86 \%$ percent chose to stay at their current employment, compared to

\footnotetext{
${ }^{14}$ For each individual-year dataset, there are no missing values for age, gender, college, or employment choice variable CHOICE. However, when all these seven datasets are merged together, individuals who exist in some years but no others would not have observations on age, college, and CHOICE in those years. An exception is the variable on gender. In the PSID, this variable is applied to all years. That is, once an individual had an observation on gender in one year, this value applies to all years from 1968 to 2005 .

${ }^{15}$ On the basis of the above reason, even if there are no observations on CHOICE because the individuals are absent in those years, there are still observations on gender, but not on age and college.
} 
only $77 \%$ of the sample under age 35 . On the contrary, merely $4 \%$ of the over- 55 sample quit jobs; that number increases to $17 \%$ for the under-35 sample. Eighty-six percent of the sample that reported having a college education stayed with the same jobs, implying that people with a college education generally have more stable employment.

TABLE 3.3

Summary Statistics: Industry and Occupation (multinomial)

\begin{tabular}{|c|c|c|c|}
\hline & FRACTION & & FRACTION \\
\hline INDUSTRY & & OCCUPATION & \\
\hline \multirow[t]{2}{*}{ MINING } & & COMPUTER SPECIALISTS AND & \\
\hline & 0.01 & ENGINEERS & 0.05 \\
\hline \multirow[t]{2}{*}{ CONSTRUCTION } & & PROFESSIONAL AND KINDRED & \\
\hline & 0.09 & WORKERS & 0.11 \\
\hline \multirow[t]{2}{*}{ MANUFACTURING } & & MANAGERS AND & \\
\hline & 0.28 & ADMINISTRATORS & 0.14 \\
\hline TRANSPORTATION AND WAREHOUSING & 0.06 & SALES WORKERS & 0.05 \\
\hline INFORMATION & & CLERICAL AND KINDRED & \\
\hline \multirow{3}{*}{ UTILITIES } & 0.02 & WORKERS & 0.09 \\
\hline & & CRAFTSMAN AND KINDRED & \\
\hline & 0.03 & WORKERS & 0.19 \\
\hline WHOLESALE AND RETAIL TRADE & 0.18 & OPERATIVES & 0.19 \\
\hline FINANCE, INSURANCE AND REAL ESTATE & 0.05 & LABORERS AND FARMERS & 0.05 \\
\hline PROFESSIONAL AND BUSINESS SERVICES; & & SERVICE WORKERS AND PRIVATE & \\
\hline EDUCATIONAL AND HEALTH SERVICES & 0.19 & HOUSEHOLD WORKERS & 0.12 \\
\hline ENTERTAINMENT AND RECREATION & 0.01 & & \\
\hline OTHER SERVICES & 0.08 & & \\
\hline TOTAL OBSERVATIONS & 26770 & TOTAL OBSERVATIONS & 26770 \\
\hline
\end{tabular}

Table 3.3 presents summary statistics about the industries and occupations included in the sample. Half of the sample is from industries such as manufacturing; professional business, education, and health services; as well as wholesale and retail trade. The other half is distributed among the other eight industries. Most of the high-rank technical or managerial occupations are embodied in categories 1, 2, or 3, which account for $30 \%$ of the sample. These three occupations are then combined into one single variable, specific. This variable takes on the value of 1 if the occupation observation falls into one of these categories; it is zero otherwise. ${ }^{16}$

\footnotetext{
${ }^{16}$ The final variable $(V A)$ in the analysis is a proxy for technological change, given by the growth of productivity per worker (from 1981-1987). Its construction is as follows. Productivity per worker is obtained by dividing annual value added GDP by the number of production workers in each industry.
} 


\subsection{Results}

\subsubsection{The Multinomial model}

Greene (2002) and Kennedy (2003) discuss two different logit models for multiple choices: the multinomial logit and the conditional logit. The former is used if the data have information on characteristics of individuals while the latter is preferred if the data have choice-specific attributes which are identical to all individuals. As put forth in the data description section, most variables in the dataset are individual-specific (such as age, gender, education, and occupation). An exception is the variable on the growth rate of industry. However, since it is used to interact with an individual's occupation variable, the interaction variable is still individual-specific. Thus, the multinomial logit model is chosen for the regression on the three employment choices: staying, being laid off, and quitting. A Hausman test shows that these three choices are not close substitutes, which ensures that the assumption of independence of irrelevant alternatives (IIA) holds.

To capture the interaction effect between technological growth and specific technical skills, an interaction variable (vaskill $=V A^{*}$ specific) was generated. Another interaction between technological change and college education (vacolg $\left.=V A^{*} C O L G\right)$ is generated in a similar way. The collinearity between these two interaction variables could be a concern. As the majority of workers associated with technology-specific jobs may have college degrees, these two variables are likely to be positively correlated. To examine how serious this problem could be, I first test the collinearity between vaskill and vacolg through correlation coefficients. The correlation coefficient between the two variables is 0.34 for the choice of being laid off and -0.45 for the choice of quitting. Kennedy (2003) suggests that a correlation coefficient of $0.8-0.9$ in absolute value indicates a high 
correlation between two independent variables. Compared to this threshold, the correlation coefficients between the vaskill and vacolg are quite low.

The multicollinearity between all independent variables in the model—except dummy variables for industries and years-is examined through the use of the correlation matrix in the linear regression model. According to the literature, muticollinearity exists if the largest variance inflation factor $(V I F)$ is greater than ten, and the mean of all the $V I F \mathrm{~s}$ is considerably larger than one. The result shows that the highest VIF, 6.7 , is the one that is associated with the interaction variable vacolg. The mean of all the VIFs is 3.72 , which is not considerably larger than one. Therefore, I speculate that multicollinearity need not be a concern in the present model.

Table 3.4 reports the results from the multinomial logit regression. The dependent variable CHOICE equals 1 if a person remained at his job, 2 if he was laid off, and 3 if he quit. The choice of staying is used as the base alternative. The coefficients on the occupation dummy (specific) are negative and significant for choices 2 and 3. The computation of marginal effects indicates that compared to the choice of staying, having a technology-intensive job reduces the probability of being laid off by $4.1 \%$ and the probability of quitting by $3.7 \%$. If productivity growth is considered, however, the technological intensity of a job becomes an irrelevant factor in determining whether a person would stay in the firm or be laid off (the result for the variable vaskill is insignificant). Intuitively, when the firm is going through a bad time, both skilled and unskilled workers face the possibility of being laid off. Analogously, when the firm is growing, the demand for both types of workers will increase. 
Nonetheless, as for the choice of quitting, the degree of specificity in skills does seem to matter during technological change. As shown in the last column of Table 3.4, having a higher-rank technical or managerial job (i.e., a job belonging to one of the first three occupation categories) increases the probability of quitting by $28 \%$. This result supports

TABLE 3.4

Results in Multinomial Logit Model

\begin{tabular}{|c|c|c|c|c|}
\hline & \multicolumn{4}{|c|}{ DEPENDENT VARIABLE: CHOICE } \\
\hline & $\begin{array}{c}\text { CHOICE }=2 \text { (laid- } \\
\text { off) }\end{array}$ & $\mathrm{dy} / \mathrm{dx}$ & $\begin{array}{c}\mathrm{CHOICE}=3 \\
\text { (quit) }\end{array}$ & $\mathrm{dy} / \mathrm{dx}$ \\
\hline OCCUPATION DUMMY (SPECIFIC) & $\begin{array}{l}-1.369 * * * \\
(0.207)\end{array}$ & $\begin{array}{c}- \\
0.041\end{array}$ & $\begin{array}{l}-0.455^{* * *} \\
(0.097)\end{array}$ & $0 . \overline{-}$ \\
\hline GROWTH IN VALUE-ADDED $\left(V^{\prime} A\right)$ & $\begin{array}{l}1.502 \\
(1.488)\end{array}$ & 0.047 & $\begin{array}{l}1.991^{* *} \\
(1.026)\end{array}$ & 0.188 \\
\hline $\begin{array}{l}\text { INTERACTION BETWEEN SKILL AND GROWTH } \\
\left(V A^{*} S P E C I F I C\right)\end{array}$ & $\begin{array}{c}2.414 \\
(2.893)\end{array}$ & 0.077 & $\begin{array}{l}2.976^{* *} \\
(1.405)\end{array}$ & 0.280 \\
\hline \multicolumn{5}{|l|}{ INDUSTRY DUMMIES } \\
\hline MINING & $\begin{array}{l}-0.453^{*} \\
(0.27)\end{array}$ & $0 . \overline{0}$ & $\begin{array}{l}-0.239 \\
(0.198)\end{array}$ & 0.021 \\
\hline CONSTRUICTION (DROPPED) & --- & --- & -- & --- \\
\hline MANUFACTURING & $\begin{array}{l}-0.812 * * * \\
(0.097)\end{array}$ & 0.027 & $\begin{array}{l}-0.605^{* * *} \\
(0.075)\end{array}$ & $\overline{-}-$ \\
\hline TRANSPORTATION AND WAREHOUSING & $\begin{array}{l}-0.634 * * * \\
(0.144)\end{array}$ & 0.022 & $\begin{array}{l}-0.321 * * * \\
(0.107)\end{array}$ & $-\overline{0}$ \\
\hline INFORMATION & $\begin{array}{l}-1.738^{* * *} \\
(0.393)\end{array}$ & $\overline{-}-$ & $\begin{array}{l}-0.602^{* * *} \\
(0.181)\end{array}$ & $\overline{-}-$ \\
\hline UTILITIES & $\begin{array}{l}-1.669 * * * \\
(0.287)\end{array}$ & $\begin{array}{c}- \\
0.058\end{array}$ & $\begin{array}{l}-0.785^{* * *} \\
(0.156)\end{array}$ & $0 . \overline{-}$ \\
\hline WHOLESALE AND RETAIL TRADE & $\begin{array}{l}-0.201 * * \\
(0.099)\end{array}$ & $\overline{-}$ & $\begin{array}{l}0.206^{* * *} \\
(0.074)\end{array}$ & 0.021 \\
\hline FINANCE, INSURANCE AND REAL ESTATE & $\begin{array}{l}-0.659^{* * *} \\
(0.167)\end{array}$ & $\overline{-}-$ & $\begin{array}{l}0.293 * * * \\
(0.097)\end{array}$ & 0.031 \\
\hline PROFESSIONAL, BUSINESS, EDUCATION AND & $-0.737 * * *$ & - & -0.078 & - \\
\hline HEALTH SER VICES & $(0.115)$ & 0.027 & $(0.077)$ & 0.005 \\
\hline ENTERTAINMENT AND RECREATION & $\begin{array}{c}-0.04 \\
(0.289)\end{array}$ & $0 . \overline{-}$ & $\begin{array}{l}0.405^{* *} \\
(0.178)\end{array}$ & 0.040 \\
\hline $\begin{array}{l}\text { OTHER SERVICES (REPAIR, PERSONAL } \\
\text { SERVICES, ETC.) }\end{array}$ & $\begin{array}{l}-0.431^{* * *} \\
(0.125)\end{array}$ & $0 . \overline{-}$ & $\begin{array}{c}0.058 \\
(0.089)\end{array}$ & 0.007 \\
\hline CONTROL FOR YEAR & Yes & & Yes & \\
\hline CONSTANT & $\begin{array}{l}-2.208^{* * *} \\
(0.114)\end{array}$ & & $\begin{array}{l}-1.751^{* * *} \\
(0.084) \\
\end{array}$ & \\
\hline $\begin{array}{l}\text { OBSERVATIONS } \\
\text { LOG LIKELIHOOD }\end{array}$ & & $\begin{array}{r}267 \\
-1390 \\
\end{array}$ & & \\
\hline
\end{tabular}

the prediction of the model that during firm growth, white-collar workers whose jobs are associated with sophisticated technology (technology professionals in occupation 
categories 1 and 2) are more likely to quit than regular technical workers. It also indicates that even if the tasks performed by workers are not directly related to technology in production, higher-rank jobs are more susceptible to technical change. This explains why managers and administrators in category 3 show higher odds of quitting than lower-rank sales or clerical workers in categories 5 and 6.

Columns 1 and 2 in Table 3.5 present the results from the multinomial logit regression after controlling for individuals' observed heterogeneity—age, gender and education. In columns 3 and 4, an additional variable (number of previous turnovers) is added to control for the unobserved heterogeneity of individuals. It turns out that there are no substantial changes to the basic results even after controlling for the heterogeneity of individuals. In general, the technological intensity of a job does affect a worker's employment choice between staying or being laid off. But this factor becomes much less important in the presence of productivity growth. In contrast, during growth, the probability of voluntarily leaving a job increases by $31.8 \%$ if the job is technologyintensive. Age has negative effects on the probability of being laid off or quitting, which is consistent with the fact that older people or people with longer tenure prefer to have stable employment. Male workers have a stronger tendency to quit a job than female workers. People with college education are $1.7 \%$ less likely to be laid off, but $2.8 \%$ more likely to quit. Experiencing a previous turnover in a career increases the probability of being laid off by $1.1 \%$, and the probability of quitting by $3.3 \%$.

The results regarding education are more subtle. On the one hand, it shows that without growth, people with college education are $1.7 \%$ less likely to be laid off, but $2.8 \%$ more likely to quit. This should not be surprising since people with college education are 
expected to have more human capital. Conversely, when the variable of college education interacts with productivity growth, its effect on job turnover becomes insignificant. This implies that when firm growth is considered, whether or not an individual possesses a college degree does not affect his choice between staying and the other two alternatives. One possible interpretation is that in general, people with a college degree have more

TABLE 3.5

Multinomial Logit Model with Individual Heterogeneity Controlled

\begin{tabular}{|c|c|c|c|c|c|c|}
\hline & \multicolumn{6}{|c|}{ DEPENDENT VARIABLE: CHOICE } \\
\hline & $\mathrm{CHOICE}=2$ & $\mathrm{CHOICE}=3$ & $\mathrm{CHOICE}=2$ & $\mathrm{dy} / \mathrm{dx}$ & $\mathrm{CHOICE}=3$ & $\mathrm{dy} / \mathrm{dx}$ \\
\hline $\begin{array}{l}\text { OCCUPATION DUMMY } \\
(\text { SPECIFIC) }\end{array}$ & $\begin{array}{l}-1.111^{* * *} \\
(0.217)\end{array}$ & $\begin{array}{l}-0.429 * * * \\
(0.109)\end{array}$ & $\begin{array}{l}-1.12^{* * *} \\
(0.217)\end{array}$ & -0.029 & $\begin{array}{l}-0.442^{* * *} \\
(0.11)\end{array}$ & $\overline{-}$ \\
\hline $\begin{array}{l}\text { GROWTH IN VALUE-ADDED } \\
(I A)\end{array}$ & $\begin{array}{r}1.313 \\
(1.512)\end{array}$ & $\begin{array}{l}2.062^{* *} \\
(1.057)\end{array}$ & $\begin{array}{c}1.144 \\
(1.506)\end{array}$ & 0.030 & $\begin{array}{l}1.877^{*} \\
(1.055)\end{array}$ & 0.151 \\
\hline $\begin{array}{l}\text { INTERACTION BETWEEN SKILL } \\
\text { AND GROWTH }\left(V A^{*} S P E C I F I C\right)\end{array}$ & $\begin{array}{c}2.391 \\
(3.065)\end{array}$ & $\begin{array}{l}3.697^{* *} \\
(1.601)\end{array}$ & $\begin{array}{l}\text { 伀.647 } \\
(3.054)\end{array}$ & 0.070 & $\begin{array}{l}3.965 * * * \\
(1.603)\end{array}$ & 0.318 \\
\hline GENDER & $\begin{array}{c}0.02 \\
(0.079)\end{array}$ & $\begin{array}{l}0.419 * * * \\
(0.048)\end{array}$ & $\begin{array}{c}0.033 \\
(0.079)\end{array}$ & 0.000 & $\begin{array}{l}0.432 * * * \\
(0.048)\end{array}$ & 0.035 \\
\hline AGE & $\begin{array}{l}-0.066^{* * *} \\
(0.003)\end{array}$ & $\begin{array}{l}-0.067^{* * *} \\
(0.002)\end{array}$ & $\begin{array}{c}-0.063 * * * \\
(0.003)\end{array}$ & -0.002 & $\begin{array}{l}-0.065^{* * * *} \\
(0.002)\end{array}$ & $\overline{-}$ \\
\hline $\begin{array}{l}\text { COLLEGE EDUCATION DUMMY } \\
(C O L G)\end{array}$ & $\begin{array}{l}-0.502 * * \\
(0.247)\end{array}$ & $\begin{array}{l}0.359^{* * *} \\
(0.118)\end{array}$ & $\begin{array}{l}-0.533^{* *} \\
(0.247)\end{array}$ & -0.017 & $\begin{array}{l}0.324 * * * \\
(0.118)\end{array}$ & 0.028 \\
\hline $\begin{array}{l}\text { INTERACTION BETWEEN SKILL } \\
\text { AND COLLEGE EDUCATION } \\
\left(V^{*} A^{*} C O L G\right)\end{array}$ & $\begin{array}{c}1.505 \\
(3.532)\end{array}$ & $\begin{array}{l}-1.99 * * * \\
(1.76)\end{array}$ & $\begin{array}{c}1.734 \\
(3.528)\end{array}$ & 0.059 & $\begin{array}{l}-1.676 \\
(1.764)\end{array}$ & $0 . \overline{143}$ \\
\hline $\begin{array}{l}\text { NUMBER OF PREVIOUS } \\
\text { TURNOVER (LAID OFF AND } \\
\text { QUIT) }\end{array}$ & & & $\begin{array}{l}0.395^{* * *} \\
(0.044)\end{array}$ & 0.011 & $\begin{array}{l}0.412 * * * \\
(0.029)\end{array}$ & 0.033 \\
\hline CONTROL FOR INDUSTRY & Yes & Yes & Yes & & Yes & \\
\hline CONTROL FOR YEAR & Yes & Yes & Yes & & Yes & \\
\hline CONSTANT & $\begin{array}{l}0.015 \\
(0.176) \\
\end{array}$ & $\begin{array}{c}0.056 \\
(0.122) \\
\end{array}$ & $\begin{array}{l}-0.364^{* *} \\
\square 0.183)\end{array}$ & & $\begin{array}{c}-0.349 * * * \\
(0.127)\end{array}$ & \\
\hline $\begin{array}{l}\text { OBSERVATIONS } \\
\text { LOG LIKELIHOOD }\end{array}$ & $\begin{array}{r}26 \\
-1308 \\
\end{array}$ & $\begin{array}{l}70 \\
3.629\end{array}$ & & $\begin{array}{r}26 \\
-129 \\
\end{array}$ & $\begin{array}{l}770 \\
2.041 \\
\end{array}$ & \\
\hline
\end{tabular}

opportunities in the market. Therefore, they are less likely to be laid off; at the same time, they have more incentive to leave whenever they feel unsatisfied at the current job. If the firm experiences growth, then many of these workers will be better off. The benefits can come in the form of either a pay raise or a better work environment, both of which alleviate job dissatisfaction and reduce incentives to leave. As a result, in the context of 
firm growth, possession of a college degree becomes an irrelevant factor in determining an individual's employment choice.

TABLE 3.6

Multinomial Logit Model: Distinguishing Increasing Technological Growth from Decreasing Growth

\begin{tabular}{|c|c|c|}
\hline & \multicolumn{2}{|c|}{ DEPENDENT VARIABLE: CHOICE } \\
\hline & $\mathrm{CHOICE}=2$ & $\mathrm{CHOICE}=3$ \\
\hline OCCUPATION DUMMY (SPECIFIC) & $\begin{array}{c}-1.124 * * * \\
(0.220)\end{array}$ & $\begin{array}{c}-0.446^{* * *} \\
(0.111)\end{array}$ \\
\hline GROWTH IN VALUE-ADDED $(V A)$ & $\begin{array}{c}1.180 \\
(1.510)\end{array}$ & $\begin{array}{r}1.926^{*} \\
(1.062)\end{array}$ \\
\hline GENDER & $\begin{array}{c}0.033 \\
(0.079)\end{array}$ & $\begin{array}{l}0.432 * * * \\
(0.048)\end{array}$ \\
\hline AGE & $\begin{array}{l}-0.063^{* * *} \\
(0.003)\end{array}$ & $\begin{array}{c}-0.065^{* * *} \\
(0.002)\end{array}$ \\
\hline COLLEGE EDUCATION DUMmY $(C O L G)$ & $\begin{array}{c}0.366 \\
(0.543)\end{array}$ & $\begin{array}{c}0.545^{*} \\
(0.303)\end{array}$ \\
\hline$V A^{*} S P E C I F I C^{*} D^{17}$ & $\begin{array}{c}2.660 \\
(3.092)\end{array}$ & $\begin{array}{l}4.011^{* *} \\
(1.627)\end{array}$ \\
\hline$V A^{*} \operatorname{SPECIFIC}^{*}(1-D)$ & $\begin{array}{c}4.437 \\
(22.934)\end{array}$ & $\begin{array}{c}3.144 \\
(8.908)\end{array}$ \\
\hline$C O L G^{*} V A^{*} D$ & $\begin{array}{c}-1.047^{*} \\
(0.599)\end{array}$ & $\begin{array}{c}-0.253 \\
(0.320)\end{array}$ \\
\hline$C O L G^{*} V A$ & $\begin{array}{c}3.647 \\
(3.678)\end{array}$ & $\begin{array}{c}-1.237 \\
(1.844)\end{array}$ \\
\hline NUMBER OF PREVIOUS TURNOVER (LAID OFF AND QUIT) & $\begin{array}{l}0.395 * * * \\
(0.044)\end{array}$ & $\begin{array}{l}0.412 * * * \\
(0.029)\end{array}$ \\
\hline CONTROL FOR INDUSTRY & Yes & Yes \\
\hline CONTROL FOR YEAR & Yes & Yes \\
\hline CONSTANT & $\begin{array}{c}-0.371 \\
(0.183) \\
\end{array}$ & $\begin{array}{c}-0.352 \\
(0.127) \\
\end{array}$ \\
\hline OBSERVATIONS & & \\
\hline LOG LIKELIHOOD & & .541 \\
\hline
\end{tabular}

Moreover, if there is a possibility that having technology-specific skills and having college education are correlated, we would expect the coefficients on both vacolg and vaskill--rather than just the coefficient on vaskill-to be positive and significant. However, it bears noting that $76 \%$ of the sample that had college education is also associated with occupations that are responsive to technological change (those occupations indexed by specific). The remaining $24 \%$ were employed as educators or

\footnotetext{
${ }^{17} d$ is a dummy variable which equals 1 if $\mathrm{VA}>0$, and 0 if $\mathrm{VA}<0$.
} 
doctors who had more stable employment and were less likely to change jobs even in the presence of technological change. Differences in the nature of occupations may explain why I obtain opposite signs for the variables vacolg and vaskill, even if they seem to be positively correlated.

It is worth mentioning that for the group who quit jobs, the positive coefficient on vaskill is interpreted as the positive effect of technological growth on voluntary job separation among workers with specific skills. But the reverse could be true, i.e., the positive sign reflects the situation where this group of people are less like to quit their jobs because of the decline of technological progress. To examine this possibility, I construct a dummy variable $(d)$ that takes value of 1 if the rate of technological growth, $V A$, is positive and 0 if it is negative. This dummy is used to interact with variable vaskill and vacolg so that the modified regression model could distinguish the effect of increasing technological growth from that of decreasing technological growth. The results are presented in Table 3.6. For technological professionals, the effect of increasing technological growth is consistently positive and significant. By contrast, the effect of decreasing technological growth also appears to be positive, and the result is insignificant.

\subsubsection{The Fixed-Effects Logit Model}

In this section, I use the fixed-effects logit model in order to control for the fixed-effects of individuals. A binomial dependent variable is constructed to replace the categorical dependent variable from the multinomial logit regression. Changes are made to the dataset to better accommodate the fixed-effects logit. First, I omit the option of being laid off and only study the two remaining options. The new sample has 6551 individuals who either stayed or voluntarily quit their jobs in each year. A dependent dummy variable 
(quit) is created. It takes on a value of one if a person quit his job and zero otherwise. All explanatory variables remain the same.

Tables 3.7 and 3.8 display some summary statistics of the new sample, which bear much resemblance of those reported in the previous sample.

TABLE 3.7

Summary Statistics: Demographic Variables (quit)

\begin{tabular}{lcccccc}
\hline & $\begin{array}{c}\text { No. of } \\
\text { Observation }\end{array}$ & $\begin{array}{c}\text { Missed } \\
\text { Observation }\end{array}$ & Total & $\begin{array}{c}\text { People } \\
\text { who quit }\end{array}$ & $\begin{array}{c}\text { People who } \\
\text { didn't quit }\end{array}$ & $\begin{array}{c}\text { Missing obs } \\
\text { on quit }\end{array}$ \\
\hline MALE & 33838 & 0 & 0.74 & 0.06 & 0.53 & 0.41 \\
FEMALE & 12019 & 0 & 0.26 & 0.07 & 0.39 & 0.53 \\
AGE & 25560 & 20297 & & & & 0 \\
$\quad<35$ & 12453 & & 0.49 & 0.18 & 0.82 & 0 \\
$35-44$ & 6098 & & 0.24 & 0.08 & 0.92 & 0 \\
$45-54$ & 3747 & & 0.15 & 0.05 & 0.95 & 0 \\
$>=55$ & 3262 & & 0.13 & 0.04 & 0.96 & 0 \\
COLLEGE & 25560 & 20297 & & & & 0 \\
DEGREE & 5558 & & 0.22 & 0.13 & 0.87 & 0 \\
YES & 20002 & & 0.78 & 0.12 & 0.88 & 0 \\
NO & & & & & & \\
\hline
\end{tabular}

TABLE 3.8

Summary Statistics: Industry (quit)

\begin{tabular}{lclc}
\hline & FRACTION & FRACTION \\
\hline INDUSTRY & & OCCUPATION & \\
\hline MINING & 0.01 & $\begin{array}{l}\text { COMPUTER SPECIALISTS AND } \\
\text { ENGINEERS }\end{array}$ & 0.06 \\
CONSTRUCTION & 0.09 & $\begin{array}{l}\text { PROFESSIONAL AND KINDRED } \\
\text { WORKERS }\end{array}$ & 0.11 \\
MANUFACTURING & 0.28 & $\begin{array}{l}\text { MANAGERS AND } \\
\text { ADMINISTRATORS }\end{array}$ & 0.15 \\
TRANSPORTATION AND WAREHOUSING & 0.06 & SALES WORKERS & 0.05 \\
INFORMATION & 0.02 & CLERICAL AND KINDRED & 0.09 \\
UTILITIES & 0.03 & WORKERS & WRAFTSMAN AND KINDRED \\
WHOLESALE AND RETAIL TRADE & 0.18 & OPERATIVES & 0.19 \\
FINANCE, INSURANCE AND REAL ESTATE & 0.05 & LABORERS AND FARMERS & 0.19 \\
PROFESSIONAL AND BUSINESS SERVICES; & 0.19 & SERVICE WORKERS AND PRIVATE & 0.05 \\
EDUCATIONAL AND HEALTH SERVICES & 0.01 & HOUSEHOLD WORKERS & 0.12 \\
ENTERTAINMENT AND RECREATION & 0.08 & & \\
OTHER SERVICES & & \\
TOTAL OBSERVATIONS & 25560 & TOTAL OBSERVATIONS & 25560 \\
\hline
\end{tabular}




\subsubsection{Results from the Conditional Fixed-Effects Logit Model}

One concern with using the fixed-effect logit is the incidental parameters problem. Katz (2001) suggests that when the period of observations is less than sixteen, the conditional estimators from a fixed-effects logit regression have a very small amount of bias (as compared to the unconditional estimators). On the basis of this argument, I present results from the conditional fixed-effects logit model in Table 3.9.

The first column in Table 3.9 reports the results from the conditional fixed-effects regression. Since the year and industry dummies are control variables, the estimated coefficients on these variables do not bear any economic implications. As shown in the previous multinomial model, educated workers tend to have a higher probability of turnover, except during firm growth. The estimated coefficient on specific is -0.537 , indicating that workers associated with technology-specific jobs are less likely to leave their jobs. The estimated coefficient on vaskill is positive, as expected, but the result is insignificant.

The major drawback to using the conditional logit regression is that 17890 out of 25560 observations are dropped because of either all positive or negative outcomes. This loss of observations risks affecting the significance of the results. To avoid this problem, I employ the linear probability model. Another reason for using the linear probability model arises from the difficulty in computing marginal effects in the conditional fixedeffects logit. The problem can be easily solved in the linear probability model since its estimated coefficients are directly related to marginal effects. The results are displayed in the second column of Table 3.9. All the signs on the estimated coefficients remain the same as in the conditional fixed-effects logit. With technological change, having a 
technology-intensive job increases the chance of quitting by $8 \%$. The result is significant at a $5 \%$ significance level.

TABLE 3.9

Conditional Fixed-Effects Model (quit only)

\begin{tabular}{lcc}
\hline \hline & \multicolumn{2}{c}{ DEPENDENT VARIABLE: QUIT } \\
\cline { 2 - 3 } & $\begin{array}{c}\text { Conditional Fixed- } \\
\text { Effects }\end{array}$ & Linear Probability \\
\hline OCCUPATION DUMMY (SPECIFIC) & $-0.537^{* * *}$ & $-0.033^{* * *}$ \\
& $(0.199)$ & $(0.097)$ \\
GROWTH IN VALUE-ADDED $(V A)$ & $3.574^{* *}$ & $0.208^{* * *}$ \\
INTERACTION BETWEEN SKILL AND GROWTH & $(1.734)$ & $(0.085)$ \\
$\left(V A^{*}\right.$ SPECIFIC) & 1.951 & $0.08^{* *}$ \\
AGE & $(2.749)$ & $(0.131)$ \\
& 0.158 & 0.005 \\
COLLEGE EDUCATION DUMMY $(C O L G)$ & $(0.109)$ & $(0.005)$ \\
INTERACTION BETWEEN SKILL AND COLLEGE & $0.849^{* * *}$ & $0.07^{* * *}$ \\
EDUCATION $(C O L G * V A)$ & $(0.287)$ & $(0.016)$ \\
NUMBER OF PREVIOUS TURNOVER & $-6.329^{* *}$ & $-0.346^{* *}$ \\
CONTROL FOR INDUSTRY & $(3.001)$ & $(0.157)$ \\
CONTROL FOR YEAR & -4.48 & $-0.394^{* * *}$ \\
CONSTANT & $(0.134)$ & $(0.005)$ \\
\hline OBSERVATIONS & Yes & Yes \\
LOG LIKELIHOOD & Yes & Yes \\
\hline
\end{tabular}

One distinctive result is the significantly negative effect of the number of previous turnovers on the probability of quitting in the current period. This implies that a person is less likely to quit his job if he had quit many times before; this contradicts what we observe in the multinomial logit model. However, recall from the previous model that both lay-offs and quits are considered "turnovers". It is reasonable to speculate that being laid off several times is a signal of bad quality -indicative of more lay-offs in the future. In the fixed-effects model, though, only the occurrence of a quit is counted as a turnover. If it takes several job experiences for a person to learn his job type, a worker characterized by several previous turnovers would be more likely to have found his job match. Thus, he settles down with his current job. 
Even though the analysis in this section is associated with voluntary job separation, we know that in some cases workers prefer to leave involuntarily. Doing so allows them to accrue the benefits gained from being laid off (i.e., severance pay or unemployment benefits). Thus, they wait until being laid off and then go to another job. Here, the two actions (voluntary and involuntary job separations) generate the same results; thus, should be treated equally. In the next section, I modify my dataset by breaking down the quit term into voluntary and involuntary quits. A voluntary quit is recorded for each individual who reported quitting his previous job and moved to another job. Similarly, an involuntary quit refers to a person who was laid off from his previous job and then became employed elsewhere. Both of these behaviors are denoted by the variable quit.

Table 3.10 presents the results from both the conditional fixed-effects logit regression and the linear probability regression. The estimated coefficients on specific continue to be negative and economically significant in both models. The significant effect of having a college degree on the probability of job turnover vanishes in the presence of firm growth. A strong negative relationship remains between the likelihood of turnover and the number of previous turnovers.

The estimated coefficient on vaskill turns out to be insignificantly different from zero in the conditional logit regression. In the linear probability model, it is positive and significant at a $10 \%$ significance level. This significance, however, is very sensitive to the specification of the model. It disappears once the interaction variable vacolg is omitted from the model. The loss of significance may be caused by the existence of collinearity between the two variables. However, since the degree of collinearity is not substantially high, as shown above, there is no strong reason to remove vacolg from the model. 


\begin{tabular}{lcc}
\hline & \multicolumn{2}{c}{ DEPENDENT VARIABLE: QUIT } \\
\cline { 2 - 3 } & $\begin{array}{c}\text { Conditional fixed- } \\
\text { effects }\end{array}$ & Linear Probability \\
\hline OCCUPATION DUMMY (SPECIFIC) & $-0.639^{* * *}$ & $-0.054^{* * *}$ \\
GROWTH IN VALUE-ADDED $(V A)$ & $(0.176)$ & $(0.012)$ \\
INTERACTION BETWEEN SKILL AND GROWTH & 2.24 & $0.149^{* * *}$ \\
$\left(V A^{*}\right.$ SPECIFIC) & $(1.466)$ & $(0.094)$ \\
AGE & 2.539 & $0.25^{*}$ \\
& $(2.446)$ & $(0.146)$ \\
COLLEGE EDUCATION DUMMY $(C O L G)$ & 0.048 & 0.002 \\
INTERACTION BETWEEN SKILL AND COLLEGE & $(0.085)$ & $(0.006)$ \\
EDUCATION $(C O L G * V A)$ & $0.445^{*}$ & $0.041^{* *}$ \\
NUMBER OF PREVIOUS TURNOVER & $(0.247)$ & $(0.018)$ \\
CONTROL FOR INDUSTRY & -4.299 & -0.217 \\
CONTROL FOR YEAR & $(2.685)$ & $(0.174)$ \\
CONSTANT & $-3.846^{* * *}$ & $-0.352^{* * *}$ \\
- & $(0.1)$ & $(0.005)$ \\
\hline OBSERVATIONS & Yes & Yes \\
LOG LIKELIHOOD & Yes & Yes \\
\hline
\end{tabular}

\subsection{Discussions}

This paper is the outgrowth of two unusual results on labor turnover from Dohmen and Pfann (2004) and Lazear (1999). It is commonly believed that firm growth spurs increasing demand for technology and skills. As a result, workers with specific skills should have more stable employment in a growing firm than workers with general or standardized skills. Paradoxically, their studies using firms' personnel data show that it is the workers from the relatively higher positions in a firm's hierarchy who tend to separate from their jobs.

To interpret the intuition behind their results, my model assumes that all skills are industry-specific, but there is variation of technological intensity amongst within-industry jobs. Jobs characterized by higher levels of technological intensity are associated with much stricter requirements to update skills. Therefore, these jobs are the most responsive 
to technological change. Taking this one step further, once a new technology is adopted, the demand for state-of-the-art skills arises. Conversely, jobs requiring a lower level of technology-based skills (the standardized skills) are less likely to be affected by technological change. As a result, the increased probability of quitting can be observed as we move up the technology-intensive hierarchy.

To test whether this turnover pattern predicted by the model is a general phenomenon, or if it is idiosyncratic to a specific firm, a panel dataset is constructed (again based on longitudinal data from the PSID). The dataset includes the employment history of 6700 individuals from 1981 to 1987 , sampled from twelve industries and nine occupations.

Lacking firm growth, the results consistently support the generally shared thoughts of labor turnover. That is, since workers with technology-specific skills have more human capital and higher productivity, a higher compensation reduces their incentive to quit. However, when firm growth is considered (in the form of an increasing rate of technological change), high-rank technology professionals tend to show a higher probability of quitting than regular production workers with less specific skills.

One variable I am unable to construct concerns whether, after leaving the previous job, a person still worked at the same occupation or in the same industry. This variable would have served as a good indicator of industry-specific skills. In the model, all skills are assumed to be industry-specific. If a person's skill does not fit in one firm, he will still find it useful elsewhere in the same industry. In this sense, a job change within the same industry can be reasonably attributed to skill mismatch. However, if a person quits his previous job and begins to work in another industry, he may use the same type of skill or have to develop different skills. Therefore, it is hard to determine whether the quit is 
caused by the mismatch in skills or other reasons, i.e., taste for variety (Åstebro and Thompson (2007)). If these across-industry job changes happen often with technology professionals, the empirical results may overestimate the effect of technology-specific skills on a worker's job decision. 


\section{REFERENCES}

Acemoglu, Daron (1999): "Changes in Unemployment and Wage Inequality: An Alternative Theory and Some Evidence." American Economic Review, 89(5): 12591278.

Åstebro, Thomas, and Peter Thompson (2007): "Entrepreneurs: Jacks of All Trades or Hobos?" Working paper.

Chin, Aimee, Chinhui Juhn, and Peter Thompson (2006): "Technical Change and the Demand for Skills during the Second Industrial Revolution: Evidence from the Merchant Marine, 1891-1912." Review of Economics and Statistics, 88(3): 572-578.

Dohmen, Thomas J., and Gerard A. Pfann (2004): "Worker Separations in a Nonstationary Corporate Environment." European Economic Review, 48(3): 645663.

Gibbons, Robert, and Michael Waldman (2003): "Enriching a Theory of Wage and Promotion Dynamics inside Firms." NBER Working paper No.9849.

Greene, William H. (2002): "Econometric Analysis." Prentice Hall, NJ.

Hill, Martha S. (1992): "The Panel Study of Income Dynamics: A User's Guide." SAGE Publications, Newbury Park, CA.

Jovanovic, Boyan (1979): "Firm-Specific Capital and Turnover." Journal of Political Economy, 87(6): 1246-1260.

Kambourov, Gueorgui, and Manovskii Iourii (2005): "Occupational Specificity of Human Capital.” Society for Economic Dynamics, Meeting Paper 197

Katz, Ethan (2001): "Bias in Conditional and Unconditional Fixed Effects Logit Estimation." Political Analysis, 9(4): 379-384.

Kennedy, Peter (2003): "A Guide to Econometrics." The MIT Press, Cambridge, MA.

Lazear, Edward P. (1999): "Personnel Economics: Past Lessons and Future Directions." NBER Working paper No.6957.

Neal, Derek (1995): "Industry-Specific Human Capital: Evidence from Displaced Workers." Journal of Labor Economics, 13(4): 653-677.

Quintin, Erwan, and John J. Stevens (2005a): "Growing Old Together: Firm Survival and Employee Turnover." Finance and Economics Discussion Series No. 2005-22.

Quintin, Erwan, and John J. Stevens (2005b): "Raising the Bar for Models of Turnover." Finance and Economics Discussion Series No. 2005-23. 
Rogerson, Richard, Robert Shimer, and Randall Wright (2004): "Search-Theoretic Models of the Labor Market: A Survey." NBER Working paper No.10655.

Saxenian, Annalee (1994): "Regional Advantage: Culture and Competiton in Silicon Valley and Route 128, Cambridge." Harvard University Press. 


\section{APPENDICES}

Appendix 1 - The KLIPS Sample and Variable Construction

The Korean Labor and Income Panel Study (KLIPS) was first conducted in 1998 (Wave 1) as a panel survey of original 5,000 Korean urban household and their family members. It has been completed up to 2005 (Wave 8). There are two types of data in the KLIPS: household data and individual data. Household data set is compiled from household questionnaires, which contains questions on household demographics, income and consumption, as well as financial status. Individual data set is constructed based on individual questionnaires, which mainly focuses on individuals' economic activity, employment characteristics, and labor market mobility.

Based on the structure of the KLIPS, I construct one subset of individual data and the other subset of household data for each interview year from $2000-2004$.

\section{Individual-Specific Variables}

The subset of individual data contains ten primary demographic and employment variables from the KLIPS: age, gender, marital status, college education, relationship to household head, employment status, main industry (previous and current), main occupation (previous and current), hourly wage, and monthly average wage. Both types of wage are measured in terms of 10,000 Korean won (KRW). ${ }^{18}$ In wave 6 , the individual questionnaire adds additional questions on respondents' siblings. Based on respondents' answers, I create a dummy variable, eldest, in the subset of the $6^{\text {th }}$ wave personal data. The variable equals 1 if a person was the eldest son and 0 otherwise.

Individuals included in each data set were either household heads or their spouses. Individuals who did not have information on hourly income or reported negative hourly

\footnotetext{
${ }^{18}$ From 2000 to 2004 , the exchange rate between won and dollars was about 1 dollar=1100 won.
} 
income are removed from each data set to limit measurement error. All five sub samples are restricted to individuals who were either working as wage earners or self-employed at the time of interview. Moreover, people who were engaged in agriculture, forestry, fishery, or military were excluded from all five sub samples.

\section{Household-Specific Variables}

The subset of household data includes information on household wealth and on parents of household heads or spouses. In each subset, twelve variables are constructed, which fall into four categories: net household assets, parents alive or not, living with parents or not (Heads or Spouses), and financial supports from / to parents if living apart (Heads or Spouses). ${ }^{19}$

Following Evans and Jovanovic (1989) and Xu (1997), the formula used to calculate wealth in each subset is: Net Assets=Investment in Real Estate + Financial Assets (including Savings, Stocks, Bonds, Insurance, Loans to friends or relatives, and other financial assets) - Debts (including balance of debt from bank/non-bank, balance borrowed from private route, balance from loans, and other debts). Respondents who reported negative or missing net household assets are dropped from the sample for reasons discussed in section 3.1.

\section{The combination of household and individual data sets}

For each interview year, the subsets of individual and household data are joined together using the household-specific identification number assigned to household in each wave (hhid**). The five joint subsets (five waves of interview) are then merged using the unique personal identification number (pid).

\footnotetext{
${ }^{19}$ For waves 4-7, five variables are generated to record whether household heads and their spouses live apart from parents and the financial exchange between them and parents.
} 
In the merged dataset, lagged values of log income, log net assets, industry, and occupation are generated. The key variable, selfe, is created so that it equals one if and only if the person was currently self-employed, but was a wage worker in the previous year. For example, selfe equals one if a person was self-employed in 2000 (Wave 3), but was a wage worker in 1999 (Wave 2). The reason for constructing this variable is to focus on the transition from wage employment to self-employment.

Appendix 2 - Mathematical Derivations in Chapter 3

\section{Proof of Proposition 2}

Let $T V\left(g^{\prime}\right)=w(g)+\beta \int_{0}^{\infty} \max \left[V\left(g^{\prime}\right), Q\right] d F\left(g^{\prime} \mid g\right)$ denote the operator defined in (7). The contracting mapping of $T V\left(g^{\prime}\right)$ can be easily proved by following the standard way in the literature.

To show $V(g)$ is decreasing in $g$, let $g^{*}$ be the value of $g$ such that $V\left(g^{*}\right)=Q$. Assume $V\left(g^{\prime}\right)$ is decreasing in $g^{\prime}$, then

$$
\int_{0}^{\bar{g}} \max \left[V\left(g^{\prime}\right), Q\right] d F\left(g^{\prime} \mid g\right)=\int_{0}^{g *} V\left(g^{\prime}\right) d F\left(g^{\prime} \mid g\right)+\int_{g^{*}}^{\bar{g}} Q d F\left(g^{\prime} \mid g\right)
$$

Integrating both terms in (A.1) by parts yields

$$
Q-\int_{0}^{g^{*}} F\left(g^{\prime} \mid g\right) V_{g^{\prime}}\left(g^{\prime}\right) d g^{\prime}
$$

Differentiating (A.2) with respect to $g$ gives us $\int_{0}^{g *} F\left(g^{\prime} \mid g\right) V_{g^{\prime}}(g) d g^{\prime}$

$$
-\int_{0}^{g *} V_{g^{\prime}}\left(g^{\prime}\right)\left[\partial F\left(g^{\prime} \mid g\right) / \partial g\right] d g^{\prime}
$$

As $V_{g^{\prime}}\left(g^{\prime}\right)<0$ and $\partial F\left(g^{\prime} \mid g\right) / \partial g<0$ by assumption, equation (A.3) indicates that the second term in (7) is decreasing in $g$. As $w(g)$ is decreasing in $g$, we have shown that $V(g)$ is decreasing in $g$ as well. Thus, quitting with value of $Q$ is chosen when $g$ is above $g^{*}$, while staying with $V(g)$ is preferable when $g$ is below $g^{*}$. 


\section{Proof of Proposition 3}

Similar to the proof in part A, assume $V(g)$ is increasing in $g^{\prime}$. Then

$$
\int_{0}^{\bar{g}} \max \left[V\left(g^{\prime}\right), Q\right] d F\left(g^{\prime} \mid g\right)=\int_{0}^{g *} Q d F\left(g^{\prime} \mid g\right)+\int_{g^{*}}^{\bar{g}} V\left(g^{\prime}\right) d F\left(g^{\prime} \mid g\right)
$$

Integrating both terms in (A.4) by parts, we have

$$
V(\bar{g})-\int_{0}^{g *} F\left(g^{\prime} \mid g\right) V_{g^{\prime}}\left(g^{\prime}\right) d g^{\prime}
$$

Differentiating (A.5) with respect to $y$ yields

$$
-\int_{g^{*}}^{\bar{g}} V_{g^{\prime}}\left(g^{\prime}\right)\left[\partial F\left(g^{\prime} \mid g\right) / \partial g\right] d g^{\prime}
$$

Since $V_{g^{\prime}}\left(g^{\prime}\right)<0$ and $w_{g}(g)>0$, equation (A.6) implies that $V(g)$ is increasing in $g$. As the worker chooses to stay in the firm in the current period, these implies that $V(g)>Q$. If we only consider the case that firms' technological change rate, $g$, is increasing all the time, $V\left(g^{\prime}\right)$ should be greater than $Q$, which indicates that the workers with $\alpha$ lower than a certain threshold would always prefer to stay in a growing firm.

\section{The Reservation Equation}

When $V(g)$ is decreasing in $g$, by using (A.2), equation (7) can be rewritten as

$$
V(g)=w(g)+\beta\left[Q-\int_{0}^{g *} V_{g^{\prime}}\left(g^{\prime}\right) F\left(g^{\prime} \mid g\right) d g^{\prime}\right]
$$

Substituting $g^{*}$ into (A.7) and rearranging it gives the reservation equation

$$
Q=\frac{1}{1-\beta} w\left(g^{*}\right)-\frac{\beta}{1-\beta} \int_{0}^{g *} V_{g^{\prime}}\left(g^{\prime}\right) F\left(g^{\prime} \mid g^{*}\right) d g^{\prime}
$$

When $V(g)$ is increasing in $g$, equation (7) can be expressed as

$$
V(g)=w(g)+\beta\left\{Q+\int_{g^{*}}^{\bar{g}}\left[V\left(g^{\prime}\right)-Q\right] d F\left(g^{\prime} \mid g\right)\right\}
$$

Replacing $g$ with $g^{*}$ in (A.8) yields the reservation equation

$$
Q=\frac{1}{1-\beta} w\left(g^{*}\right)+\frac{\beta}{1-\beta} \int_{g^{*}}^{\bar{g}}\left[V\left(g^{\prime}\right)-Q\right] d F\left(g^{\prime} \mid g^{*}\right)
$$


VITA

\section{JING CHEN}

2001

B.A. Economics

Nanjing University

Nanjing, China

2004

M.A. Economics

Nanjing University

Nanjing, China

2010

Doctoral Candidate in Economics

Florida International University

Miami, Florida

\section{RESEARCH AND PRESENTATIONS}

Chen, Jing (2006). The Growth Effects of Intrinsically Worthless Education. Working paper, Florida International University

Chen, Jing (2007).Who Benefits from Firm Growth? An Analysis of Technology Effects on Job Turnover. Working paper. Florida International University

Astebro, Thomas, Chen, Jing, and Thompson, Peter (2008). Stars and Misfits: A Theory of Occupational Choice. Paper presented at

- The 6th International Industrial Organization Conference, Marymount University, May 2008

- The 14th Society of Labor Economists Meetings (Poster Session), Boston, May 2009

Chen, Jing (2008). Wealth Constraints and Self-Employment: Evidence from Birth Order. Paper presented at

- The Department of Economics, Florida International University, November 2008

- The 8th Annual Roundtable for Engineering Entrepreneurship Research, Georgia Institute of Technology, November 2008

- The 14th Society of Labor Economists Meetings, Boston, May 2009

Chen, Jing (2009). Selection and Serial Entrepreneurs. Paper presented at

- The Department of Economics, Florida International University, November 2009

- The 79th Annual Conference of the Southern Economic Association, San Antonio, November 2009 
- The Department of Economics and Decision Sciences, HEC-Paris, December 2009

- Kauffman Entrepreneurship Mentoring Workshop, Atlanta, January 2010

- Queen's School of Business, Kingston CA, January 2010

Thompson, Peter, and Chen, Jing (2010). Employee Spinoffs and the Solipsistic Entrepreneur. Paper presented at

- The Department of Economics, Florida International University, September 2009

- The Department of Innovation and Organizational Economics, Copenhagen Business School, September 2009

- The $9^{\text {th }}$ Annual Roundtable for Engineering Entrepreneurship Research, Georgia Institute of Technology, November 2009 